Aus der Klinik für Anästhesiologie

Klinikum der Ludwig-Maximilians-Universität München

Vorstand: Professor Dr. Bernhard Zwißler

\title{
Etablierung eines adaptierbaren Akutschmerzmodells zur Induktion nozizeptiver Stimuli definierter Intensität und Dauer mittels thermischer Reize
}

\author{
Dissertation \\ zum Erwerb des Doktorgrades der Medizin \\ an der Medizinischen Fakultät \\ der Ludwig-Maximilians-Universität zu München
}

\author{
vorgelegt von \\ Philipp Lüke \\ aus
}

Bremen

2021 
Mit Genehmigung der Medizinischen Fakultät

der Universität München

Berichterstatter:

Mitberichterstatter:

Mitbetreuung durch den

promovierten Mitarbeiter:

Dekan:

Tag der mündlichen Prüfung:
Prof. Dr. Shahnaz Christina Azad

PD Dr. Beate Averbeck

Prof. Dr. Andreas Straube

PD. Dr. Volker Huge

PD Dr. Benjamin Luchting

Prof. Dr. Thomas Gudermann

23.12.2021 


\section{Inhaltsverzeichnis}

Abbildungsverzeichnis_______

Tabellenverzeichnis___ VI

Abkürzungsverzeichnis___________II

1. EINLEITUNG

1.1. DEFINITION UND VERSTÄNDNIS VON SCHMERZ UND NOZIZEPTION __ 1

1.2. ASSESSMENTVERFAHREN ZUR ERHEBUNG VON SCHMERZEN___ 1

1.3. THEORETISCHE GRUNDLAGEN __ 2

1.3.1. Physiologie der Nozizeption

1.3.2. TRP-Kanäle und ihre Rolle bei der Nozizeption __ 3

1.3.3. Der TRPV1-Kanal und Capsaicin __ 4

1.3.4. Der TRPM8-Kanal und Menthol _ 5

1.3.5. Zentrale Organisation der somatoviszeralen Sensibilität __ 6

1.3.6. Neuronale Plastizität _ 7

1.4. BISHERIGE SCHMERZMODELLE___ 8

1.4.1. Schmerzinduktion durch mechanische Reize

1.4.2. Schmerzinduktion durch thermische Reize _ 9

1.4.2.1. Transduktion von nozizeptiven Hitzestimuli _ 9

1.4.2.2. Transduktion von nozizeptiven Kältestimuli 9

1.4.3. Schmerzinduktion durch chemische Reize 10

1.4.4. Schmerzinduktion durch elektrische Reize _ 10

2. ZIELSETZUNG DER STUDIE _ _ 10

3. MATERIAL UND METHODIK___ 11

3.1. ProbandenKollekTiV

3.2. FRAGEBöGEN UND ASSESSMENT

3.3. ENTWICKLUNG DER AKUTSCHMERZMODELLE__ 12

3.3.1. Das QST-Gerät__ 12

3.3.2. Versuchsvorbereitung 13

3.3.3. Vorversuch "Detektion der thermischen Schmerzschwellen“ 14

3.3.4. Vorversuch "Detektion der zeitlichen Aspekte der Schmerzadaptation“_ 15

3.3.5. Hauptversuch „Etablierung und Validierung der Hitze- und Kälteschmerzmodelle __ 15

3.3.6. Nachversuch "Erweiterung der Versuchsdauer"

3.4. STATISTISCHE METHODIK __ 16

4. ERGEBNISSE — 17

4.1. VORVERSUCH „DETEKTION DER THERMISCHEN SCHMERZSCHWELLEN“__ 17

4.2. VORVERSUCH „DETEKTION DER ZEITLICHEN ASPEKTE DER SCHMERZADAPTATION“__ 18

4.3. HAUPTVERSUCH „ETABLIERUNG DER SCHMERZMODELLE“

4.3.1. Das Hitzeschmerzmodell

4.3.2. Das Kälteschmerzmodell 26

4.4. HAUPTVERSUCH „VALIDIERUNG DER SCHMERZMODELLE“ _ 27

4.5. NACHVERSUCH „ERWEITERUNG DER VERSUCHSDAUER“

5. DISKUSSION — 32

5.1. ZUSAMMENFASSUNG DER HAUPTERGEBNISSE

5.2. DISKUSSION DER METHODIK__ 32

5.2.1. Ausschluss von Bias - endogene Faktoren _ 32

5.2.2. Ausschluss von Bias - exogene Faktoren 33 
5.2.2.1. Umgebungstemperatur __ 33

5.2.2.2. Tageszeitpunkt__ 33

5.2.2.3. Reliabilität und Validät der QST- Messung ___ 33

5.2.2.4. Anpressdruck der Thermode___ 34

5.2.2.5. Studiendesign___ 34

5.3. DISKUSSION DER ERGEBNISSE __ 34

5.3.1. Adaptation und Sensibilisierung___ 34

5.3.2. Geschlechterspezifische Unterschiede __ 36

5.4. AUSBLICK _ 36

5.4.1. Erweiterung der Versuchsanordnung durch Menthol___ 36

5.4.2. Dynamische Schmerzmodelle __ 37

5.4.3. Anpassung der Parameter des Schmerzmodells __ 37

5.4.4. Limitationen _ 38

5.5. FAZIT — 38

6. LITERATURVERZEICHNIS _ 39

7. ZUSAMMENFASSUNG _ 45

8. ANHANG

9.1. KAB SCORE

9.2. BEFUNDBOGEN__ 47

9. DANKSAGUNG _— 49

10. EIDESSTATTLICHE VERSICHERUNG _ 50

11. STELLUNGNAHME ZUR VORVERÖFFENTLICHUNG _ 51 


\section{Abbildungsverzeichnis}

Abbildung 1 - Aufbau von TRP-Kanälen................................................................................ 4

Abbildung 2 - Strukturformel von Capsaicin........................................................................ 4

Abbildung 3 - Aktivierung des TRPV1-Kanals.......................................................................... 5

Abbildung 4 - Zentrale Organisation der somatoviszeralen Sensibilität ......................................... 7

Abbildung 5 - Einflussfaktoren auf klinischen und experimentellen Schmerz ................................. 8

Abbildung 6-Gerät zur Quantitativ Sensorischen Testung ................................................. 13

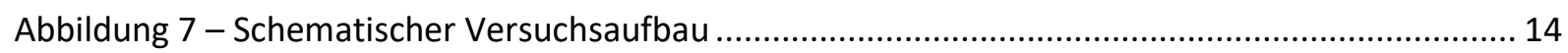

Abbildung 8 - Adaptationskurven bei $46^{\circ} \mathrm{C}$ ohne Vorbehandlung mit Capsaicin .............................. 19

Abbildung 9 - Adaptationskurve bei $46{ }^{\circ} \mathrm{C}$ ohne Vorbehandlung mit Capsaicin ................................20

Abbildung 10 - Adaptationskurven bei $38{ }^{\circ} \mathrm{C}$ nach Vorbehandlung mit Capsaicin.............................2 21

Abbildung 11 - Adaptationskurve bei $38{ }^{\circ} \mathrm{C}$ nach Vorbehandlung mit Capsaicin.............................. 21

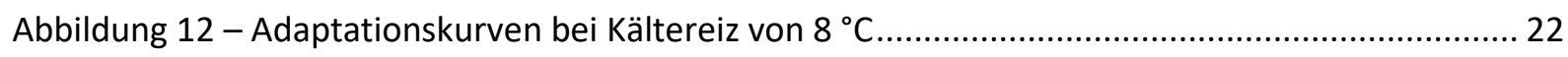

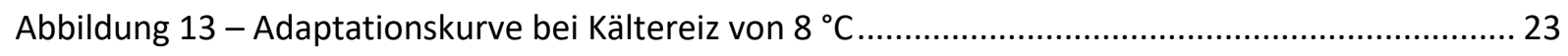

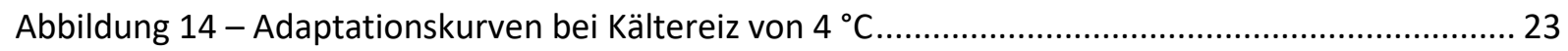

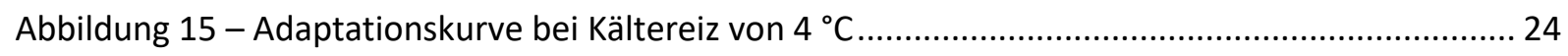

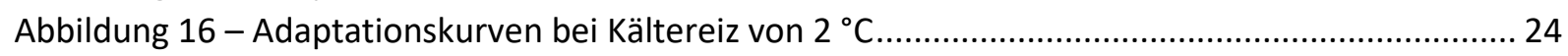

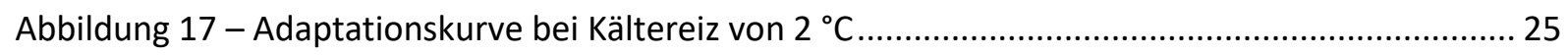

Abbildung 18 - Schematische Darstellung des Hitzeschmerzmodells. .............................................26

Abbildung 19 - Schematische Darstellung des Kälteschmerzmodells .......................................... 27

Abbildung 20 - Durchschnittlich empfundene Schmerzintensitäten im Hauptversuch ..................... 29

Abbildung 21 - Durchschnittlich empfundene Schmerzintensitäten im Nachversuch...................... 31 


\section{Tabellenverzeichnis}

Tabelle 1 - Probandenkollektiv des Vorversuchs „Detektion der thermischen Schmerzschwellen“ ... 17

Tabelle 2 - Schmerzschwelle für Hitzereize ohne Vorbehandlung mit Capsaicin ................................ 17

Tabelle 3 - Schmerzschwelle für Hitzereize nach Vorbehandlung mit Capsaicin ............................... 17

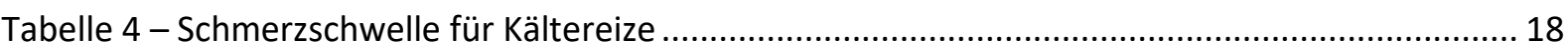

Tabelle 5 - Probandenkollektiv des Vorversuchs „Detektion der zeitlichen Aspekte der

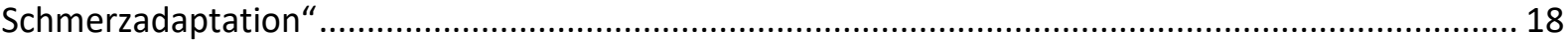

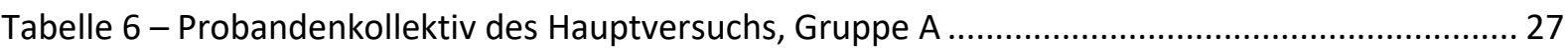

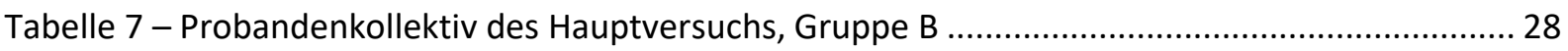

Tabelle 8 - Probandenkollektiv des Hauptversuchs, Gruppe C ....................................................... 28

Tabelle 9 - Durchschnittlich empfundene Schmerzintensitäten in Abhängigkeit von der

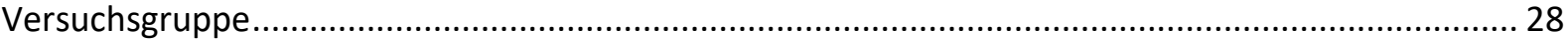

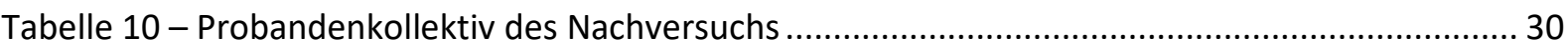

Tabelle 11 - Durchschnittliche erhobene Schmerzintensität im Nachversuch................................... 30 


\section{Abkürzungsverzeichnis}

IASP

BESD

PAINAD

CGRP

TRP

ATP

CAP

DRG

WDR

VPL

VPI

VPM

Vmpo

MDvc

PAG

ZNS

NMDA

AMPA

NGF

NRS

QST

MW

STABW

$\mathrm{KAB}$

DFNS

EEG

TENS
International Association for the Study of Pain

Beurteilung von Schmerzen bei Demenz

Pain Assessment in Advanced Dementia

Calcitonin Gene-Related Peptide

Transient receptor potential

Adenosintriphosphat

Capsaicin

Dorsal root ganglion (Hinterwurzelganglion)

Wide dynamic range (Neurone)

Nuclei ventrales posterolaterales

Nucleus ventralis posterior inferior

Nucleus ventralis posteromedialis

Nucleus ventromedialis posterior

Nucleus mediodorsalis pars ventrocaudalis

Periaquäduktales Höhlengrau

Zentrales Nervensystem

N-Methyl-D-Aspartat (Rezeptor)

a-Amino-3-Hydroxy-5-Methyl-4-Isoxazolepropionic Acid (Rezeptor)

Nerve growth factor

Numeric Rating Scale (Numerische Schmerzskala)

Quantitativ Sensorische Testung

Mittelwert

Standardabweichung

Kurzfragebogen zur aktuellen Beanspruchung

Deutscher Forschungsverbund Neuropathischer Schmerz

Elektroencephalogramm

Transkutane elektrische Nervenstimulation 


\section{Einleitung}

\subsection{Definition und Verständnis von Schmerz und Nozizeption}

Nach der Definition der International Association for the Study of Pain (IASP) ist Schmerz ein unangenehmes Sinnes- oder Gefühlserlebnis, das mit tatsächlicher oder potentieller Gewebeschädigung einhergeht oder mit den Begriffen einer solchen Schädigung beschrieben wird [1]. Die Nozizeption beschreibt hingegen die objektivierbaren peripheren und zentralen Vorgänge, die zur Schmerzwahrnehmung führen [2]. Nach der im Jahr 1994 aufgestellten Taxonomie der IASP sind Schmerzen immer subjektiv. Heute ist bekannt, dass Schmerz ein komplexer Wahrnehmungsprozess ist, der sensorisch-diskriminative, kognitiv-verhaltensbestimmende und emotional-affektive Komponenten beinhaltet $[3,4]$. Diese Erweiterung des Verständnisses der Schmerzwahrnehmung um psychosoziale Einflussfaktoren wurde unter anderem von Chapman im Jahr 1990 sowie Turk und Flor im Jahr 1999 beschrieben [5, 6]. Heute ist bekannt, dass nicht nur genetische Faktoren, das Geschlecht oder bereits stattgefundene Erkrankungen die Schmerzwahrnehmung modulieren, sondern auch Erfahrungen und das soziokulturelle Umfeld $[5,7,8]$.

Vor diesem Hintergrund wurden seit Beginn der Schmerzforschung zahlreiche Akutschmerzmodelle für gesunde Versuchsprobanden entwickelt. Ziele dieser Studien waren unter anderem die Erforschung pathophysiologischer Mechanismen von Schmerzen oder die Untersuchung der Wirksamkeit pharmakologischer Therapieverfahren. Aufgrund der guten Zugänglichkeit haben sich vor allem Schmerzmodelle bewährt, die mechanische, thermische oder elektrische Schmerzstimuli auf der Haut induzieren. Übersichtsarbeiten bereits etablierter Verfahren lieferten Curatolo et al. im Jahr 2000 und Olesen et al. im Jahr 2012 [9, 10].

Bei der Erstellung und Anwendung eines Akutschmerzmodells offenbart sich ein wissenschaftliches Dilemma: Ein Grundpfeiler guter wissenschaftlicher und ärztlicher Praxis ist die ethische Vertretbarkeit des Handelns gemäß dem Paradigma „primum nil nocere“. Der nozizeptive Stimulus eines Akutschmerzmodells darf folglich nicht mit schweren reversiblen oder gar irreversiblen Gewebeschäden einhergehen. Um hingegen aussagekräftige Forschungsergebnisse erzielen zu können, bedarf es eines signifikanten nozizeptiven Stimulus. Für die Signifikanz sind dabei eine ausreichende Dauer und Intensität des Schmerzstimulus maßgeblich [11]. Da durch die Gefahr von Gewebeschäden vor allem die Intensität eines nozizeptiven Stimulus limitiert ist, kommt der Stimulusdauer besondere Bedeutung zuteil.

\subsection{Assessmentverfahren zur Erhebung von Schmerzen}

Die Erhebung von Schmerzen in der klinischen Praxis stellt das Gesundheitspersonal vor erhebliche Probleme: Im Jahr 1987 propagierte das National Institutes of Health folgende, noch zeitgemäße Aussage: "The single most reliable indicator of the existence and intensity of acute pain - and any resultant affective discomfort or distress - is the patient's self-report". Da Biomarker zur Quantifizierung von Schmerzen (noch) nicht existieren, werden auch heute noch basierend auf Angaben von Patienten ${ }^{1}$ Art und Umfang einer analgetischen Therapie festgelegt. Dabei verwendete Erhebungsverfahren sind häufig eindimensionale Skalen, mithilfe derer die Intensität von empfundenen Schmerzen verbal, visuell oder numerisch erhoben wird $[12,13]$. Eine erweiterte Schmerzerfassung bietet zum Beispiel die Hamburger- Adjektiv- Liste,

${ }^{1}$ Es sind stets Personen männlichen und weiblichen Geschlechts gleichermaßen gemeint; aus Gründen der Lesbarkeit wird im Folgenden nur die männliche Form verwendet. 
die mehrdimensional affektive und sensorische Schmerzqualitäten erfasst. Nicht immer gelingt diese Art der Erhebung. Für Patienten, die sich aufgrund ihres Alters, ihrer Grunderkrankung oder im Rahmen einer Narkose oder Sedierung nicht mitteilen können, bedarf es anderer Verfahren zur Quantifizierung von Schmerzen. Surrogatmarker, z. B. erhöhter Blutdruck, gesteigerte Herzfrequenz oder Stöhnen sind oft unspezifisch und münden nicht selten in einer unzureichenden Schmerztherapie. Folglich wurden Skalen etabliert, die neben biophysiologischen Aspekten auch psychosoziale und psychomotorische Auswirkungen von Schmerzen berücksichtigen. Beispielhaft dafür sind die BESD-Skala (Beurteilung von Schmerzen bei Demenz), die auf Grundlage der amerikanischen PAINAD-Scale (Pain Assessment in Advanced Dementia) entwickelt wurde [14], oder die Dolo-Plus-2-Skala, die eine gute Sensitivität und zuverlässige Verlaufsbeurteilung bietet, jedoch eine gute Schulung des anwendenden Personals voraussetzt. $[15,16]$. Studien haben gezeigt, dass trotz dieser weiterentwickelter Assessment-Verfahren bis zu $80 \%$ der Patienten in Pflegeeinrichtung unter unzureichend behandelten Schmerzen leiden $[17,18]$. Neben dem individuellen Leid ist auch der volkswirtschaftliche Schaden von Schmerzen immens. Das Ausmaß ist in Gänze schwer abzuschätzen, da valide Daten zu den indirekten und direkten Kosten der Gesamtheit akuter und chronischer Schmerzen fehlen. Betrachtet man nur chronische Rückenschmerzen, so lassen sich anhand einer von 2003 bis 2006 durchgeführten Longitudinalstudie die indirekten und direkten Kosten auf bis zu 49 Milliarden Euro allein in Deutschland schätzen, mit einem größten Teil in den Bereichen Krankengeld, Arbeitsausfall und Frühberentung $[19,20]$.

\subsection{Theoretische Grundlagen}

\subsubsection{Physiologie der Nozizeption}

Nozizeption (von lateinisch: nocere $=$ schädigen und capere $=$ nehmen, ergreifen) beschreibt die Aufnahme potentiell oder tatsächlich schädlicher Reize. Schmerz ist eine daraus resultierende Empfindung, die einen komplexen Wahrnehmungsprozess darstellt. Aufgenommen werden die Reize über sogenannte Nozizeptoren, freie Nervenendigungen von Nervenfasern,

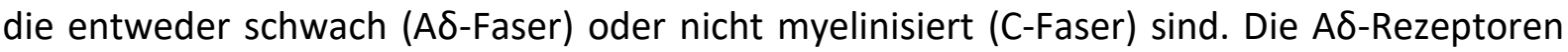
reagieren entweder auf hochschwellige mechanische oder thermische Reize $\left(>45{ }^{\circ} \mathrm{C}\right.$ oder $<5{ }^{\circ} \mathrm{C}$ ), sie sind monospezifisch disponiert. Die C-Nozizeptoren hingegen sind polyspezifisch disponiert und reagieren auf mechanische, thermische und chemische Reize. Auch bei der Entstehung von Juckreiz nehmen die C-Nozizeptoren eine bedeutende Rolle ein, da sie im Rahmen degranulierter Mastzellen durch Histamin erregt werden können. Die Leitgeschwindigkeit der C-Fasern liegt bei $<1 \mathrm{~m} / \mathrm{s}$. Sie vermitteln einen verzögerten und als „dumpf “ beschrie-

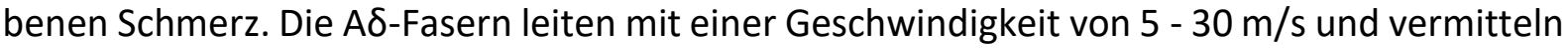
einen schnellen, sogenannten "hellen" Schmerz $[2,21]$.

Bei der Aktivierung von Nozizeptoren kann man neben der afferenten Signaltransduktion Begleitreaktionen im umliegenden Gewebe beobachten. Die nozizeptiven Fasern setzen sekretorische Vesikel frei, die Neuropeptide wie Substanz P und Calcitonin Gene-Related Peptide (CGRP) beinhalten. Durch diese Entzündungsmediatoren (man spricht auch von einem Axonreflex) kommt es durch Permeabilitätssteigerung der Gefäße und Relaxation der Gefäßwandmuskulatur zur Hyperämie und Schwellung, die neben der empfundenen Schmerzsensation wichtige Kardinalsymptome der Inflammation darstellen. 
Zur Unterscheidung der Nozizeptoren werden unterschiedliche Transduktionsmechanismen beschrieben. Ionotrope Rezeptoren stellen im Wesentlichen nicht selektive, ligandengesteuerte Kationenkanäle dar. Sie werden durch Capsaicin, Hitze oder Säure (transient receptor potential channel, Typ Vanilloid-Rezeptor, TRPV1-Kanal) oder im Rahmen von Gewebsschäden durch Adenosintriphosphat ATP (P2X-Kanal) sowie Serotonin aus aktivierten Thrombozyten (5HT3-Kanal) aktiviert. Metabotrope, nozizeptive Rezeptoren spielen eine wichtige Rolle in der Erhöhung der Empfindlichkeit von Nozizeptoren. Bradykinin und Prostaglandine, wie Prostaglandin E2, bewirken über G-Protein-gekoppelte Rezeptoren u. a. durch Phosphorylierung von TRPV1- und $\mathrm{Na}^{+}-$Kanäle eine periphere Sensibilisierung der Nozizeptoren mit einhergehender Hyperalgesie [21].

\subsubsection{TRP-Kanäle und ihre Rolle bei der Nozizeption}

Eine wichtige Rolle in der Nozizeption nehmen die TRP-Kanäle (transient receptor potential channel) ein, von denen die klassischen TRP-Kanäle derzeit anhand ihrer Aminosäurensequenz in sechs Subgruppen unterteilt werden: TRPC (canonical), TRPV (vanilloid), TRPM (melastin), TRPA (ankyrin), TRPML (mucolipin) und TRPP (polycystin) [22]. Alle TRP-Kanäle sind unselektiv durchlässig für das monovalente Kation $\mathrm{Na}^{+}$, sowie die divalenten Kationen $\mathrm{Ca}^{2+}$ und $\mathrm{Mg}^{2+}$. Gemeinsam haben sie auch ihre molekulare Struktur: Die TRP-Kanäle bestehen aus sechs Transmembrandomänen mit einer für Kationen permeablen Pore zwischen dem fünften und sechsten Segment. Carboxyl- und Aminogruppen liegen cytoplasmatisch (s. Abbildung 1) [23]. Überwiegend sind TRP-Kanäle an der Plasmamembran lokalisiert, Studien weisen vor allem für die Subtypen TRPV1 und TRPM8 aber auch ein Vorkommen an intrazellulären Membranen nach [24]. Die Funktionen der TRP-Kanäle sind vielseitig. Beim Menschen sind sie unter anderem bei der sensorischen Signaltransduktion von Hitze und Hitzeschmerz (insbesondere TRPV1 und TRPV2), Kälte (u. a. TRPM8 und TRPA1), mechanischen Reizen und Geschmack beteiligt [25-28]. Der bekannteste Vertreter ist der TRPV1-Kanal, der als erster Thermo-TRP-Kanal kloniert wurde [26]. Er wird von unterschiedlichen nozizeptiven Stimuli wie Hitze $\left(>42{ }^{\circ} \mathrm{C}\right)$, Säure und durch chemische Reize wie Capsaicin aktiviert (s. Abbildung 2) [29]. TRPV1-Kanäle werden dabei in besonders hoher Dichte an Hinterwurzelganglien (DRG) und trigeminalen Neuronen exprimiert, vorwiegend an unmyelinisierten C-Faser-Neuronen, aber auch an myelinisierten Aס-Neuronen [30]. Des Weiteren finden sich hohe Vorkommen von TRPV1-Kanälen in der Haut, aber auch in der Cornea, in Muskeln oder in olfaktorischen Regionen [31-33]. 

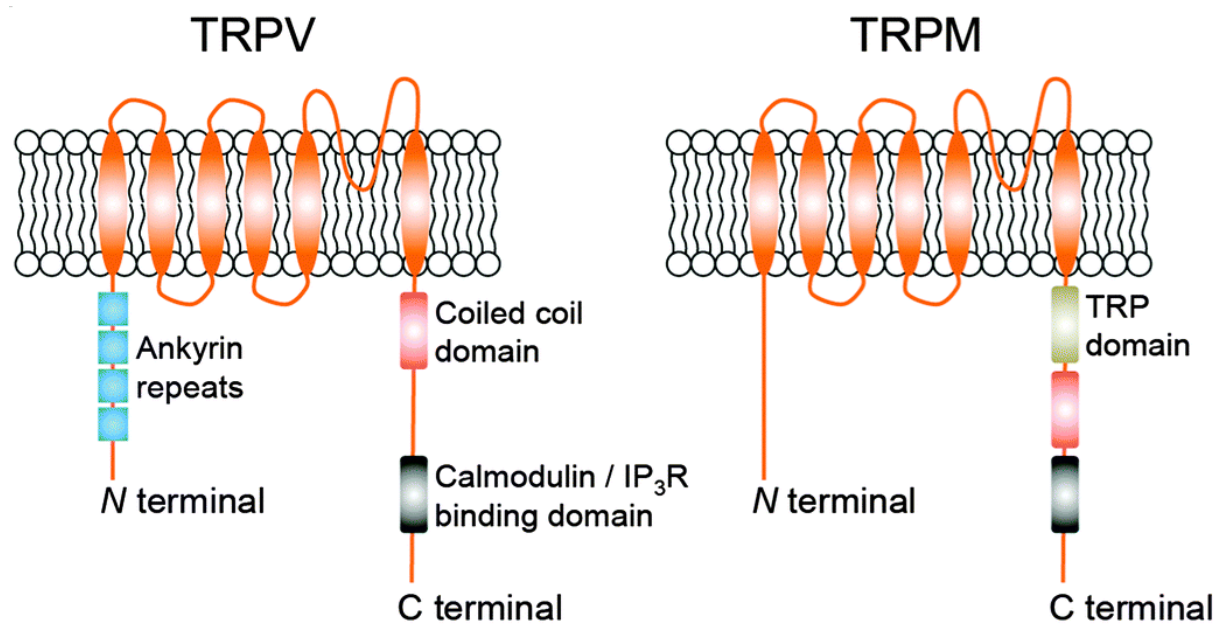

Abbildung 1 - Aufbau von TRP-Kanälen [34]

\subsubsection{Der TRPV1-Kanal und Capsaicin}

Der Wirkstoff Capsaicin (trans-8-Methyl-N-Vanillyl-6-Nonensäureamid) gehört zu den Alkaloiden und lässt sich in verschiedenen Pflanzenarten der Gattung Capsicum, aus der Familie der Nachtschattengewächse (Solanaceae), nachweisen (s. Abbildung 2). Hierzu zählen unter anderem die Chilipflanzen und Paprika. Der Verzehr Capsaicin-haltiger Speisen löst eine scharfe bis brennende Missempfindung in der Mundhöhle aus [35].<smiles>COc1cc(CNC(=O)CCCC/C=C/C(C)C)ccc1O</smiles>

Abbildung 2 -Strukturformel von Capsaicin

Capsaicin wirkt agonistisch am TRPV1-Kanal. Durch Aktivierung TRPV1-exprimierender Nozizeptoren kommt es zur Freisetzung proinflammatorischer Neuropeptide wie Substanz P. Die konsekutive Durchblutungssteigerung und Erhöhung der Gefäßpermeabilität lassen sich bei lokaler Applikation von Capsaicin morphologisch als Rötung und Schwellung beobachten. Im Rahmen dieser neurogenen Entzündung kommt es zur peripheren Sensibilisierung und Hyperalgesie mit Erniedrigung der Hitzeschmerzschwelle [36]. Nach langfristiger topischer Applikation oder intradermaler Injektion konnte für Capsaicin hingegen auch eine analgetische Wirkung nachgewiesen werden, die auf eine axonale Degeneration von Nervenfasern zurückzuführen ist [37]. 

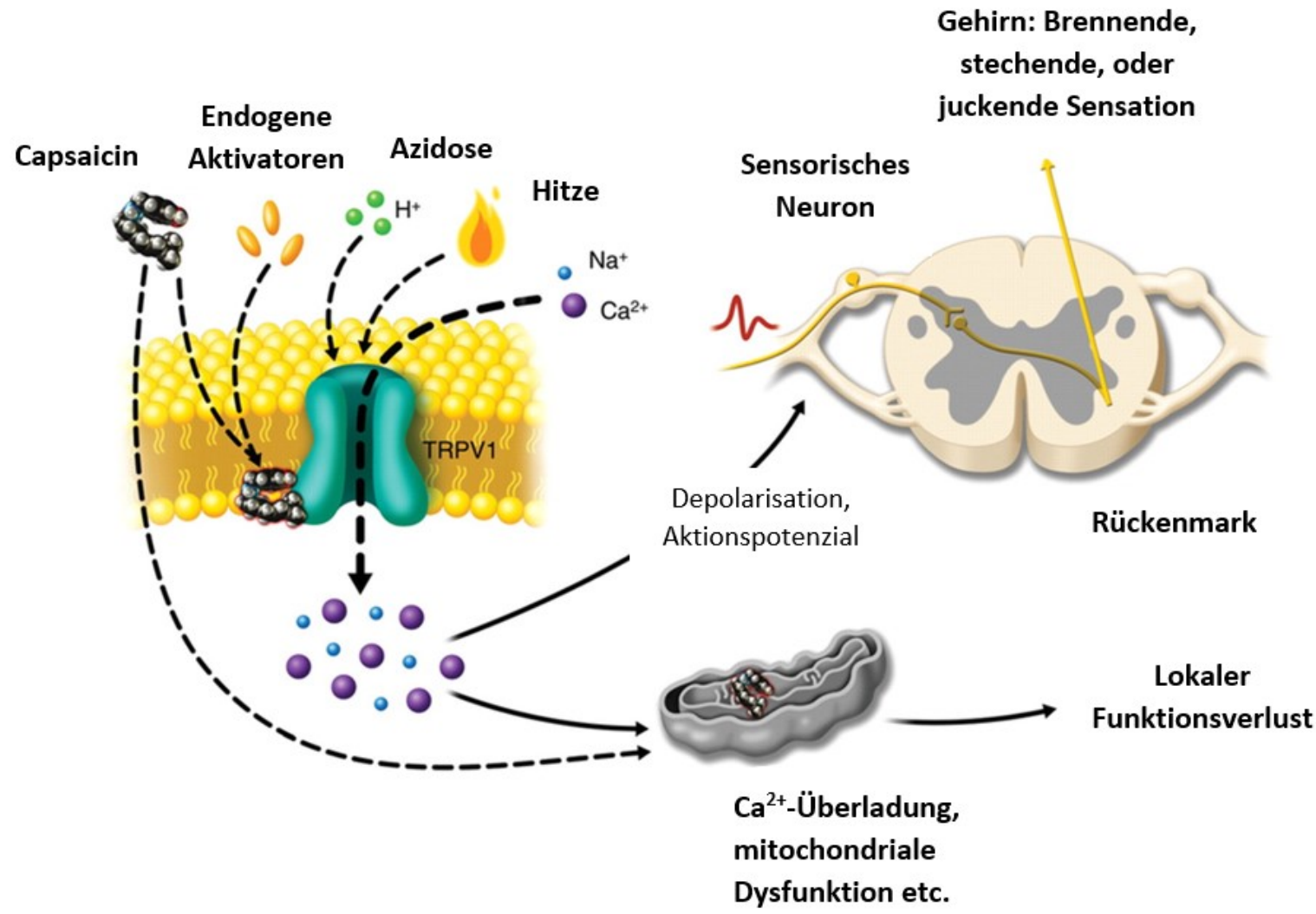

Abbildung 3-Aktivierung des TRPV1-Kanals [38]

\subsubsection{Der TRPM8-Kanal und Menthol}

Der TRPM8-Rezeptor, auch bekannt als Kälte-Menthol-Rezeptor, ist maßgeblich an der somatosensorischen Transduktion von Kälte und Kälteschmerz beteiligt [27, 39] Der Wirkstoff Menthol (2-Isopropyl-5-Methyl-Cyclohexanol) gehört zu den Monoterpen-Alkoholen und findet sich in Pflanzen der Gattung Mentha wieder. Bereits im Jahr 1951 konnte im Tiermodell nachgewiesen werden, dass in Lösung befindliches Menthol nach oraler Applikation die Kältesensitivität trigeminaler Neurone verändert und die Temperaturschwelle zur Aktivierung kältespezifischer Rezeptoren anhebt [40]. Besonders hohe Konzentrationen (40\%) von topisch angewandtem Menthol führen lokal zu einer schmerzhaften Sensation und Herabsetzung der thermischen Schmerzschwelle für Kältereize [41]. Neben dieser Sensibilisierung auf Kältereize wurden jedoch auch anästhetische Effekte von Menthol beschrieben. In niedriger Dosierung ( $<1 \%)$ bewirkt Menthol eine herabgesetzte kutane Nozizeption durch Desensibilisierung nozizeptiver C-Fasern [42]. Der anästhetische Effekt wird unter anderem auf eine schwache Natriumkanalblockade und Interaktion mit spannungsabhängigen Natriumkanälen zurückgeführt [43-45]. 


\subsubsection{Zentrale Organisation der somatoviszeralen Sensibilität}

Die Afferenzen der A $\delta$ - und C-Fasern gelangen über die Hinterwurzel in das Rückenmark und werden nach Eintritt in das Hinterhorn synaptisch umgeschaltet (vornehmlich in Laminae I - II nach Rexed). Diese Umschaltung kann monosynaptisch oder über Interneurone stattfinden. Ihre Axone bilden den Vorderseitenstrang, in dem die Projektionsneurone zum Thalamus gelangen. Die nozizeptiv-spezifischen Neurone, die überwiegend in den Lamina-I-Neuronen lokalisiert sind, verlaufen nach Kreuzung auf Rückenmarksebene im Tractus spinothalamicus lateralis nach kranial. Die nicht modalitätsspezifischen Wide-Dynamic-Range-Neurone (WDR), die primär in den Lamina-V-Neuronen vorzufinden sind, erreichen den Thalamus nach Kreuzung auf Rückenmarksebene über den Tractus spinothalamicus ventralis (anterior). Die WDRNeurone zeichnen sich durch Konvergenz nozizeptiver und nicht nozizeptiver A $\delta$-, C- und A $\beta$ Fasern aus. Die Zielneurone der Vorderseitenstrangbahn liegen in zahlreichen Kerngebieten des Thalamus. Lamina-I-Neurone enden im lateralen Thalamus in den Nuclei (Ncll.) ventrales posterolaterales (VPL), im Nucleus (Ncl.) ventralis posterior inferior (VPI) und im Ncl. ventromedialis posterior (Vmpo). Medial enden die Neurone im ventrokaudalen Teil des $\mathrm{Ncl}$. mediodorsalis (MDvc). Lamina-V-Neurone enden lateral im VPL, VPI, und in den Ncll. ventrales posteromediales (VPM), sowie medial im Ncl. centrolateralis. Der primäre somatosensible Kortex bezieht seine Projektion vor allem aus VPM und VPL, während VPI in den sekundären somatosensiblen Kortex projiziert. Im Gyrus cinguli, der einen Teil des limbischen Systems darstellt, und in Teilen des Inselkortex enden Neurone aus dem VMpo und MDvc [21, 46, 47] (s. Abbildung 4).

Als Teil der von Melzack beschriebenen Schmerzmatrix nehmen Inselcortex und Gyrus cinguli als Bestandteile des limbischen Systems wichtige Funktionen bei der emotionalen und motivationalen Komponente bewusster und unbewusster Schmerzwahrnehmung ein [48, 49]. Ausgehend von den Laminae I sowie IV - VI ziehen Neurone vom Rückenmark extrathalamisch zum Hirnstamm, interagieren dort mit dem Periaquäduktalen Höhlengrau (PAG), dem Ncl. cuneiformes und dem Colliculus superior. Diese Strukturen sind Teil der deszendierenden Schmerzhemmung und spielen eine wichtige Rolle bei der Ausbildung aversiver motorischer Reaktionen. Auch autonome Reaktionen des Organismus auf nozizeptive Reize werden extrathalamisch über Kollateralen des Tractus spinothalamicus zur Formatio reticularis vermittelt(s. Abbildung 4) [50]. 


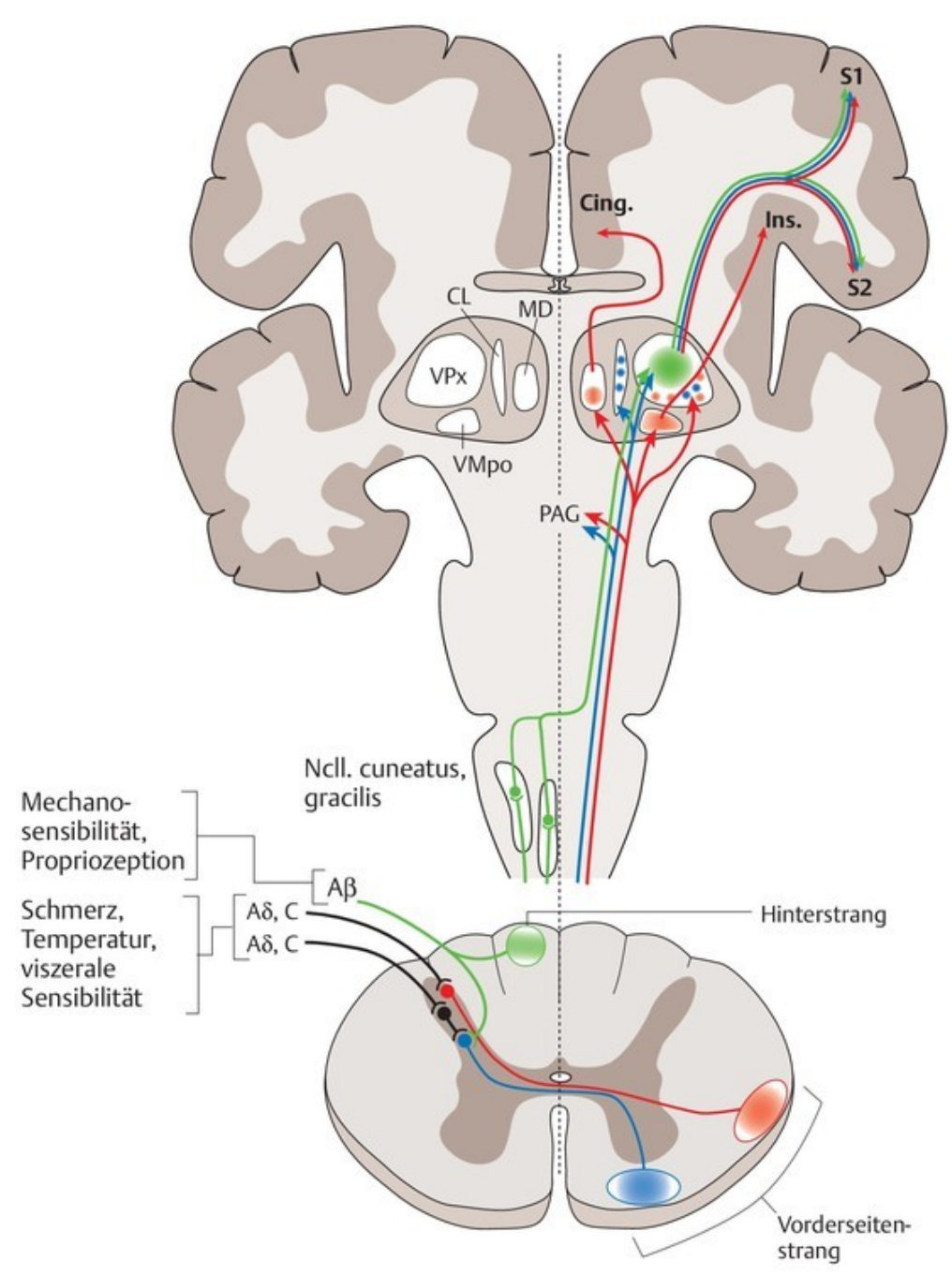

PAG = periaquäduktales Höhlengrau $\mathrm{VMpo}=$ Pars posterior des Ncl. Ventromedialis

$\mathrm{MD}=\mathrm{Ncl}$. Mediodorsalis

$\mathrm{CL}=\mathrm{Ncl}$. Centrolateralis

$\mathrm{VPx}=$ ventroposteriorer Kernkomplex, Cing. $=$ Gyrus cinguli Ins. = Inselkortex

S1, S2 = primärer und sekundärer somatosensibler Kortex

Grün: Lemniskales (Hinterstrang-) System

Blau: Tractus spinothalamicus anterior, ausgehend von WDR- Neuronen in Lamina $V$

Rot: Tractus spinothalamicus lateralis, ausgehend von Lamina I-Neuronen

Abbildung 4 - Zentrale Organisation der somatoviszeralen Sensibilität [21]

\subsubsection{Neuronale Plastizität}

Bei der Verarbeitung besonders starker und anhaltender Schmerzen kommt es im Hinterhorn des Rückenmarks sowie in nachgeschalteten Regionen des ZNS zu plastischen Veränderungen, man spricht von synaptischer Plastizität. Eine schmerzbedingte, vermehrte Ausschüttung exzitatorischer Transmitter, insbesondere Glutamat und Substanz $\mathrm{P}$, führt zu einer Aktivierung unterschiedlicher ionotroper und metabotroper Rezeptoren. Eine besondere Rolle bei der synaptischen Plastizität nimmt der ionotrope NMDA-Rezeptor ein. Dieser ist ein ligandengesteuerter, spannungsabhängiger lonenkanal, der durch freigesetztes Glutamat bei leicht vordepolarisierter Zellmembran aktiviert wird. Diese Vordepolarisation wird durch Bindung von Glutamat an metabotrope oder ionotrope Rezeptoren vom Typ Kainat und AMPA ( $\alpha$-Amino-3Hydroxy-5-Methyl-4-Isoxazolepropionic Acid), sowie durch Bindung von Substanz $P$ am Neurokinin-1-Rezeptor verursacht. Hierdurch wird eine durch Magnesium ausgelöste Blockade des NMDA-Rezeptors aufgehoben. Die Aktivierung führt nachfolgend zu einem starken Anstieg der freien cytosolischen Kalziumkonzentration, einem Trigger für zahlreiche Signaltransduktionswege: Es kommt zur Aktivierung von kalziumabhängigen Enzymen, unter anderem verschiedenen Proteinkinasen (v. a. Proteinkinase $\mathrm{C}$ und Calmodulin-abhängige Proteinkinase 
II), die zur Phosphorylierung von Proteinen, z. B. Glutamatrezeptoren, führen. Zusätzlich erfolgt die Bildung von sogenannten „immediate early genes“, die eine veränderte Genexpression bedingen und so unter anderem die Ausbildung neuer Rezeptoren fördern. Es kommt zu strukturellen und funktionellen Veränderungen der Nervenzelle mit konsekutiv erhöhter Reaktionsbereitschaft auf eingehende Reize. Dieses der Langzeitpotenzierung ähnliche Phänomen wird als Wind-Up bezeichnet. Man spricht von einer zentralen Sensibilisierung, die z. B. mit einer Allodynie oder Hyperalgesie einhergeht [21, 51-54].

\subsection{Bisherige Schmerzmodelle}

Unterschiedliche Faktoren wie Emotionen, Kognition und Grunderkrankung modulieren das Empfinden von Schmerz [48]. Darüber hinaus existieren auch Unterschiede bei der Schmerzwahrnehmung zwischen den Geschlechtern und unterschiedlichen Kulturen $[55,56]$. Oft korreliert daher der empfundene Schmerz nicht mit der Schwere der Pathologie [8]. Experimentelle Schmerzmodelle zur Untersuchung pathophysiologischer Grundlagen müssen daher an gesunden Versuchsprobanden durchgeführt werden, um einen größtmöglichen Ausschluss von Bias zu gewährleisten.

Ein wichtiges Basiskonzept eines Schmerzmodells stellt dabei die Kontrolle über die applizierten Schmerzparameter und Erhebungsverfahren dar [57]. Die Lokalisation, Dauer und Intensität bestimmen die Quantität nozizeptiver Informationen, die das zentrale Nervensystem aus der Peripherie erhält. Daher müssen diese Parameter standardisiert und kontrolliert werden [58].

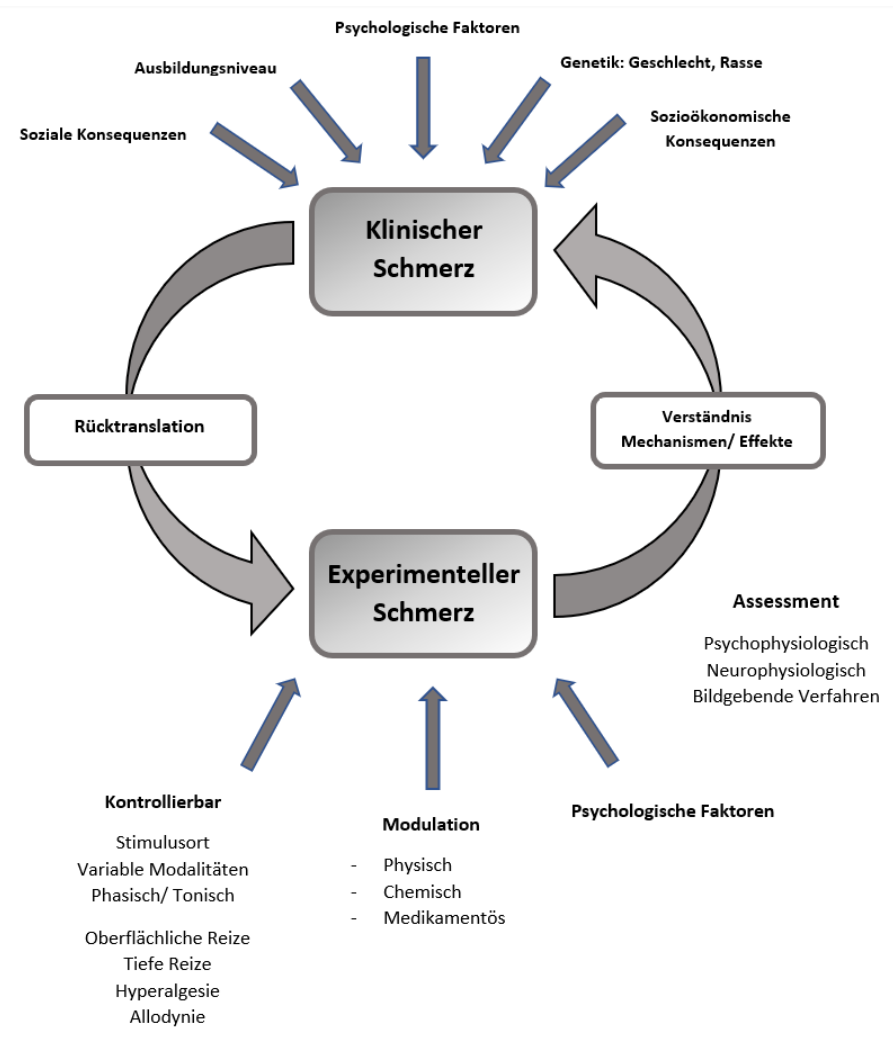


Bisherige Schmerzmodelle befassten sich vor allem mit der Induktion nozizeptiver Stimuli auf der gut zugänglichen Haut. Häufig beschrieben sind thermische, mechanische, chemische und elektrische Methoden. Einen Überblick der bisher etablierten Schmerzmodelle lieferten Curatolo et al. im Jahr 2000 und Olesen et al. im Jahr 2012 [9, 10].

\subsubsection{Schmerzinduktion durch mechanische Reize}

Mechanische Schmerzreize bieten den Vorteil einer exakten und reproduzierbaren Schmerzinduktion. Hierfür werden z. B. kalibrierte Frey Filamente verwendet, die, vermittelt über A- $\delta$ Fasern, eine nadelstichartige Sensation hervorrufen. Diese Methodik ist limitiert, da ausreichend starke mechanische Schmerzstimuli ohne Gewebsschäden nicht realisierbar sind. Hingegen spielen Frey Filamente eine wichtige Rolle bei der Identifizierung einer Hyperalgesie oder Allodynie im Rahmen der Diagnostik neuropathischer Schmerzen [9, 59]. Die Anwendung von Druckalgometern kann die Intensität eines mechanischen Schmerzreizes erhöhen. Die Methodik ermöglicht aber keinen schnellen und präzise kontrollierbaren Stimulus [60].

\subsubsection{Schmerzinduktion durch thermische Reize}

In den meisten Schmerzmodellen findet sich die Anwendung schmerzhafter Hitze- oder Kältestimuli. Etablierte Modelle zur Induktion von Hitze- oder Kältereizen nutzen unter anderem Thermoden mit Peltiereffekt oder Eiswasserimmersion [61]. Nachteile thermischer Schmerzinduktion sind individuelle Schmerzschwellen und die Gefahr thermischer Gewebeschäden [62]. Die Transduktionsmechanismen von thermischen Schmerzreizen sind komplex und nach aktuellem Stand der Forschung nicht vollständig verstanden. Da das hier etablierte Schmerzmodell thermische Reize zur Schmerzinduktion verwendet, wird im Folgenden näher auf die Transduktionsmechanismen von Hitze- und Kältestimuli eingegangen.

\subsubsection{Transduktion von nozizeptiven Hitzestimuli}

Oberhalb der thermischen Schmerzschwelle von circa $40-45^{\circ} \mathrm{C}$ zeigen unterschiedliche Klassen von Nozizeptoren (unter anderem der TRPV1-Kanal) eine erhöhte Aktivität, die über mehrere Subtypen von Nervenfasern Aktionspotentiale zum zentralen Nervensystem leiten [63, 64]. Gemäß ihrer Aktivierbarkeit durch mechanische (M) oder hitzevermittelte $(H)$ Schmerzreize werden die nozizeptiven $\mathrm{C}$ - und $\mathrm{A} \delta$-Fasern in Subtypen unterteilt (unter anderem $\mathrm{C}-\mathrm{MH}$, C-M, C-H, A-MH Typ I, A-MH Typ II, A-M). Die Aktivierung von A - -Fasern (A-MH Typ II) vermittelt einen raschen „ersten Schmerz". Dieser unterliegt einer ausgeprägten Adaptation bei repetitiven Stimuli. Die A-MH Typ II-Fasern zeigen außerdem eine Sensibilisierung nach topischer Applikation von Capsaicin [65-67]. Der sogenannte „zweite Schmerz“, entwickelt sich deutlich langsamer, ist schlechter zu lokalisieren und wird durch die Aktivierung von C-Fasern und A-MH Typ II-Fasern verursacht $[60,63,68]$.

\subsubsection{Transduktion von nozizeptiven Kältestimuli}

Die Transduktion nozizeptiver Kältestimuli ist zum aktuellen Stand der Wissenschaft wenig verstanden. Das Abkühlen der Haut unter die thermische Schmerzschwelle aktiviert sowohl A $\delta$ - als auch C-Fasern. Ein wichtiger Rezeptor zur Wahrnehmung von Kälte ist der TRPM8Rezeptor, dessen Aktivitätsspektrum auch in den Bereich nozizeptiver Kältestimuli reicht [69, 70]. Ein weiterer Nozizeptor für schmerzhafte Kältereize ist der TRPA1-Rezeptor. Im Vergleich zum TRPM8-Rezeptor weist dieser eine signifikant niedrigere Aktivierungstemperatur auf (19 ${ }^{\circ} \mathrm{C}$ versus $25^{\circ} \mathrm{C}$ ), und zeigt einen deutlich längeren Verlauf zur Entwicklung der maximalen 
Rezeptorantwort. Karashima et al. konnten im Jahr 2009 nachweisen, dass TRPA1-Neurone 80 $\%$ der Maximalantwort erst nach etwa $84 \pm 6$ Sekunden ausbilden, im Vergleich zu TRPM8Neuronen, die $33 \pm 2$ Sekunden benötigen [71]. TRPA1-Rezeptoren werden zusammen mit TRPV1-Rezeptoren auf afferenten C-Faser-Neuronen koexprimiert [72].

\subsubsection{Schmerzinduktion durch chemische Reize}

Die Applikation chemischer Substanzen kann afferente nozizeptive Fasern nicht nur aktivieren, sondern auch eine Sensibilisierung der Nozizeptoren mit konsekutiver Hyperalgesie und Allodynie bewirken. Charakteristisch sind hierdurch erniedrigte Schmerzschwellen für multimodale Schmerzreize. Oft lässt sich die neurogene Inflammation als Rötung und Schwellung objektivieren. Sie ist $u$. a. auf die CGRP-vermittelte Vasodilatation durch aktivierte $A \delta$ - und CFasern zurückführen [62]. Die chemische Induktion kutaner Hyperalgesie und Allodynie war bereits häufig Gegenstand der Forschung: Hierfür wurden Substanzen wie Capsaicin, Menthol oder Nerve Growth Factor (NGF) verwendet, die entweder topisch oder intradermal appliziert wurden und durch verschiedene molekulare Mechanismen eine neurogene Inflammation bedingen. Da es hierdurch auch zu erniedrigten Schmerzschwellen für thermische Reize kommt, basieren viele beschriebene Schmerzmodelle auf der Kombination von topisch applizierten, chemischen Agenzien und thermischen Stimuli $[41,73,74]$.

\subsubsection{Schmerzinduktion durch elektrische Reize}

Mithilfe von auf der Haut positionierten Elektroden kann eine elektrische Stimulation erfolgen, die in ihrer Frequenz, Wellenform, und Stimulusdauer zahlreiche Variationen bietet. Nozizeptive Fasern werden unter Umgehung ihrer Rezeptoren direkt axonal stimuliert. Der Vorteil ist eine bessere Kontrolle über die nozizeptive Aktivität. Es konnte gezeigt werden, dass elektrische Stimuli von $50 \mathrm{~mA}$ mit einer Dauer von 0,5 ms eine sekundäre mechanische Hyperalgesie mit Rötung verursachen [75]. C-Fasern weisen dabei eine höhere Aktivierungsschwelle als Aठ-Fasern auf [60].

\section{Zielsetzung der Studie}

Akutschmerzmodelle fanden in den letzten Jahren bei der Erforschung pathophysiologischer Mechanismen von Schmerzen und zur Validierung analgetischer Therapien Anwendung. Die beschriebenen Verfahren unterscheiden sich zum Teil deutlich und es fehlen standardisierte Protokolle, oft bedingt durch die Anpassung der jeweiligen Modelle an individuelle Fragestellungen der Studien. Daher sind die bisher erhobenen Daten und Erkenntnisse oft nur bedingt vergleich- und reproduzierbar. Darüber hinaus sind die bestehenden Akutschmerzmodelle überwiegend durch kurze Versuchsdauern (Sekunden bis Minuten) charakterisiert, sodass die Übertragbarkeit wissenschaftlicher Erkenntnisse auf klinischen Schmerz zumindest kritisch hinterfragt werden sollte.

Ziel dieses Forschungsprojekts war daher die Etablierung eines standardisierten Protokolls für ein randomisiertes Akutschmerzmodell, das unter größtmöglichem Ausschluss von Bias signifikante, phasische Schmerzreize variabler Versuchsdauer induzieren kann. 
„Folgende Anforderungen wurden dabei an das zu etablierende Akutschmerzmodell gestellt:

1. Hohe Toleranz der nozizeptiven Stimuli durch Studienteilnehmer mit der Möglichkeit des sofortigen Versuchsabbruchs bei Intoleranz

2. Vermeidung von schweren reversiblen oder irreversiblen Gewebeschäden

3. Hohe Intensität des Schmerzstimulus mit einer durchschnittlich empfundenen Schmerzstärke von $\geq 6$ auf einer Numerischen Ratingskala (NRS) von 0 - 10

4. Erweiterung der Versuchsdauer unter Einhaltung zuvor genannter Anforderungen“ [11]

Die Induktion nozizeptiver Reize erfolgte mittels eines Geräts zur Quantitativ Sensorischen Testung (QST). Über das Peltier-Element des QST-Geräts können Hitze- und Kältestimuli auf der Haut induziert werden. Um das Risiko thermischer Gewebeschäden zu minimieren, fand in dem etablierten Model topisch appliziertes Capsaicin Anwendung. Dieses führt nach lokaler Anwendung zu einer neurogenen Inflammation mit Hyperalgesie und somit zu einer signifikanten Absenkung der Schmerzschwelle für Hitzereize.

„Unter Berücksichtigung der oben genannten Anforderungen an das Akutschmerzmodell wurde der folgende Versuchsablauf festgelegt:

1. Vorversuch: Detektion der Hitze- und Kälteschmerzschwellen zur Festlegung der Ausgangstemperatur (supramaximaler Reiz) der Thermode

2. Vorversuch: Detektion der zeitlichen Aspekte zentraler und peripherer Adaptationsmechanismen auf Schmerzreize zur Festlegung der Dauer der Hitze- und Kältestimuli

3. Hauptversuch: Etablierung und Validierung eines Hitze- und Kälteschmerzmodells anhand der aus den Vorversuchen erhobenen Daten

4. Nachversuch: Erweiterung der Versuchsdauer „, [11]

\section{Material und Methodik}

\subsection{Probandenkollektiv}

Für die experimentellen Untersuchungen wurden gesunde, volljährige, schmerzfreie Probanden akquiriert. Eingeschlossen wurden insgesamt 15 Frauen (Alter von 20 - 51 Jahren, MW = 29,3 STABW = 8,0) und 15 Männer (Alter von $24-43$ Jahren, $M W=29,1 \mathrm{STABW}=5,0$ ). Eine Schwangerschaft war ebenso Kontraindikation für den Einschluss in die Studie wie akute oder chronische Erkrankungen. Eine Schmerzakzeptanz war bei allen Teilnehmern gegeben. Alle Teilnehmer gaben ihr schriftliches Einverständnis, nachdem eine schriftliche und mündliche Aufklärung über die Studiengrundlage und den Versuchsablauf stattgefunden hatte. Die Untersuchungen wurden entsprechend der Richtlinien der Deklaration von Helsinki und des von der Ethikkommission der Ludwig-Maximilians-Universität in München genehmigten Studienprotokolls (Protokollnummer: 363-15) durchgeführt.

\subsection{Fragebögen und Assessment}

Mithilfe eines standardisierten Fragebogens (s. Anhang) wurden von jedem Probanden Daten bezüglich des Geschlechts, des Alters, des Bildungsstandes, der Körpergröße und des Gewichts 
erfasst. Neben einer aktuell bestehenden oder stattgehabten Kranken- und Schmerzanamnese wurde auch die medikamentöse Schmerztherapie der letzten vier Wochen eruiert. Vor dem Hintergrund des biopsychosozialen Modells von Schmerzen musste zusätzlich ein Anamnesebogen zur aktuellen Beanspruchung ausgefüllt werden (Kurzfragebogen zur aktuellen Beanspruchung, KAB-Score, s. Anhang). Die empfundene Schmerzintensität wurde zu mehreren Zeitpunkten anhand einer numerischen Schmerzskala (NRS) von 0-10 gemessen. 0 steht hierbei für keinen, 10 für einen maximal vorstellbaren Schmerz.

\subsection{Entwicklung der Akutschmerzmodelle}

Die Anforderung an das Schmerzmodell war die Induktion eines thermischen Schmerzstimulus von variabler Dauer mit einer durchschnittlichen Schmerzintensität von $\geq 6 / 10$ auf einer numerischen Schmerzskala. Zur Erstellung eines geeigneten Schmerzmodells zur Induktion thermischer Schmerzreize wurden, gemäß der Zielsetzung der Studie, zunächst Vorversuche zur Detektion der Hitze- und Kälteschmerzschwellen, sowie zu zeitlichen Aspekten der peripheren und zentralen Schmerzadaptation unter den beschriebenen Versuchsbedingungen durchgeführt. Mithilfe der erhobenen Daten konnten die Parameter der Hitze- und Kälteschmerzmodelle festgelegt und im Hauptversuch validiert werden. Hierfür wurden drei Versuchsgruppen etabliert: Eine Kälteschmerz-, eine Hitzeschmerz- und eine Kontrollgruppe. Die Probanden der Kälteschmerzgruppe durchliefen ein Kälteschmerzmodell, während die Versuchsteilnehmer der Hitzeschmerz- und Kontrollgruppe ein identisches Hitzeschmerzmodell durchliefen. Die Versuchsteilnehmer der Hitzeschmerzgruppe wurden zur Schmerzverstärkung mit einer Capsaicin-Creme behandelt. Dadurch konnten die verwendeten Thermodentemperaturen signifikant gesenkt und somit auch die Gefahr thermischer Schäden minimiert werden [76].

\subsubsection{Das QST-Gerät}

Das in dieser Studie etablierte Schmerzmodell nutzte ein Gerät zur Quantitativ Sensorischen Testung, um schmerzhafte, thermische Reize zu induzieren (QST, TSA-II NeuroSensory Analyzer, Medoc Ltd. Advanced Medical Systems Inc., Ramat Ishai, Israel) (s. Abbildung 6). Die Kontaktfläche der Thermode des TSA II hatte eine Auflagefläche von $3 \times 3 \mathrm{~cm}$ und erzeugte über den Peltiereffekt bei Stromdurchfluss Wärme oder Kälte. Die verwendete Software war Medoc Main Station Version 6.4.0.2.2 TSA II. Die Thermode des QST-Gerätes wurde mithilfe eines Klettverschlusses über den Versuchsarealen an den volaren Unterarmseiten, etwa $2 \mathrm{~cm}$ proximal der Handgelenksfalten, fixiert. Ein Temperaturspektrum von $0-50^{\circ} \mathrm{C}$ wurde nicht überoder unterschritten, um thermische Gewebeschäden zu vermeiden. 


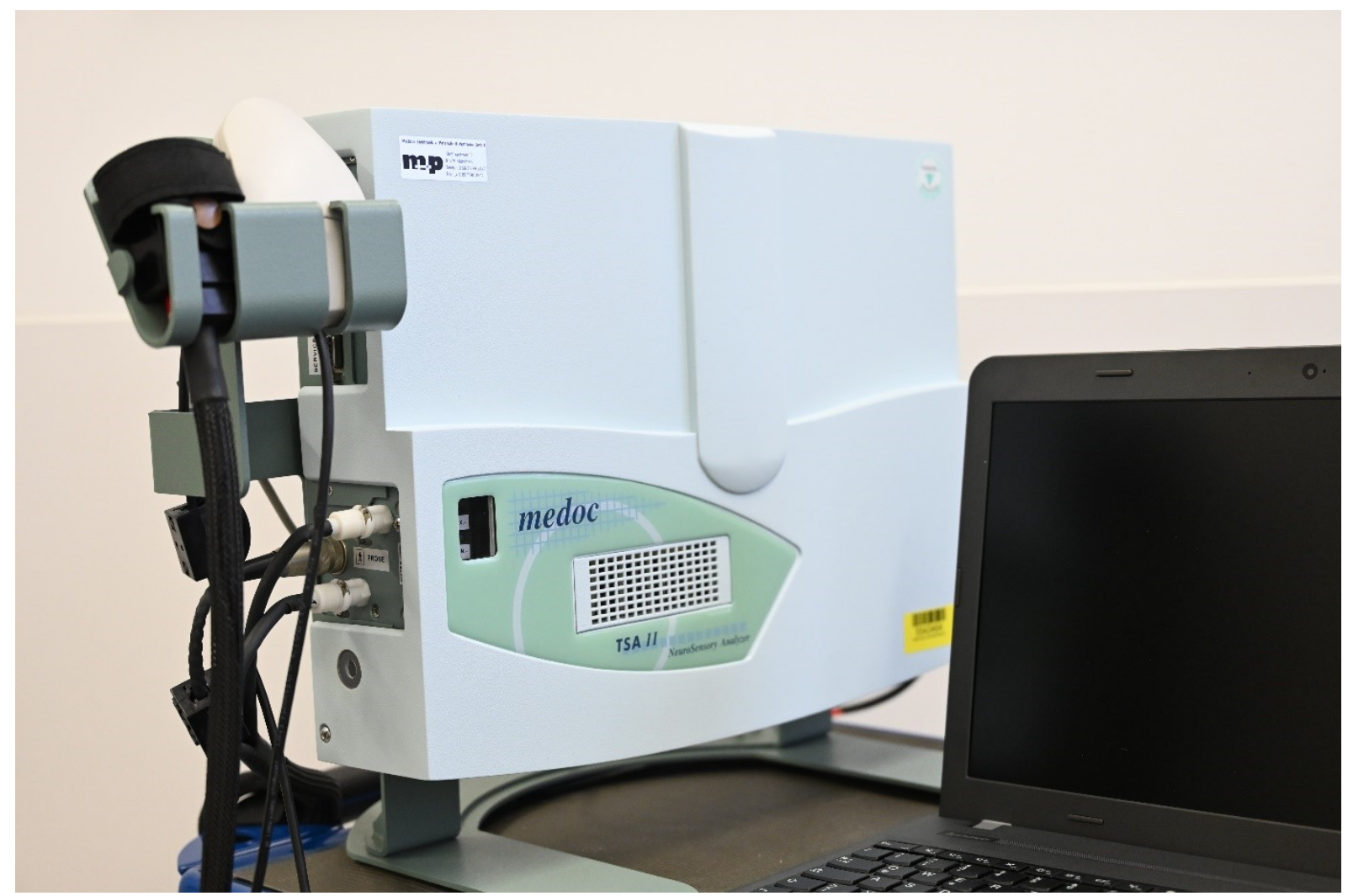

Abbildung 6-Gerät zur Quantitativ Sensorischen Testung

\subsubsection{Versuchsvorbereitung}

In den Vor- und Hauptversuchen erfolgte, entsprechend den jeweiligen Versuchsvorgaben, zunächst eine Vorbereitung der Versuchsareale der Probanden. Aus Gründen der Verblindung erhielt jeder Proband eine topische Anwendung einer Creme. Je nach Gruppeneinteilung wurde dazu entweder eine handelsübliche und frei verkäufliche Capsaicin-Creme (Beiersdorfer AG: Hansaplast ABC Wärmecreme, 750 mg/g, Hamburg, Deutschland) oder eine handelsübliche Feuchtigkeits-Creme (Silonda Healthcare Hautlotion, Ecolab Inc., Saint Paul, USA) verwendet.

Die Vorbereitung begann mit der Reinigung eines etwa $4 \times 4 \mathrm{~cm}$ großen Hautareals, ca. $2 \mathrm{~cm}$ proximal der volaren Handgelenksfalte, mit einem alkoholischen Desinfektionsmittel (Softasept N, B. Braun AG, Melsungen, Deutschland. Es folgte das Auftragen einer etwa haselnussgroßen Menge der jeweiligen Creme. Anschließend wurde ein Okklusivverband (Opsite Flexifix PU Folie, Smith \& Nephew GmbH, London, UK) zur Wirkverstärkung angelegt. Dabei bewirkt der Okklusivverband durch den wasserdichten Verschluss eine Quellung der Hornhautschicht. Die perkutane Absorption wird so um ein Vielfaches erhöht [77, 78]. Nach 20 Minuten Einwirkzeit wurde der Okklusivverband entfernt, die Creme-Rückstände entfernt und das Versuchsareal mit alkoholischem Desinfektionsmittel gereinigt. Es folgte die Fixierung der Thermode des QST-Gerätes über dem zuvor behandelten Areal mit dem Klettverschluss. Hierbei wurde auf einen einheitlichen, nicht zu festen oder zu unsicheren Sitz geachtet, um Messverfälschungen zu minimieren (s. Abbildung 7). 
Zur Vermeidung von Gewebeschäden wurde die maximale Reizinduktionsdauer pro Versuchsareal auf 5 Minuten begrenzt. Daher wurden in den Haupt- und Nachversuchen entsprechend den unten genannten Aufführungen mehrere Versuchsareale an den volaren Unterarmen vorbehandelt. Der Thermodenwechsel erfolgte bei mehreren Programmdurchläufen stets an den kontralateralen Arm. Neben der Reduktion der Gefahr von Gewebeschäden, können so zentrale Sensibilisierungsprozesse ausgenutzt werden: Ein in seiner Intensität gleicher Stimulus wird als schmerzhafter empfunden, wenn er konsekutiv am gegenüberliegenden Arm gesetzt wird [79].
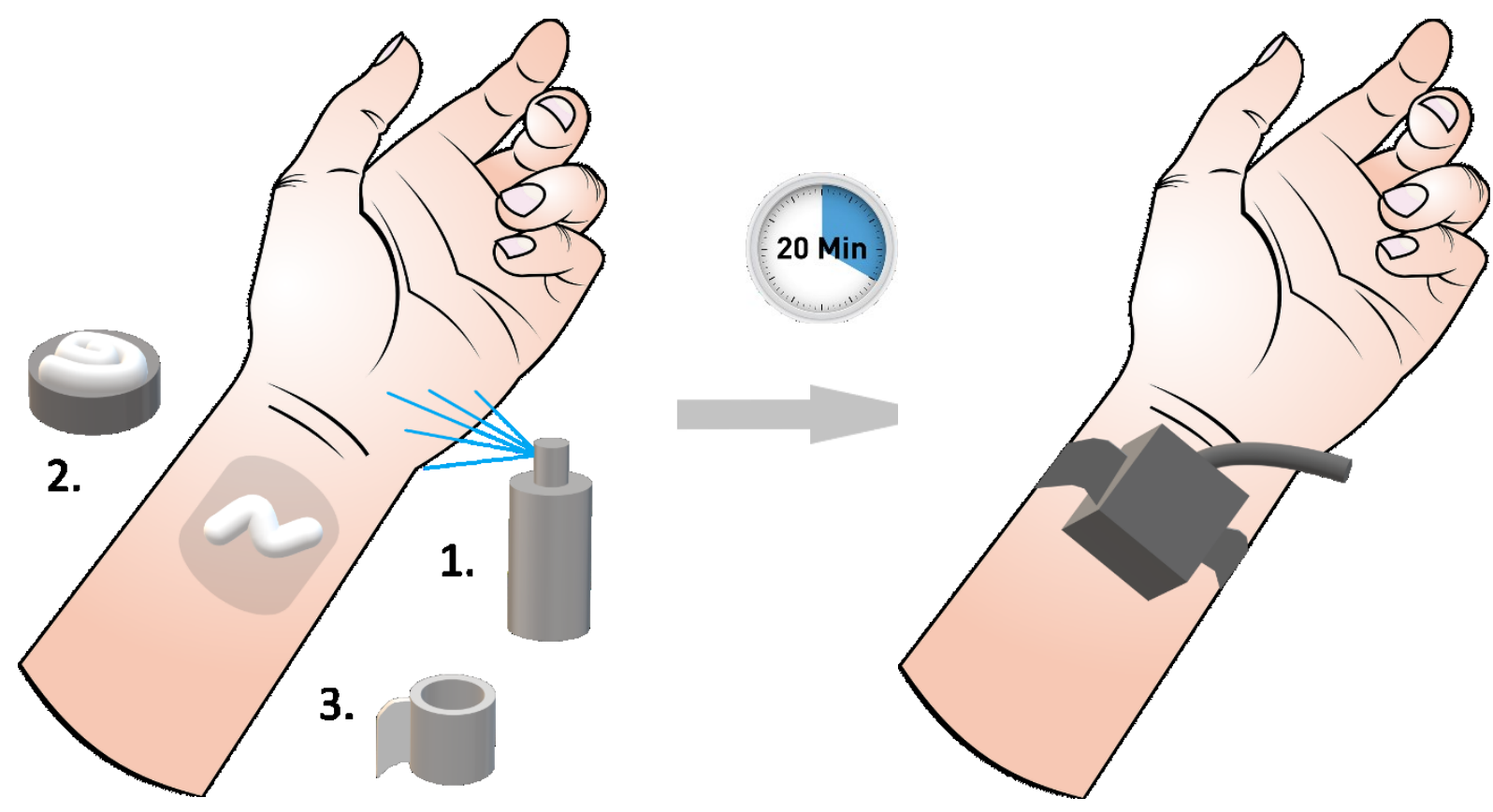

Abbildung 7-Schematischer Versuchsaufbau. Links: Zunächst wird das Hautareal mit alkoholischer Desinfektionslösung gereinigt (1.). Die Creme wird anschließend auf einem $4 \times 4 \mathrm{~cm}$ großen Areal am volaren Unterarm appliziert (2.). Es erfolgt die Anlage eines Okklusivverbands für eine 20 Minuten lange Einwirkzeit (3.). Rechts: Anschließend wird mit der Testung begonnen.

\subsubsection{Vorversuch „Detektion der thermischen Schmerzschwellen“}

Damit ein signifikanter Schmerzreiz über die gesamte Versuchsdauer erzielt werden konnte, musste die initiale Thermodentemperatur bereits im Schmerzbereich der Kälte- bzw. Hitzerezeptoren liegen. Bezüglich der physiologischen Schmerzschwellen im Hitze- und Kältebereich liegt eine umfangreiche Datenlage vor. Als Vergleichsgruppe diente die Kontrollgruppe der DFNS (Deutscher Forschungsverbund Neuropathischer Schmerz). Die Schmerzschwellen sind gut erforscht und liegen je nach Studie bei $45 \pm 0,5^{\circ} \mathrm{C}$ und $0-10{ }^{\circ} \mathrm{C}[80,81]$.

Zunächst erfolgte mit 5 randomisiert ausgewählten Probanden eine Untersuchung der Kälteund Wärmeschmerzschwelle nach dem Protokoll der Quantitativ Sensorischen Testung der DFNS [81]. In einer weiteren Versuchsreihe wurde der Einfluss von topisch appliziertem Capsaicin auf die Hitzeschmerzschwelle untersucht. Die Vorbereitung der Versuchsteilnehmer wurde entsprechend der Anleitung unter 3.3.2. durchgeführt. Nach Protokoll des DFNS wur- 
den nacheinander die Schmerzschwellen für einen Hitze- und Kältestimulus geprüft. Die Thermode startete bei einer Ausgangstemperatur von $32{ }^{\circ} \mathrm{C}$ und erhitzte oder kühlte sich mit einer Rate von $1{ }^{\circ} \mathrm{C} /$ Sek. Der Proband gab durch das Betätigen einer Fernbedienung an, bei welcher Temperatur die Hitze- oder Kälteschmerzschwelle erreicht war. Das Programm fiel auf die Ausgangstemperatur (Baseline) von $32{ }^{\circ} \mathrm{C}$ zurück und begann mit einer erneuten Messung. Die Messung wurde jeweils fünf Mal wiederholt. Zur Vermeidung einer temporalen Schmerzsummation lag zwischen den einzelnen Stimuli ein Pausenintervall von 10 Sekunden Dauer.

\subsubsection{Vorversuch „Detektion der zeitlichen Aspekte der Schmerzadaptation“}

Zentrale und periphere Adaptationsmechanismen haben einen maßgeblichen Einfluss auf die Schmerzwahrnehmung. Um einen signifikanten, experimentellen Schmerzreiz über mehrere Minuten aufrecht erhalten zu können, muss daher die Dauer eines jeden Hitze- oder Kältestimulus angepasst werden. Um die zeitlichen Aspekte der Schmerzadaptation zu untersuchen, wurde folgender Vorversuch durchgeführt: Ein thermischer Schmerzreiz von 60 Sekunden Dauer wurde 5 randomisiert ausgewählten Probanden zugefügt und die empfundene Schmerzstärke im 5 Sekunden Intervall erhoben.

Diese Versuchsanordnung wurde für einen Hitzestimulus ohne Capsaicin, einen Hitzestimulus nach topischer Applikation einer Capsaicin-Creme und einen Kältestimulus durchgeführt. Die Temperatur des zu setzenden Stimulus ließ sich aus der vorherigen Versuchsreihe "Messung der Hitze- und Kälteschmerzschwelle" ableiten. Der Versuchsaufbau mit Vorbereitung der Versuchsareale war identisch zum Vorversuch (s. 3.3.2.).

\subsubsection{Hauptversuch „Etablierung und Validierung der Hitze- und Kälteschmerzmodelle}

Mithilfe der Daten aus den Vorversuchen konnten die Parameter "Thermodentemperatur“ und „Stimuluslänge“ für das Hitze- und Kälteschmerzmodell festgelegt und drei Schmerzmodelle erstellt werden:

1. Hitzeschmerzmodell mit Applikation einer Placebo-Creme

2. Hitzeschmerzmodell mit Applikation einer Capsaicin-Creme

3. Kälteschmerzmodell mit Applikation einer Placebo-Creme

Zur Erhöhung der Verfahrenssicherheit wurden ein Temperaturspektrum von $0-50^{\circ} \mathrm{C}$ eingehalten, ebenso kam es nach 5 Minuten zur automatischen Abschaltung der Programme. Mithilfe einer Fernbedienung konnten die Versuchsteilnehmer das Programm bei Schmerzintoleranz jederzeit unterbrechen.

Die Probanden wurden zunächst randomisiert drei Gruppen (A, B und C) mit jeweils 10 Personen zugeteilt. Jeder Proband wurde zum Zweck der Verblindung vor Versuchsbeginn im Bereich der Versuchsareale mit einer Creme behandelt. Im Falle der Kälteschmerz- oder Hitzeschmerzgruppe ohne Capsaicin-Creme wurde eine Placebo-Creme aufgetragen (s. 3.3.2.).

Eine versuchsunabhängige Person führte folgende Schritte durch: Zunächst wurden zwei Petrischalen mit der Feuchtigkeits-Creme und eine Petrischale mit der o. g. Capsaicin-Creme befüllt. Willkürlich wurden diese Petrischalen mit den Buchstaben A, B und C versehen. AnschlieBend wurde die Bezeichnung der drei im QST-Gerät hinterlegten Schmerzmodelle ebenfalls in 
A, B und $C$ geändert. Wichtig war, dass die Zuordnung der Capsaicin-Creme zu einem der beiden Hitzeschmerzmodelle gewährleistet wurde. Jedem Probanden konnten nun, entsprechend seiner zufällig zugeteilten Versuchsgruppe, eine Petrischale und ein Versuchsprogramm zugeordnet werden.

Die Vorbereitung der Versuchsteilnehmer erfolgte gemäß den Angaben unter Kapitel 3.3.2. „Versuchsvorbereitung“. Die Schmerzmodelle wurden im Hauptversuch für eine Versuchsdauer von 10 Minuten getestet. Daher wurden entsprechend der obigen Angaben (5 Minuten Programmdauer) beide Unterarme vorbereitet.

Nachdem das der Versuchsgruppe zugeordneten Programm gestartet ist, wurde die empfundene Schmerzintensität während des Versuchs jede Minute erfragt. Nach fünf Minuten endete das Programm und die Thermode wurde umgehend am kontralateralen Versuchsbereich befestigt. Das Programm wurde erneut gestartet und die Erhebung der Schmerzintensität über weitere 5 Minuten fortgeführt.

Abschließend wurden eine Stunde nach Applikation der Creme die Versuchsareale auf Rötung inspiziert und eine finale Erhebung der gegebenenfalls noch bestehenden Schmerzintensität durchgeführt.

\subsubsection{Nachversuch „Erweiterung der Versuchsdauer"}

Nachdem im Hauptversuch die Akutschmerzmodelle für eine Versuchsdauer von 10 Minuten validiert wurden, sollte aufgezeigt werden, dass bei gleichbleibender Schmerzintensität und akzeptanz eine Verlängerung der Versuchsanordnung möglich ist. Hierfür wurde an 10 randomisiert ausgewählten Probanden das zuvor beschriebene Hitzeschmerzmodell nach Applikation einer Capsaicin-Creme für eine Gesamtdauer von 20 Minuten angewendet. Der Versuchsaufbau erfolgte äquivalent zum Hauptversuch. Bei einer Gesamtversuchsdauer von 20 Minuten wurden entsprechend vier Versuchsareale vorbehandelt. Nach 5 Minuten Reizinduktion erfolgte der Wechsel der Thermode stets nach kontralateral.

\subsection{Statistische Methodik}

Die Randomisierung und Auswertung der erhobenen Daten erfolgte mithilfe SPSS, Version 24, IBM Statistics. Die Auswertung von Unterschieden in der mittleren empfundenen Schmerzstärke zwischen den Versuchsgruppen gelang mittels einfaktorieller Varianzanalyse und posthoc-Auswertungen (LSD). Unverbundene, nicht parametrische Daten, z. B. geschlechtsspezifischer Unterschiede, wurden mittels Mann-Whitney-U-Test analysiert. 


\section{Ergebnisse}

\subsection{Vorversuch "Detektion der thermischen Schmerzschwellen“}

Zunächst wurden bei 5 Probanden die Hitze- und Kälteschmerzschwellen nach Protokoll der DFNS und unter den hier vorgegebenen Versuchsbedingungen bestimmt (s. Tabelle 1).

Tabelle 1 - Probandenkollektiv des Vorversuchs "Detektion der thermischen Schmerzschwellen"

\begin{tabular}{|c|c|c|c|c|}
\hline & & & & Probandenkollektiv \\
\hline & & & & $\begin{array}{l}\text { Messung Hitze- und } \\
\text { Kälteschmerzschwellen }\end{array}$ \\
\hline & & & Anzahl & Alter $(\mathrm{MW} \pm \mathrm{STABW})$ \\
\hline & Geschlecht & $\mathrm{m}$ & 3 & $33,7 \pm 8,6$ \\
\hline Alter & & w & 2 & $22,5 \pm 0,7$ \\
\hline & Gesamt & & 5 & $29,2 \pm 8,6$ \\
\hline
\end{tabular}

Die Messung der Hitze- und Kälteschmerzschwellen erfolgte jeweils fünf Mal. Anhand der erhobenen Daten wurden Mittelwerte errechnet (s. Tabelle 2-4).

Tabelle 2-Schmerzschwelle für Hitzereize ohne Vorbehandlung mit Capsaicin

\begin{tabular}{|llll|}
\hline Schmerzschwelle & \multicolumn{3}{l|}{ Hitze ohne Capsaicin } \\
\hline Proband & $\mathrm{MW}$ & VAR & STABW \\
\hline 1 & $45,7^{\circ} \mathrm{C}$ & 3,4 & 2,1 \\
2 & $46,8^{\circ} \mathrm{C}$ & 1,7 & 1,5 \\
3 & $47,8^{\circ} \mathrm{C}$ & 0,9 & 1,0 \\
4 & $44,3^{\circ} \mathrm{C}$ & 2,4 & 1,7 \\
5 & $42,1^{\circ} \mathrm{C}$ & 0,4 & 0,7 \\
\hline MW & $\mathbf{4 5 , 3}{ }^{\circ} \mathrm{C}$ & $\mathbf{1 , 7}$ & $\mathbf{1 , 4}$ \\
\hline MW = Mittelwert, VAR $=$ Varianz, & & \\
STABW = Standardabweichung & & & \\
\hline
\end{tabular}

Tabelle 3 -Schmerzschwelle für Hitzereize nach Vorbehandlung mit Capsaicin

\begin{tabular}{|llll|}
\hline Schmerzschwelle & \multicolumn{3}{l|}{ Hitze mit Capsaicin } \\
\hline Proband & MW & VAR & STABW \\
\hline 1 & $38,2^{\circ} \mathrm{C}$ & 0,6 & 0,8 \\
2 & $37,0^{\circ} \mathrm{C}$ & 0,1 & 0,3 \\
3 & $36,9{ }^{\circ} \mathrm{C}$ & 0,3 & 0,6 \\
4 & $35,3^{\circ} \mathrm{C}$ & 0,0 & 0,2 \\
5 & $35,3^{\circ} \mathrm{C}$ & 0,4 & 0,7 \\
\hline MW & $\mathbf{3 6 , 5}{ }^{\circ} \mathrm{C}$ & $\mathbf{0 , 3}$ & $\mathbf{0 , 5}$ \\
\hline MW = Mittelwert, VAR = Varianz, & & \\
STABW = Standardabweichung & &
\end{tabular}


Tabelle 4 - Schmerzschwelle für Kältereize

\begin{tabular}{|llll|}
\hline Schmerzschwelle & Kälte & & \\
\hline Proband & $\mathrm{MW}$ & VAR & STABW \\
\hline 1 & $3,0^{\circ} \mathrm{C}$ & 3,0 & 1,9 \\
2 & $13,1^{\circ} \mathrm{C}$ & 6,2 & 2,8 \\
3 & $6,1{ }^{\circ} \mathrm{C}$ & 2,0 & 1,6 \\
4 & $11,5^{\circ} \mathrm{C}$ & 5,8 & 2,7 \\
5 & $11,8^{\circ} \mathrm{C}$ & 9,6 & 3,5 \\
\hline MW & $\mathbf{9 , 1}{ }^{\circ} \mathrm{C}$ & $\mathbf{5 , 3}$ & $\mathbf{2 , 5}$ \\
\hline MW = Mittelwert, VAR = Varianz, & & \\
STABW = Standardabweichung & & & \\
\hline
\end{tabular}

Es zeigte sich, wie in bereits anderen Studien beschrieben [76, 82], eine signifikante Erniedrigung der Schmerzschwelle für Hitzereize nach topischer Applikation von Capsaicin. Im Mittelwert war die zu applizierende Temperatur für einen Hitzeschmerz nach Vorbehandlung mit einer Capsaicin-Creme signifikant niedriger $\left(\Delta \mathrm{T}_{\mathrm{MW}}=8,7^{\circ} \mathrm{C}\right.$, STABW $\left.=2,1\right)$ als in der Vergleichsgruppe ohne Capsaicin $(p<0,05)$. Es zeigte sich kein statistisch signifikanter Geschlechterunterschied bezüglich der thermischen Schmerzschwellen, weder für Kältereize $(p=0,20)$, noch für Hitzereize ohne $(p=1,00)$ oder mit Vorbehandlung mittels Capsaicin $(p=0,40)$.

\subsection{Vorversuch "Detektion der zeitlichen Aspekte der Schmerzadaptation“} In diesem Vorversuch wurden die zeitlichen Aspekte zentraler und peripherer Adaptationsmechanismen auf Schmerzreize an 5 randomisiert ausgewählten Probanden untersucht (s. Tabelle 5).

Tabelle 5 - Probandenkollektiv des Vorversuchs „Detektion der zeitlichen Aspekte der Schmerzadaptation“

\begin{tabular}{|c|c|c|c|c|}
\hline & & & & Probandenkollektiv \\
\hline & & & & Schmerzadaptation \\
\hline & & & Anzahl & Alter $(\mathrm{MW} \pm \mathrm{STABW})$ \\
\hline & Geschlecht & $\mathrm{m}$ & 3 & $32,3 \pm 7,5$ \\
\hline Alter & & w & 2 & $24,0 \pm 0,0$ \\
\hline & Gesamt & & 5 & $29,0 \pm 7,0$ \\
\hline
\end{tabular}

In diesem Vorversuch wurde ein 60 Sekunden anhaltender, thermischer Schmerzreiz gesetzt. Die Temperatur wurde anhand der zuvor ermittelten thermischen Schmerzschwellen bestimmt: Die Thermodentemperatur wurde für den Hitzeschmerz ohne Capsaicinapplikation auf $46^{\circ} \mathrm{C}$ und nach topischer Capsaicin-Creme auf $38^{\circ} \mathrm{C}$ festgelegt. Die Induktion eines Kälteschmerzes wurde zunächst bei $8^{\circ} \mathrm{C}$ durchgeführt. Die Probanden bewerteten im 5 Sekunden Intervall ihre empfundene Schmerzintensität.

Bei einer Thermodentemperatur von $46{ }^{\circ} \mathrm{C}$ ohne vorherige Applikation von Capsaicin gaben die Versuchsteilnehmer die maximale empfundene durchschnittliche Schmerzintensität von 
NRS $=6,2$ (STABW $=0,8)$ nach 10 Sekunden Dauer an. Nach 30 Sekunden betrug die durchschnittliche NRS $=4,6$ (STABW $=0,5$ ) und zum Zeitpunkt von 60 Sekunden lag sie nur noch bei einer NRS von 2,4 (STABW =0,5) (s. Abbildung 8 und 9).

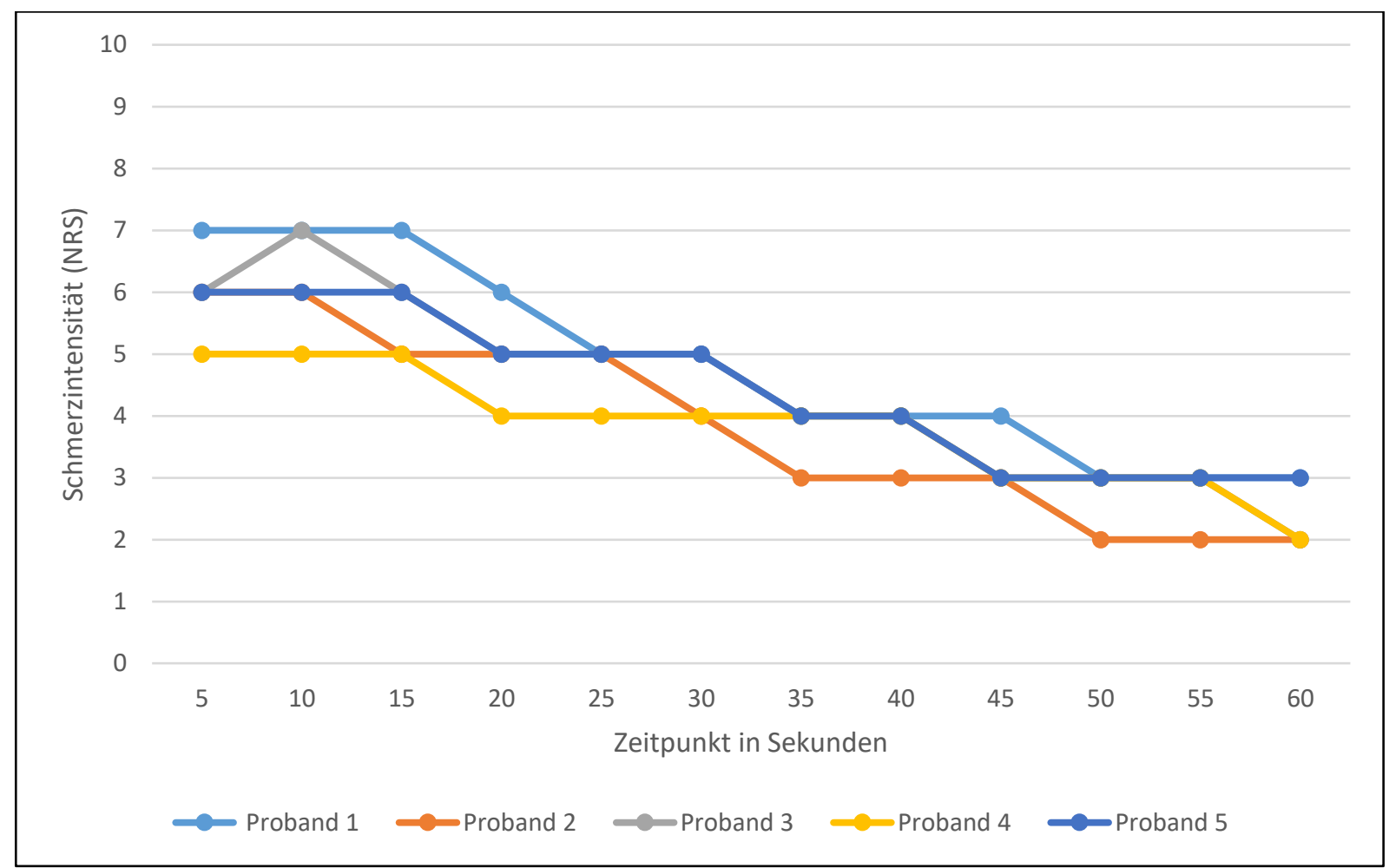

Abbildung 8 - Adaptationskurven bei $46{ }^{\circ} \mathrm{C}$ ohne Vorbehandlung mit Capsaicin. Dargestellt ist die empfundene Schmerzintensität eines tonischen Hitzestimulus von $46{ }^{\circ} \mathrm{C}$ ohne Applikation von Capsaicin in Abhängigkeit von der Versuchsdauer [11]. 


\section{Ergebnisse}

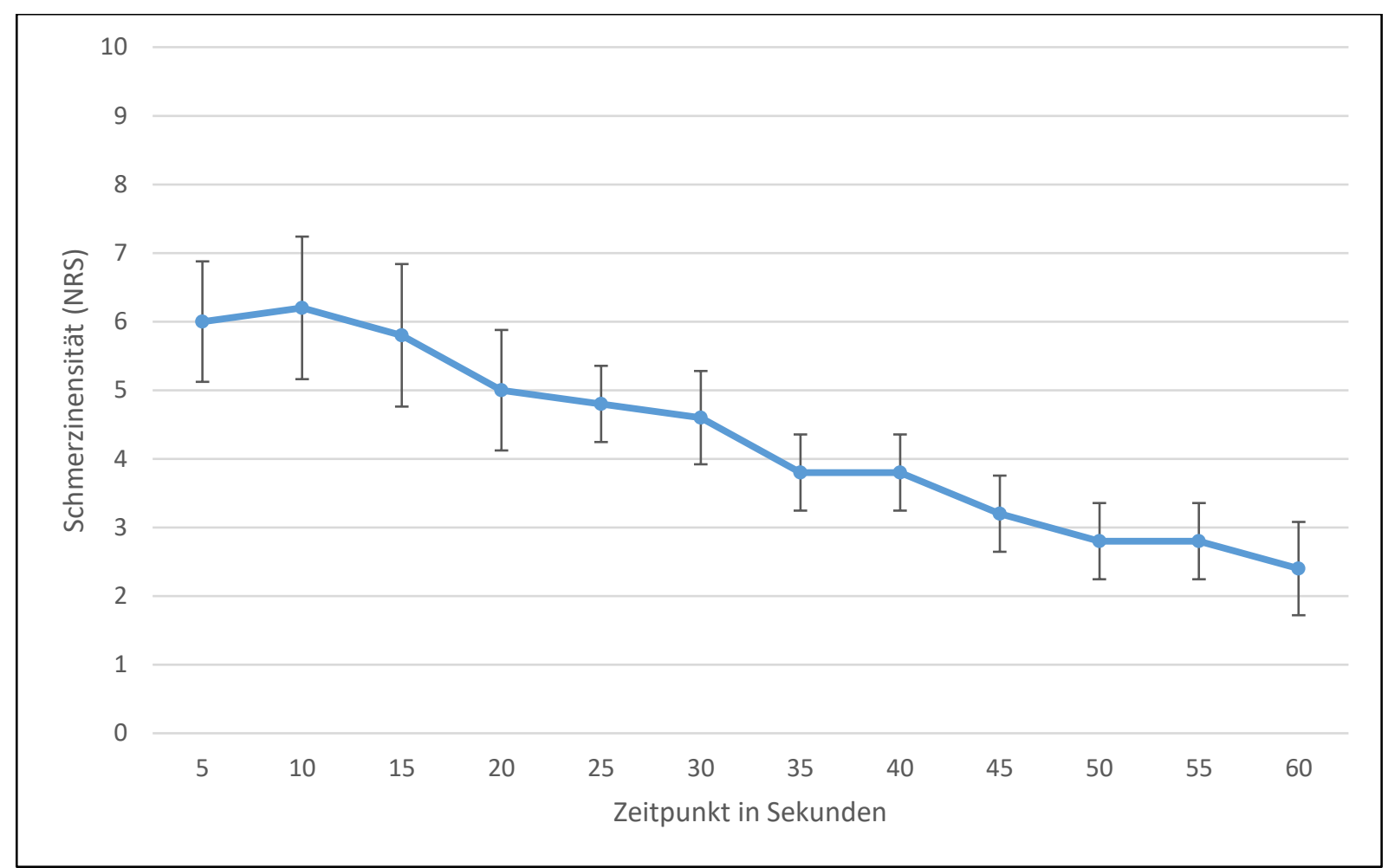

Abbildung 9-Adaptationskurve bei $46^{\circ} \mathrm{C}$ ohne Vorbehandlung mit Capsaicin. Dargestellt sind die durchschnittlich empfundene Schmerzintensität eines tonischen Hitzestimulus von $46^{\circ} \mathrm{C}$ ohne Applikation von Capsaicin in Abhängigkeit von der Versuchsdauer sowie die dazugehörigen $95 \%$ Konfidenzintervalle [11].

Bei einer Thermodentemperatur von $38^{\circ} \mathrm{C}$ nach vorheriger Behandlung mit Capsaicin zeigte sich bereits nach 5 Sekunden Versuchsdauer die durchschnittlich maximale empfundene Schmerzintensität von NRS $=6,2$ (STABW $=0,8$ ). Nach 30 Sekunden betrug die durchschnittliche Schmerzintensität NRS $=5($ STABW $=0,6)$. Zum Zeitpunkt von 60 Sekunden lag die beobachtete empfundene Schmerzstärke bei NRS $=3(\mathrm{STABW}=0,6)$ (s. Abbildung 10 und 11). 


\section{Ergebnisse}

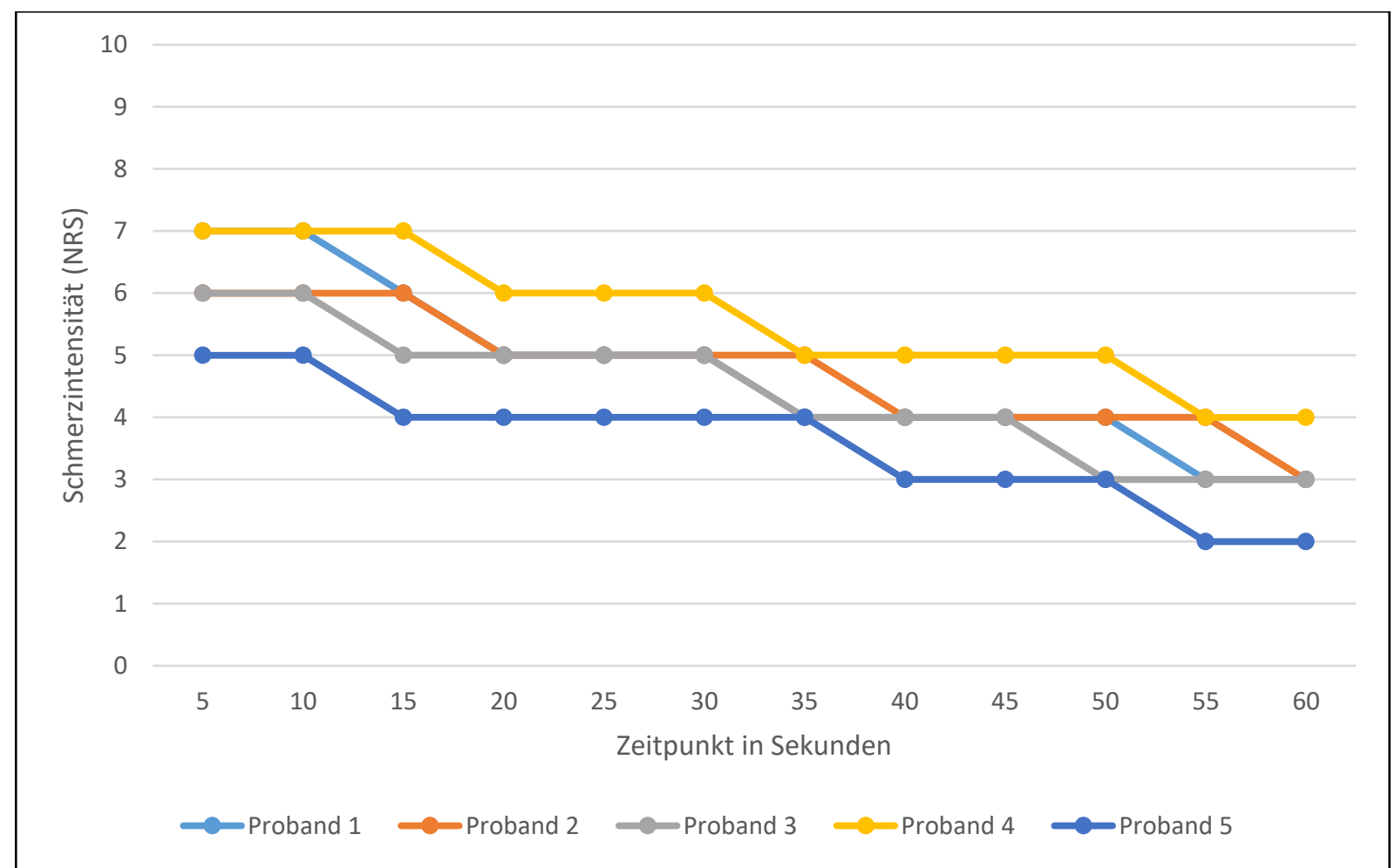

Abbildung 10 - Adaptationskurven bei $38^{\circ} \mathrm{C}$ nach Vorbehandlung mit Capsaicin. Dargestellt ist die empfundene Schmerzintensität eines tonischen Hitzestimulus von $38^{\circ} \mathrm{C}$ nach Applikation von Capsaicin in Abhängigkeit von der Versuchsdauer [11].

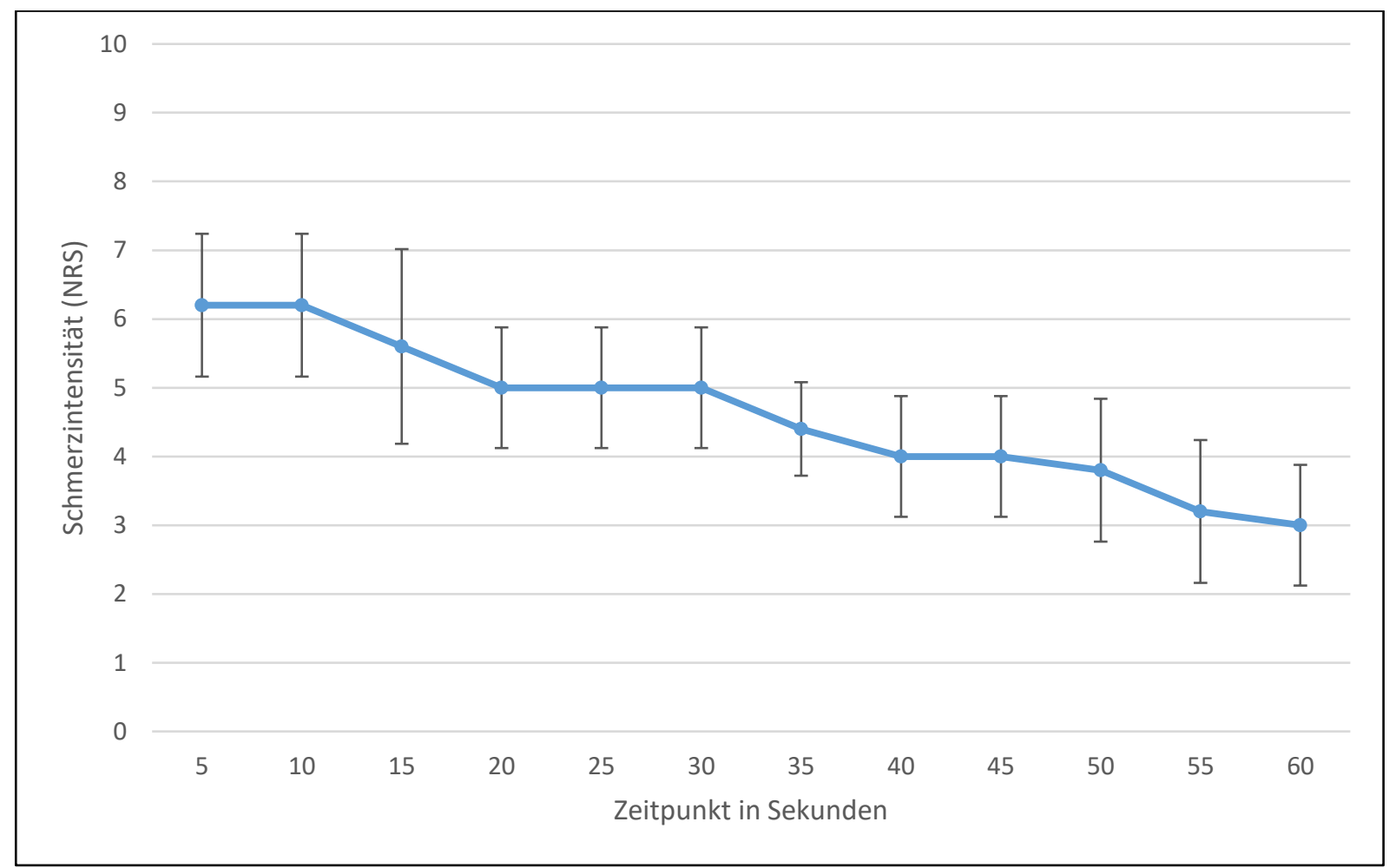

Abbildung 11 - Adaptationskurve bei $38^{\circ} \mathrm{C}$ nach Vorbehandlung mit Capsaicin. Dargestellt sind die durchschnittlich empfundene Schmerzintensität eines tonischen Hitzestimulus von $38^{\circ} \mathrm{C}$ nach Applikation von Capsaicin in Abhängigkeit von der Versuchsdauer sowie die dazugehörigen $95 \%$ Konfidenzintervalle [11]. 
Bei der Untersuchung der Adaptationszeiten für Kältereize zeigte sich, dass eine Thermodentemperatur von $9^{\circ} \mathrm{C}$ nur ein Schmerzintensitätsmaximum von NRS $=3,2(S T A B W=0,8)$ generieren konnte und somit deutlich unter der festgelegten Anforderung einer Mindestschmerzintensität von NRS $\geq 6$ lag (s. Abbildung 12 und 13). Daher erfolgten weitere Versuchsreihen mit Kälteimpulsen von $4^{\circ} \mathrm{C}$ und $2{ }^{\circ} \mathrm{C}$.

Die Probanden, die einen Kältereiz von $4{ }^{\circ} \mathrm{C}$ erhielten, gaben nach einer Induktion von $35 \mathrm{Se}-$ kunden Dauer die maximale durchschnittliche Schmerzintensität von NRS 4,2 (STABW =0,8) an (s. Abbildung 14 und 15). In der Versuchsanordnung mit einer Thermodentemperatur von $2{ }^{\circ} \mathrm{C}$ wurde ebenfalls die maximale Schmerzintensität mit einer NRS von 5,8 (STABW $\left.=0,8\right)$ nach 35 Sekunden angegeben (s. Abbildung 16 und 17). In den Adaptationskurven bei $4{ }^{\circ} \mathrm{C}$ und $8{ }^{\circ} \mathrm{C}$ fällt ein Schmerzintensitätsplateau auf, welches von Beginn der jeweiligen Maximalschmerzstärke bis etwa 45 Sekunden Reizdauer anhält. Nach 45 Sekunden nehmen die empfundenen Schmerzintensitäten bei $8{ }^{\circ} \mathrm{C}$ und $4{ }^{\circ} \mathrm{C}$ Thermodentemperatur ab. Bei $2{ }^{\circ} \mathrm{C}$ ist das Plateau weniger stark ausgeprägt, die empfundene Schmerzstärke nimmt zwischen $35-40$ Sekunden wieder ab.

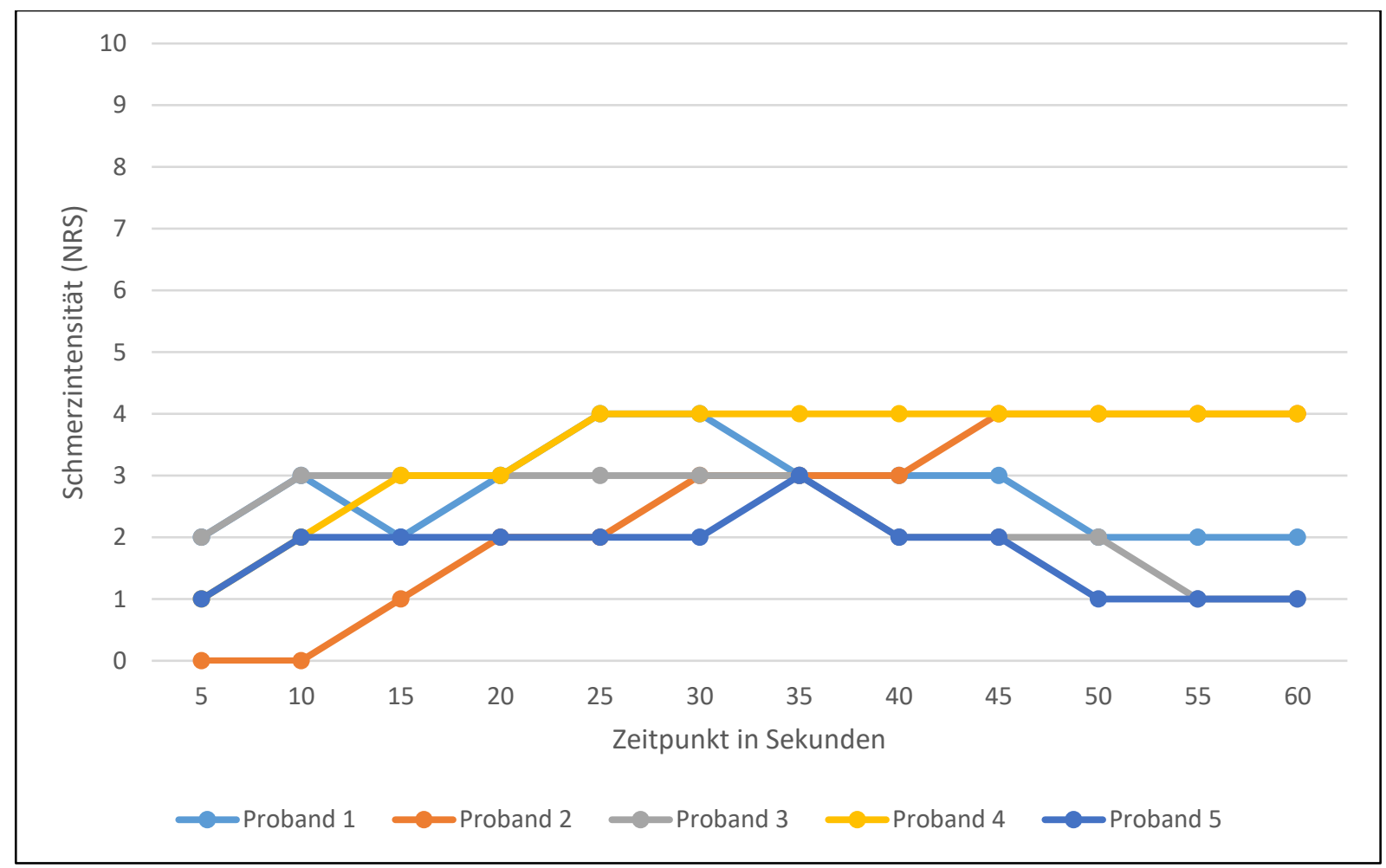

Abbildung 12 - Adaptationskurven bei Kältereiz von $8{ }^{\circ} \mathrm{C}$. Dargestellt ist die empfundene Schmerzintensität eines tonischen Kältestimulus von $8^{\circ} \mathrm{C}$ in Abhängigkeit von der Versuchsdauer. 


\section{Ergebnisse}

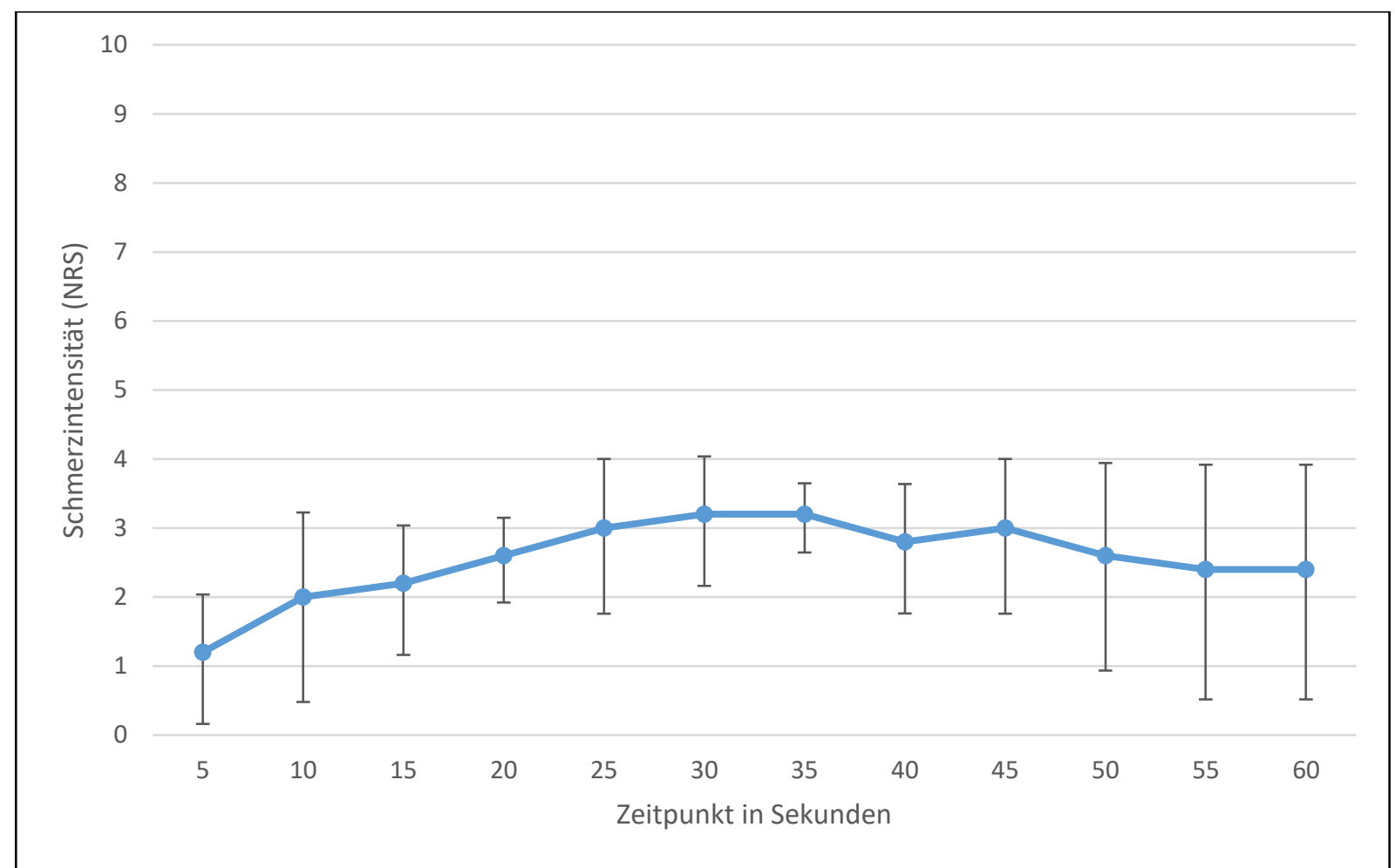

Abbildung 13 - Adaptationskurve bei Kältereiz von $8{ }^{\circ} \mathrm{C}$. Dargestellt sind die durchschnittlich empfundene Schmerzintensität eines tonischen Kältestimulus von $8{ }^{\circ} \mathrm{C}$ in Abhängigkeit von der Versuchsdauer sowie die dazugehörigen $95 \%$ Konfidenzintervalle.

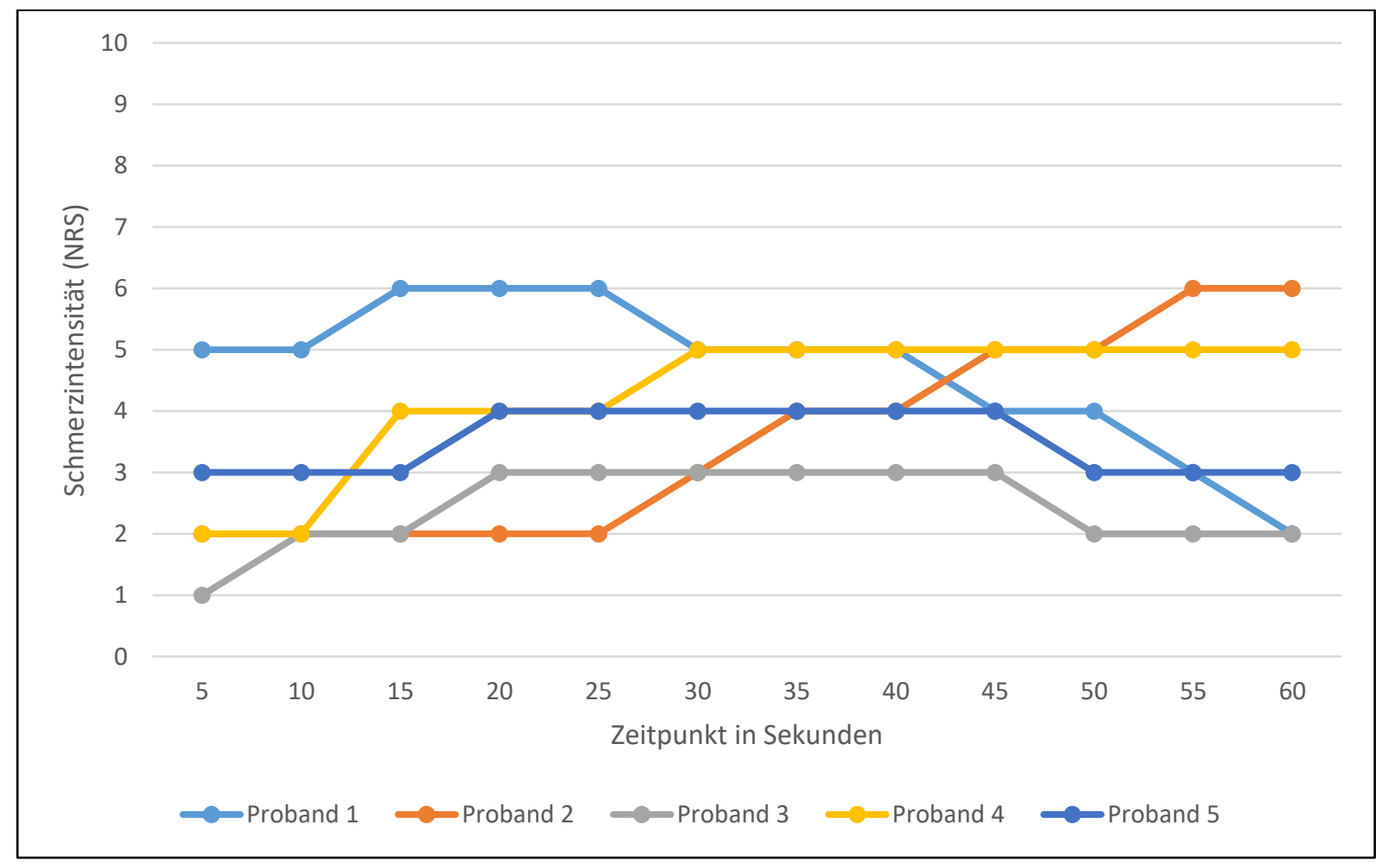

Abbildung 14 - Adaptationskurven bei Kältereiz von $4{ }^{\circ} \mathrm{C}$. Dargestellt ist die empfundene Schmerzintensität eines tonischen Kältestimulus von $4{ }^{\circ} \mathrm{C}$ in Abhängigkeit von der Versuchsdauer. 


\section{Ergebnisse}

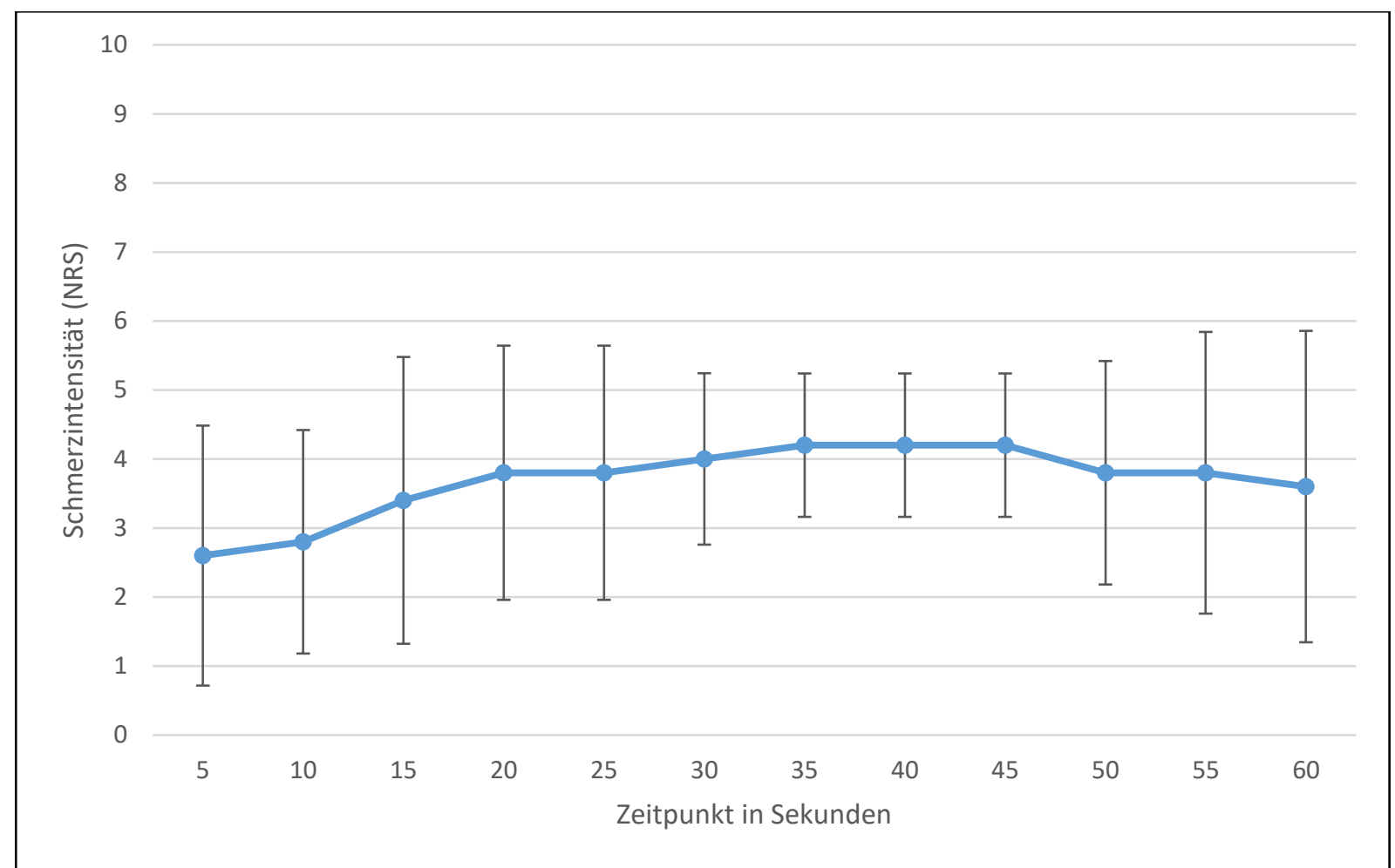

Abbildung 15 - Adaptationskurve bei Kältereiz von $4{ }^{\circ} \mathrm{C}$. Dargestellt sind die durchschnittlich empfundene Schmerzintensität eines tonischen Kältestimulus von $4{ }^{\circ} \mathrm{C}$ in Abhängigkeit von der Versuchsdauer sowie die dazugehörigen $95 \%$ Konfidenzintervalle.

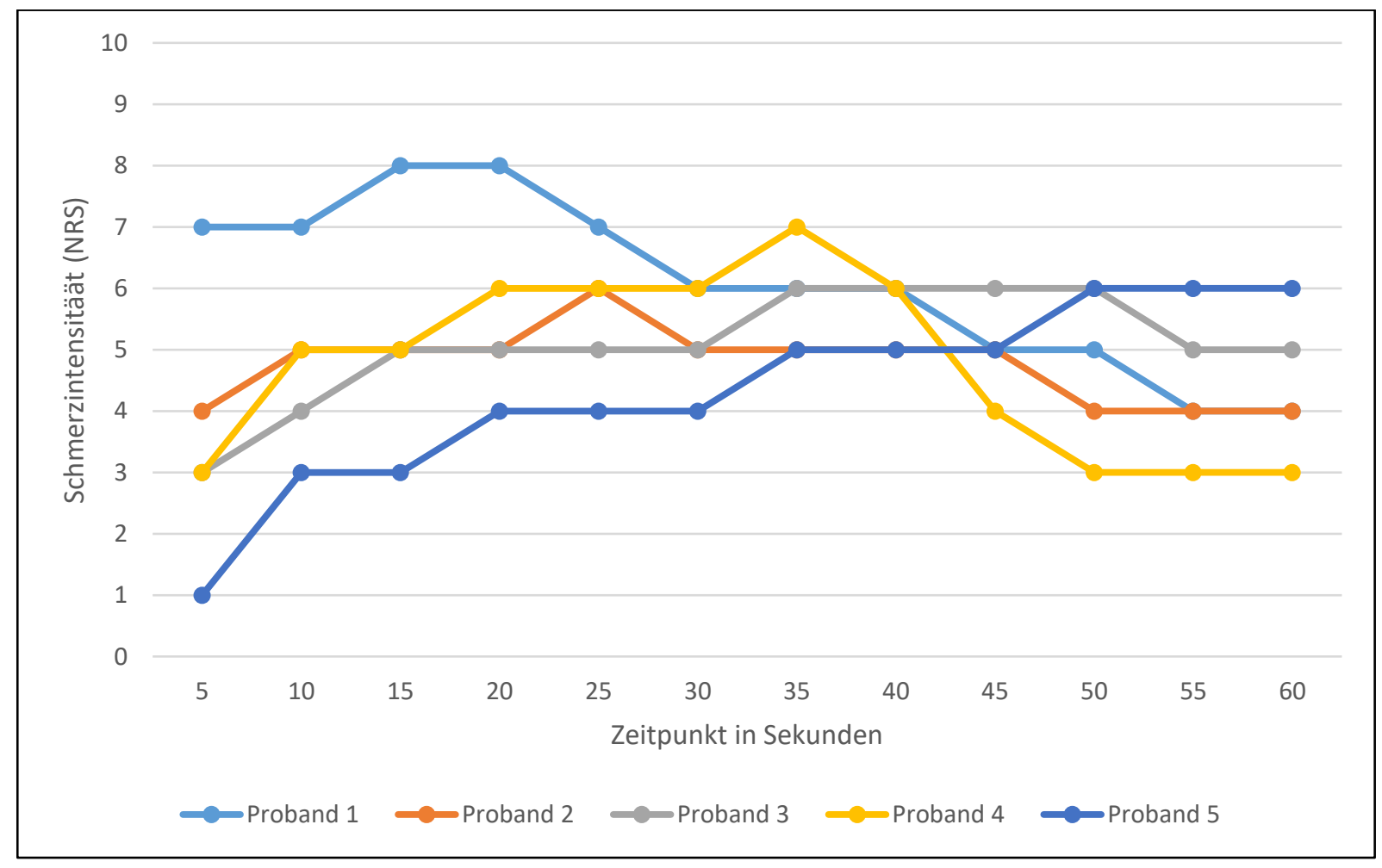

Abbildung 16 - Adaptationskurven bei Kältereiz von $2{ }^{\circ} \mathrm{C}$. Dargestellt ist die empfundene Schmerzintensität eines tonischen Kältestimulus von $2{ }^{\circ} \mathrm{C}$ in Abhängigkeit von der Versuchsdauer [11]. 


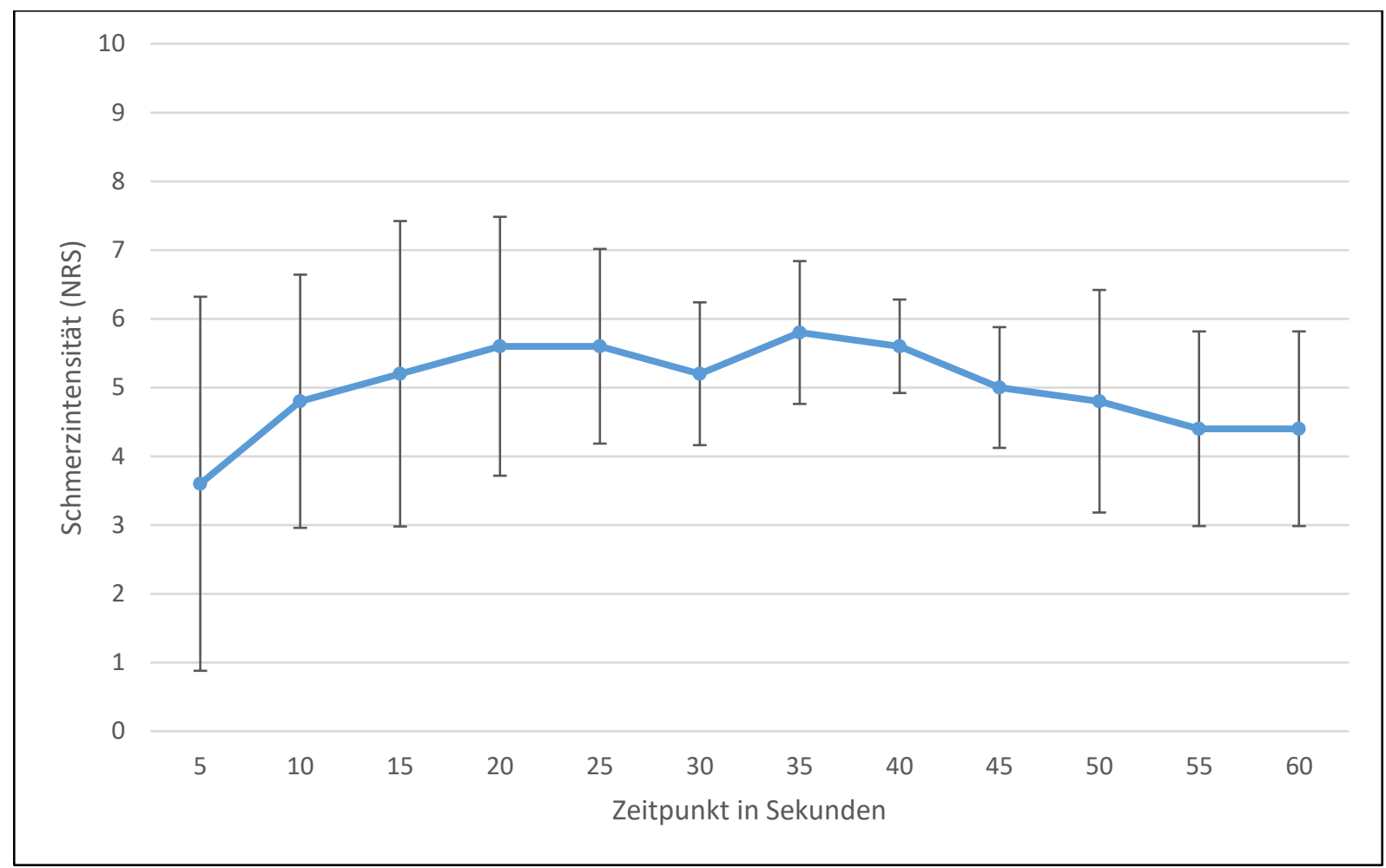

Abbildung 17 - Adaptationskurve bei Kältereiz von $2{ }^{\circ} \mathrm{C}$. Dargestellt sind die durchschnittlich empfundene Schmerzintensität eines tonischen Kältestimulus von $2{ }^{\circ} \mathrm{C}$ in Abhängigkeit von der Versuchsdauer sowie die dazugehörigen 95 \% Konfidenzintervalle [11].

\subsection{Hauptversuch „Etablierung der Schmerzmodelle“}

\subsubsection{Das Hitzeschmerzmodell}

Die Ausgangstemperatur der Thermode für das Hitzeschmerzmodell wurde entsprechend der Ergebnisse aus den Vorversuche Thermode auf $38^{\circ} \mathrm{C}$ festgelegt. Sie lag oberhalb der detektierten Schmerzschwelle für Hitzereize nach Anwendung von Capsaicin lag und konnte bereits nach 5 Sekunden Induktion eine Durchschnittsintensität oberhalb des gesetzten Signifikanzniveaus von NRS $\geq 6$ erzielen. Die Dauer eines Hitzeimpulses wurde auf 20 Sekunden festgesetzt. Obwohl in den Vorversuchen die mittlere empfundene Schmerzintensität zum Zeitpunkt 20 Sekunden bereits auf eine Schmerzintensität von NRS $=5$ (STABW $=0,7)$ fiel, war durch das Auftreten des sekundären Schmerzes nach repetitiven Hitzereizen ein Aufrechterhalten der geforderten Schmerzintensität von NRS $\geq 6$ zu erwarten. Das Hitzeschmerzmodell startete bei einer Baseline-Temperatur von $32^{\circ} \mathrm{C}$. Mit einer Steigerung von $10^{\circ} \mathrm{C} / \mathrm{s}$ wurde die Zieltemperatur von $38^{\circ} \mathrm{C}$ erreicht und 20 Sekunden gehalten. Es folgte eine Pause von 0,5 Sekunden, in der die Thermodentemperatur auf die definierte Baseline von $32{ }^{\circ} \mathrm{C}$ zurückfiel. Der nachfolgende Stimulus wurde jeweils mit einer um $1{ }^{\circ} \mathrm{C}$ erhöhten Thermodentemperatur durchgeführt (s. Abbildung 18). Nach fünf Minuten schaltete das Programm ab. Die Thermode wurde rasch am kontralateralen Arm des Probanden befestigt und das Programm erneut gestartet. Eine Maximaltemperatur der Thermode von $50{ }^{\circ} \mathrm{C}$ wurde nicht überschritten. 


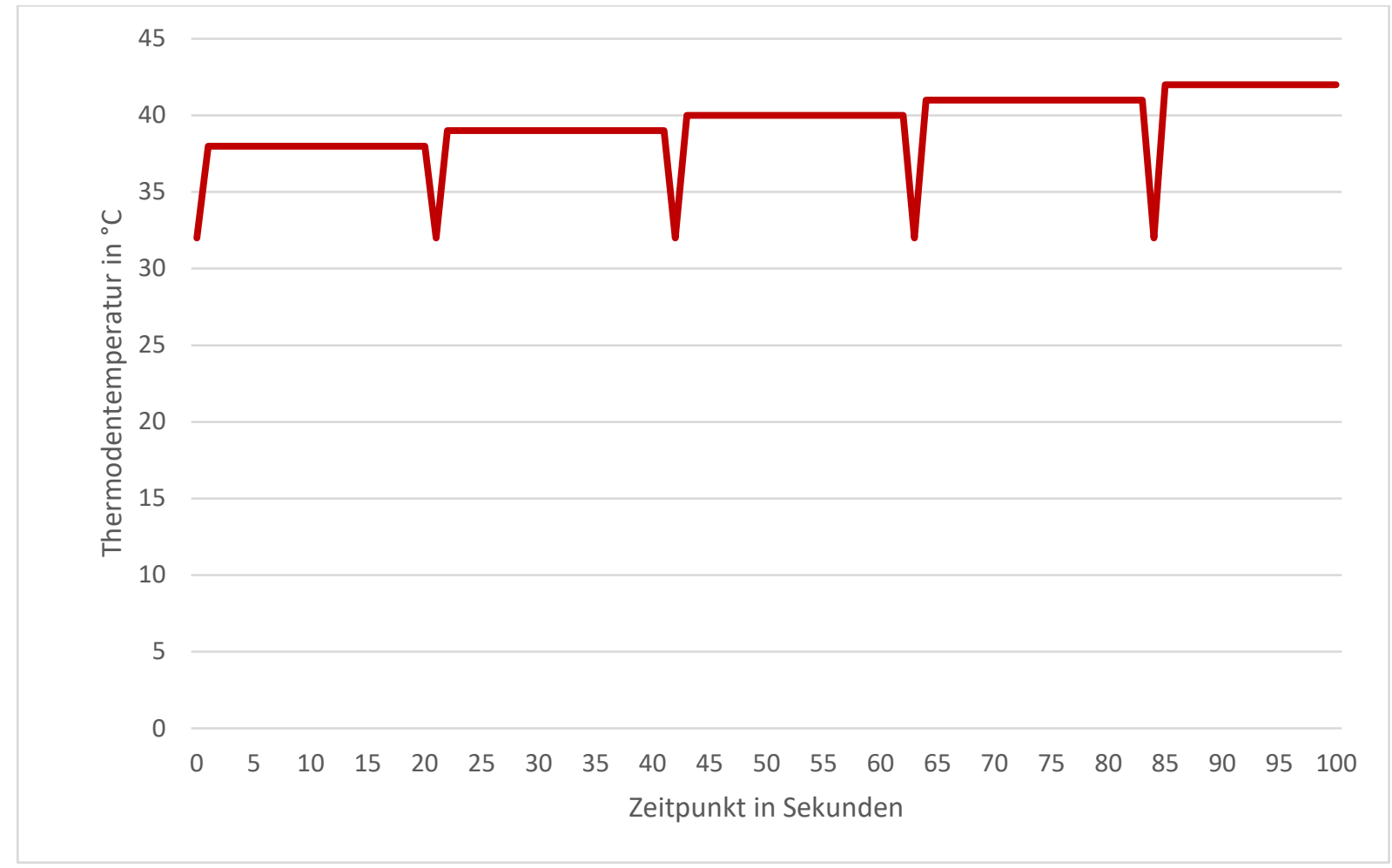

Abbildung 18-Schematische Darstellung des Hitzeschmerzmodells. Ausgehend von der Baseline-Temperatur von $32^{\circ} \mathrm{C}$ kommt es nach jedem Stimulus von 20 Sekunden zur konsekutiven Steigerung der Thermodentemperatur um $1{ }^{\circ} \mathrm{C}$. Eine Maximaltemperatur von $50{ }^{\circ} \mathrm{C}$ wird nicht überschritten [11].

\subsubsection{Das Kälteschmerzmodell}

Für das Kälteschmerzmodell wurde die Ausgangstemperatur der nozizeptiven Stimuli entsprechend der Ergebnisse des Vorversuches auf $2{ }^{\circ} \mathrm{C}$ festgelegt. Obwohl die Schmerzschwelle für Kältestimuli in dem Vorversuch bei $9,1^{\circ} \mathrm{C}$ lag (STABW = 2,5), ließen sich in dem Versuch zur Untersuchung der Schmerzadaptation weder bei einer Thermodentemperatur von $8{ }^{\circ} \mathrm{C}$ noch bei einer Thermodentemperatur von $4{ }^{\circ} \mathrm{C}$ signifikante Schmerzstimuli induzieren.

Die Stimulusdauer wurde auf 40 Sekunden festgelegt, da die beobachtete mittlere Schmerzintensität bis zu diesem Zeitpunkt anstieg oder konstant blieb. Ausgehend von einer Ausgangstemperatur von $32{ }^{\circ} \mathrm{C}$ sank die Temperatur der Thermode nach Versuchsbeginn um $10{ }^{\circ} \mathrm{C} / \mathrm{s}$ auf $2{ }^{\circ} \mathrm{C}$ ab und hielt diese Temperatur für eine Dauer von 40 Sekunden. Es folgte eine Pause von 4 Sekunden mit einem Rückgang der Thermodentemperatur auf eine Baseline von $15^{\circ} \mathrm{C}$. Anschließend wurde mit einem um $0,5^{\circ} \mathrm{C}$ erniedrigtem Kältereiz fortgesetzt. Die Temperatur der Thermode blieb zwischen den Intervallen stets bei $15{ }^{\circ} \mathrm{C}$ (s. Abbildung 19). Sie erreichte bei Induktion der nozizeptiven Stimuli nie eine Temperatur von unter $0^{\circ} \mathrm{C}$. Nach einer Gesamtprogrammdauer von 5 Minuten wurde zur Vermeidung von Gewebeschäden auf das Versuchsareal der kontralateralen Seite gewechselt. 


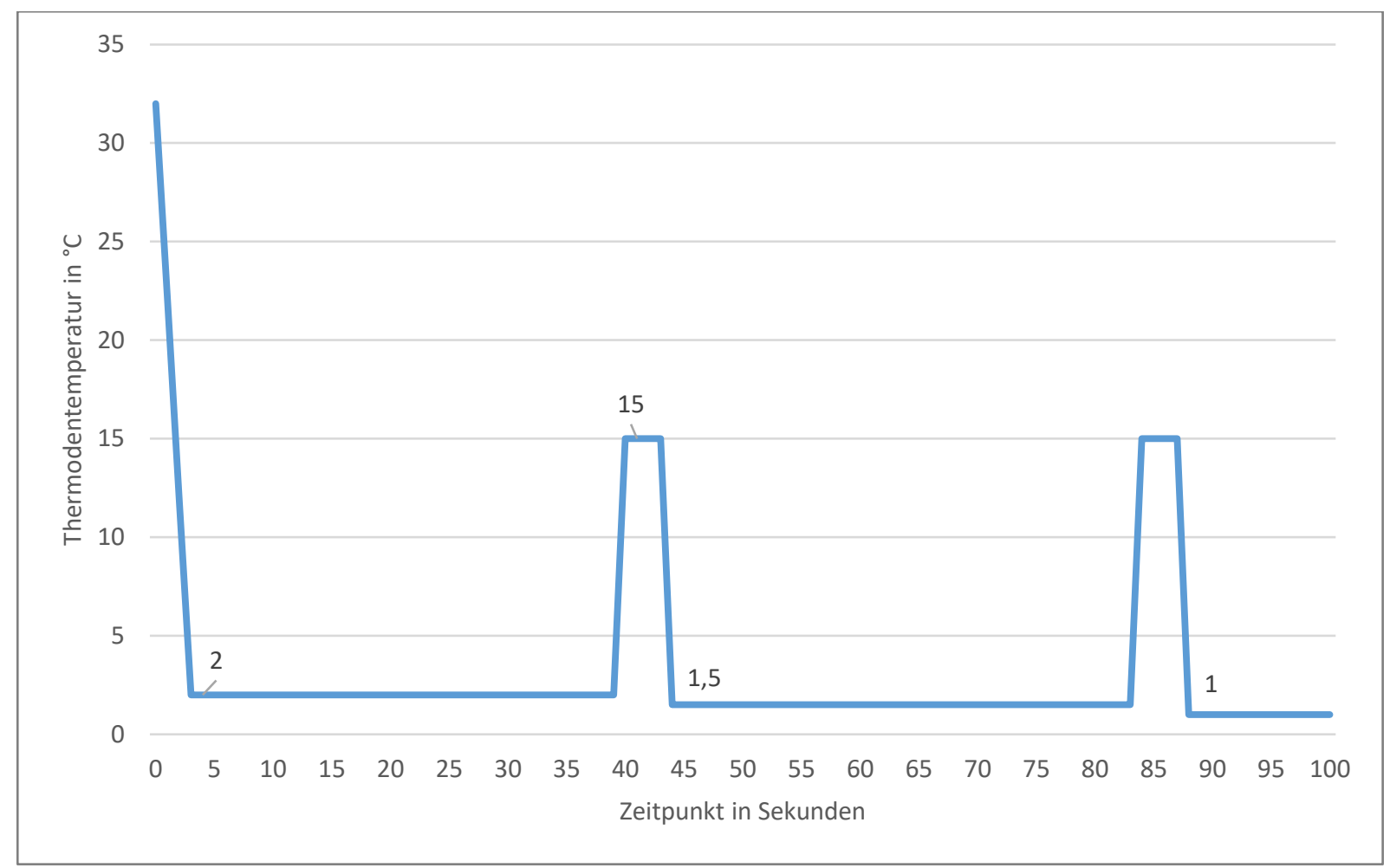

Abbildung 19 - Schematische Darstellung des Kälteschmerzmodells. Ausgehend von der Baseline-Temperatur von $15{ }^{\circ} \mathrm{C}$ kommt es nach jedem Stimulus von 40 Sekunden Dauer zum konsekutiven Absenken der Thermodentemperatur um $0,5{ }^{\circ} \mathrm{C}$. Eine Minimaltemperatur von $0{ }^{\circ} \mathrm{C}$ wird nicht unterschritten [11].

\subsection{Hauptversuch "Validierung der Schmerzmodelle“} Insgesamt nahmen 30 Probanden am Hauptversuch teil (15 Frauen, 15 Männer). Jeweils 10 Versuchsteilnehmer wurden randomisiert drei Gruppen zugeordnet (s. Tabellen 6 bis 8). Es gab keinen statistisch signifikanten Altersunterschied zwischen den Geschlechtern $(p=0,62)$. Aus der Gruppe $C$ wurde nachträglich ein Proband wegen pathologischer Hypästhesie ausgeschlossen. Die Schmerzstimuli durch das QST-Gerät wurden von allen Probanden während der gesamten Versuchsdurchführung toleriert.

Tabelle 6-Probandenkollektiv des Hauptversuchs, Gruppe A

\begin{tabular}{|ll|ll|}
\hline \multirow{2}{*}{} & \multicolumn{2}{|c|}{ Probandenkollektiv } \\
\cline { 3 - 4 } & & \multicolumn{2}{|c|}{ Gruppe A } \\
\cline { 3 - 4 } & & Anzahl & Alter (MW \pm STABW) \\
\hline \multirow{3}{*}{ Alter } & Geschlecht & 4 & $27,0 \pm 3,2$ \\
& & 6 & $25,3 \pm 2,3$ \\
& Gesamt & 10 & $26,2 \pm 2,7$ \\
\hline m = männlich, w = weiblich, MW = Mittelwert, STABW = Standardabweichung \\
\hline
\end{tabular}


Tabelle 7-Probandenkollektiv des Hauptversuchs, Gruppe B

\begin{tabular}{|c|c|c|c|c|}
\hline & & & & Probandenkollektiv \\
\hline & & & & Gruppe B \\
\hline & & & Anzahl & Alter (MW \pm STABW) \\
\hline & Geschlecht & $\mathrm{m}$ & 5 & $31,6 \pm 6,8$ \\
\hline Alter & & w & 5 & $33,6 \pm 9,8$ \\
\hline & Gesamt & & 10 & $32,6 \pm 8,0$ \\
\hline
\end{tabular}

Tabelle 8 - Probandenkollektiv des Hauptversuchs, Gruppe C

\begin{tabular}{|c|c|c|c|c|}
\hline & & & & Probandenkollektiv \\
\hline & & & & Gruppe C \\
\hline & & & Anzahl & Alter $(\mathrm{MW} \pm \mathrm{STABW})$ \\
\hline & Geschlecht & $\mathrm{m}$ & 6 & $28,3 \pm 3,9$ \\
\hline Alter & & w & 3 & $29,3 \pm 10,7$ \\
\hline & Gesamt & & 9 & $28,7 \pm 6,2$ \\
\hline
\end{tabular}

In dieser Studie durchliefen die Studienteilnehmer der Gruppe A das Hitzeschmerzmodell nach topischer Applikation einer handelsüblichen Feuchtigkeitscreme. Gruppe B erhielt die Capsaicin-Creme und durchlief ebenfalls das Hitzeschmerzmodell, Gruppe C durchlief das Kälteschmerzmodell. In Tabelle 9 und Abbildung 20 sind die durchschnittlich empfundenen Schmerzintensitäten in Abhängigkeit von der Versuchsdauer und Versuchsgruppe gegenübergestellt.

Tabelle 9-Durchschnittlich empfundene Schmerzintensitäten in Abhängigkeit von der Versuchsgruppe

\begin{tabular}{|c|c|c|c|c|c|c|c|c|c|c|c|c|c|}
\hline \multirow[b]{3}{*}{ Gruppe } & \multicolumn{13}{|c|}{ Durchschnittliche Schmerzintensität auf einer NRS von 0-10 } \\
\hline & \multicolumn{13}{|c|}{ T= Minuten } \\
\hline & TO & $\mathrm{T} 1$ & $\mathrm{~T} 2$ & T3 & $\mathrm{T} 4$ & T5 & T6 & $\mathrm{T7}$ & T8 & T9 & T10 & T60 & T1-T10 \\
\hline A: Hitze ohne Capsaicin & 0 & 0 & 0,1 & 0,6 & 1,5 & 2,6 & 0 & 0 & 0,5 & 1,6 & 3,1 & 0 & 1 \\
\hline B: Hitze mit Capsaicin & 0,1 & 4,1 & 5,7 & 6,6 & 7,5 & 7,9 & 4,6 & 5,6 & 6,4 & 7,3 & 8,3 & 0,3 & 6,4 \\
\hline C: Kälte & 0,1 & 4,6 & 6,2 & 6,4 & 6,2 & 5,8 & 6,3 & 7,3 & 6,9 & 6,1 & 5,9 & 0,1 & 6,2 \\
\hline
\end{tabular}




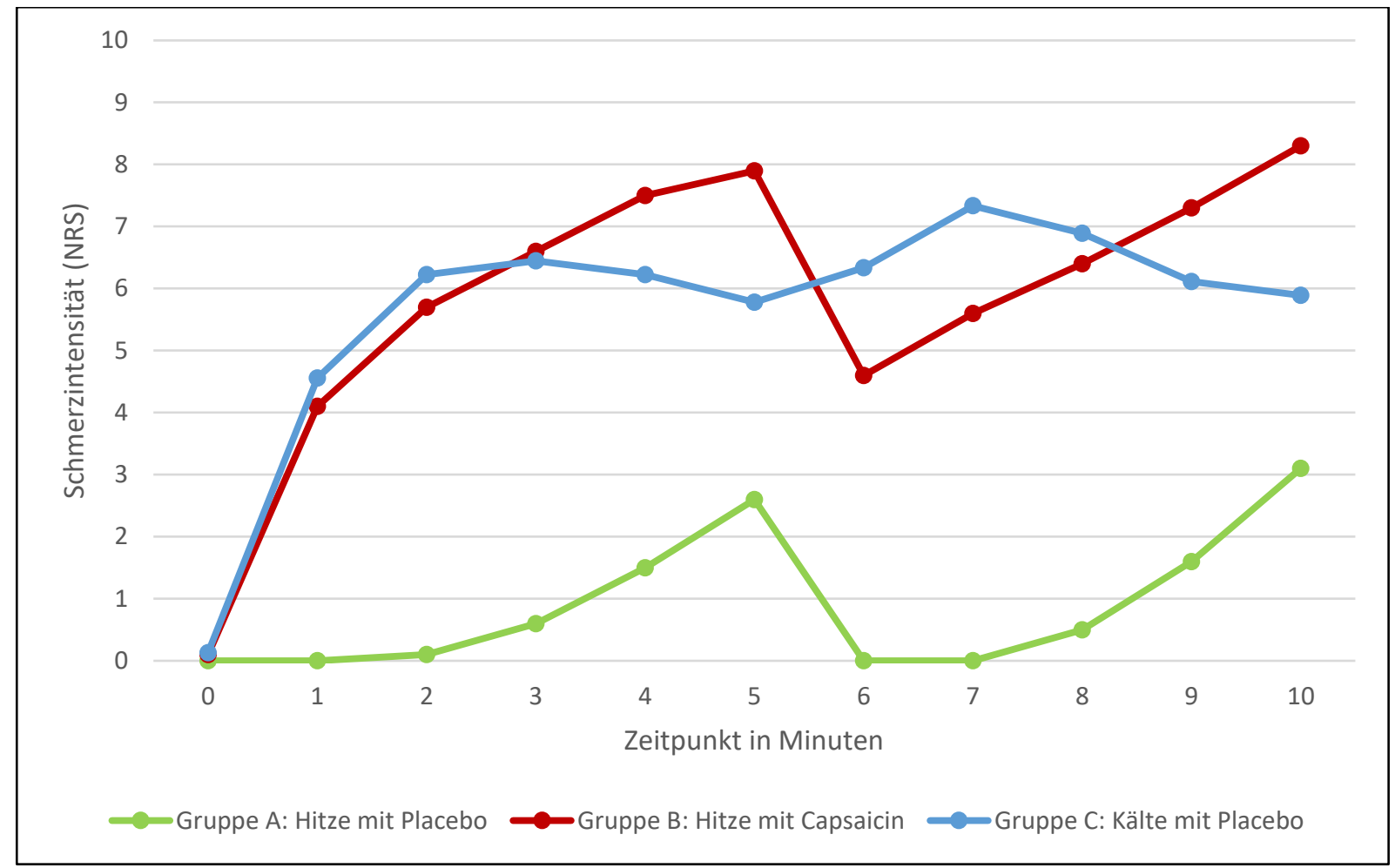

Abbildung 20 - Durchschnittlich empfundene Schmerzintensitäten der drei Versuchsgruppen im Hauptversuch in Abhängigkeit von der Versuchsdauer [11]

In der Gruppe A (Hitzeschmerzmodell nach Applikation der Placebo-Creme) zeigte sich bei 10 Minuten Versuchsdauer eine durchschnittlich empfundene Schmerzintensität von NRS = 1 (STABW = 0,5). Die höchste durchschnittliche Schmerzintensität wurde zum Zeitpunkt von 10 Minuten mit NRS = 3,1 angegeben (STABW = 1,5). Die durchschnittliche Schmerzintensität lag bei den Männern niedriger (NRS $=0,9$ ) als bei den Frauen (NRS $=1,0$ ). Der Unterschied war statistisch nicht signifikant $(p=1,00)$.

In der Gruppe B (Hitzeschmerzmodell nach Applikation der Capsaicin-Creme), zeigte sich eine durchschnittlich empfundene Schmerzintensität von NRS =6,4 (STABW =1,4). Die maximale, durchschnittlich empfundene Schmerzintensität wurde ebenfalls zum Zeitpunkt von 10 Minuten mit NRS $=8,3$ (STABW $=0,8$ ) beobachtet. Die durchschnittliche Schmerzintensität unter den Männern lag bei NRS = 5,9 (STABW $=1,0)$ und bei den Frauen bei NRS = 6,9 (STABW =0,9). Der Unterschied zwischen Männern und Frauen war statistisch nicht signifikant $(p=0,09)$. Der geforderte Mindestschmerz von NRS $\geq 6$ konnte bei Männern für 5 Minuten, bei Frauen für 6 Minuten erreicht werden. 60 Minuten nach Versuchsbeginn gaben noch 3 Probanden einen leichten, persistierenden Schmerz im Versuchsbereich von NRS $=1$ an. Bei allen Teilnehmern dieser Versuchsgruppe war zu diesem Zeitpunkt noch eine Rötung im Versuchsbereich der volaren Unterarme zu erheben.

In der Gruppe C (Kälteschmerzmodell nach Applikation der Placebo-Creme) zeigte sich eine durchschnittlich empfundene Schmerzintensität von NRS = 6,2 (STABW = 1,4). Die maximale mittlere Schmerzstärke von NRS $=7,3(\mathrm{STABW}=1,5)$ trat zum Zeitpunkt von 7 Minuten auf. Die Männer lagen mit einer durchschnittlich empfundenen Schmerzintensität von NRS $=6,1$ $(\mathrm{STABW}=1,3)$ niedriger als die Frauen mit einer NRS $=6,3(\mathrm{STABW}=2,0)$. Der Unterschied 
zwischen den Geschlechtern war nicht signifikant $(p=0,71)$. Einen Kälteschmerz von NRS $\geq 6$ konnte in dieser Versuchsgruppe bei Frauen für durchschnittlich 6 Minuten, bei Männern für durchschnittlich 7 Minuten induziert werden.

In der einfaktoriellen Varianzanalyse ließ sich nachweisen, dass der Unterschied der empfundenen Schmerzstärke innerhalb der drei Gruppen signifikant war $(p<0,05)$. Im Post-Hoc-Test (LSD) zeigte sich ein signifikanter Unterschied der empfundenen Schmerzstärke der Hitzeschmerzgruppe und Kälteschmerzgruppe zur Kontrollgruppe $(p<0,05)$, innerhalb der Schmerzgruppen (Hitze- und Kälteschmerzgruppe) hingegen nicht $(p=0,643)$.

\subsection{Nachversuch „Erweiterung der Versuchsdauer"}

Im Nachversuch sollte demonstriert werden, dass eine Erweiterung der Versuchsdauer bei gleichbleibender Schmerzintensität und -toleranz möglich ist. Dazu wurde eine weitere Versuchsreihe mit 10 randomisiert ausgewählten Probanden über einen Zeitraum von 20 Minuten durchgeführt (s. Tabelle 10). Exemplarisch wurde dafür das Hitzeschmerzmodell mit Capsaicin-Applikation herangezogen, die Reizinduktion erfolgte an vier volaren Versuchsarealen.

Tabelle 10 - Probandenkollektiv des Nachversuchs

\begin{tabular}{|c|c|c|c|c|}
\hline & & & & Probandenkollektiv \\
\hline & & & & Nachversuch 20 Min. \\
\hline & & & Anzahl & Alter $(\mathrm{MW} \pm \mathrm{STABW})$ \\
\hline & Geschlecht & $\mathrm{m}$ & 5 & $32,2 \pm 6,4$ \\
\hline Alter & & w & 5 & $28,8 \pm 13,0$ \\
\hline & Gesamt & & 10 & $30,5 \pm 9,8$ \\
\hline
\end{tabular}

Der Altersunterschied zwischen den Männern und Frauen war statistisch nicht signifikant $(p=0,15)$. Gemäß dem Versuchsprotokoll wurde jede Minute die durchschnittliche empfundene Schmerzintensität der jeweils letzten 60 Sekunden erhoben (s. Tabelle 11 und Abbildung 21).

Tabelle 11 - Durchschnittliche erhobene Schmerzintensität im Nachversuch [11]

\begin{tabular}{|l|l|l|l|l|l|l|l|l|l|l|l|}
\cline { 2 - 14 } \multicolumn{1}{c|}{} & \multicolumn{10}{c|}{ Durchschnittliche Schmerzintensität auf einer NRS von 0 - 10 } \\
\cline { 2 - 15 } & \multicolumn{10}{c|}{ T1 Minuten } \\
\hline \multirow{3}{*}{$\begin{array}{l}\text { Gruppe: } \\
\text { Hitze mit Capsaicin }\end{array}$} & 1,5 & 4,4 & 5,4 & 6,1 & 7,1 & 8,1 & 4,3 & 5,3 & 6,7 & 7,3 & 8,3 \\
\cline { 2 - 13 } & & & & & & & & & & & \\
\cline { 2 - 12 } & T11 & T12 & T13 & T14 & T15 & T16 & T17 & T18 & T19 & T20 & T1-T20 \\
\cline { 2 - 12 } & 4,8 & 5,3 & 6,4 & 7,3 & 7,8 & 4,9 & 5,5 & 6,0 & 7,1 & 8,4 & 6,3 \\
\hline
\end{tabular}




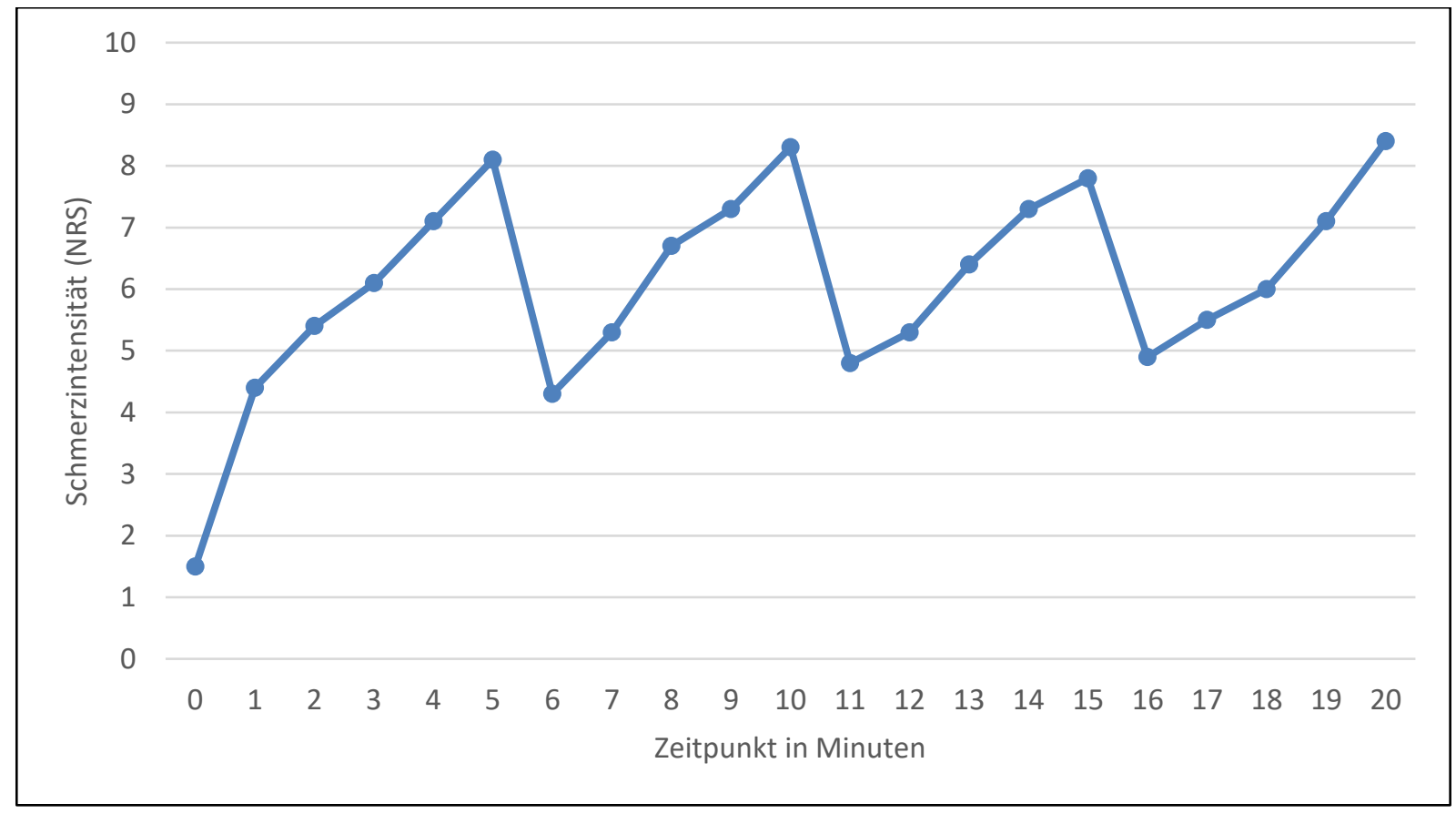

Abbildung 21 - Durchschnittlich empfundene Schmerzintensitäten im Nachversuch, Hitzeschmerzmodell mit Capsaicin-Applikation über eine Gesamtversuchsdauer von 20 Minuten (an vier Versuchsarealen) [11].

Im Nachversuch konnte eine durchschnittlich empfundene Schmerzintensität von NRS 6,3 $(S T A B W=1,2)$ erreicht werden. Auch in diesem Versuch war kein statistisch signifikanter Unterschied bei den empfundenen Schmerzstärken zwischen den Geschlechtern festzustellen ( $p$ $=0,31$ ). Die durchschnittliche Schmerzintensität über 20 Minuten Versuchsdurchführung lag bei den Männern bei NRS = 6,6 (STABW = 1,2), bei den Frauen bei NRS = 6,1 (STABW = 1,3). Während der 20-minütigen Versuchsdurchführung konnte bei Männern eine durchschnittlich empfundene Schmerzintensität von NRS $\geq 6$ für 12 Minuten, bei Frauen für 10 Minuten beobachten werden (s. Abbildung 21).

Es kam auch bei einer Gesamtversuchsdauer von 20 Minuten zu keinem durch Schmerzintoleranz bedingten Versuchsabbruch. 


\section{Diskussion}

\subsection{Zusammenfassung der Hauptergebnisse}

Ziel der Studie war es, ein standardisiertes Protokoll eines Akutschmerzmodells zu etablieren. Die Anforderung an das Schmerzmodell war hierbei die Induktion von reproduzierbaren, signifikanten und standardisierten Schmerzreizen mit variabler Versuchsdauer bei größtmöglicher Toleranz durch die Studienteilnehmer. Das in dieser Studie beschriebene Schmerzmodell nutzt als nozizeptive Stimuli Hitze- und Kältereize, die mittels eines Geräts zur quantitativen sensorischen Testung induziert werden. Durch die Kombination mit topisch appliziertem Capsaicin konnte die Gefahr thermischer Schäden an der Haut reduziert und eine deutliche Amplifizierung der empfundenen Schmerzintensitäten für Hitzestimuli erzielt werden. Aus Vorversuchen zu thermischen Schmerzschwellen und zeitlichen Aspekten der Schmerzadaptation wurden die Parameter Thermodentemperatur und Stimulusdauer der Akutschmerzmodelle festgelegt. Im Hauptversuch konnte validiert werden, dass nach dem hier beschriebenen Versuchsprotokoll Hitze- und Kältestimuli mit einer durchschnittlich empfundenen Schmerzintensität von NRS $\geq 6$ über eine variable Versuchsdauer induziert werden können. Das etablierte Schmerzmodell zeichnet sich durch eine hohe Toleranz der Stimuli vonseiten der Probanden aus. So kam es bei keinem der Versuchsteilnehmer zu einem durch Schmerzintoleranz bedingten Versuchsabbruch.

\subsection{Diskussion der Methodik}

\subsubsection{Ausschluss von Bias - endogene Faktoren}

Wie bereits in der Einleitung beschrieben, ist Schmerz ein komplexer Wahrnehmungsprozess, der aus sensorisch-diskriminativen, kognitiv-verhaltensbestimmenden und emotional-affektiven Komponenten besteht $[3,4]$. Nicht nur vorhandene Grunderkrankungen sondern auch psychosoziale Einflussfaktoren wie Erziehung, Erfahrungen oder das soziokulturelle Umfeld haben großen Einfluss auf die Wahrnehmung von Schmerzen [5, 6, 48, 55, 56]. Experimenteller Schmerz sollte daher an einer homogenen und gesunden Probandenklientel durchgeführt werden, um einen größtmöglichen Ausschluss von Bias gewährleisten zu können.

Unter Berücksichtigung dieser Erkenntnisse wurden in dem etablierten Schmerzmodell von jedem Probanden vor Versuchsbeginn mittels eines standardisierten Fragebogens Daten zu den beschriebenen Aspekten erhoben. Eine ausführliche Kranken- und Schmerzanamnese wurden erfragt, sodass im Vorfeld Probanden mit potentiellen Störfaktoren ausgeschlossen werden konnten. Vor dem Hintergrund des biopsychosozialen Schmerzmodells führten die Teilnehmer der Studie einen Kurzanamnesebogen zur aktuellen Beanspruchung aus. Etabliert wurde dieser von Müller und Basler im Jahr 1993. Es ist ein schnell durchzuführendes Verfahren, bei dem durch bipolar angeordnete Adjektive das aktuelle Befinden auf einer Ratingskala von 0 - 6 beschrieben wird. Er zeichnet sich durch eine hohe Reliabilität und Validität aus [83].

Viele Studien, wie z. B. von Price et. al aus dem Jahr 2018, nutzten häufig eine festgelegte, zu empfindende Schmerzstärke bei der Induktion experimenteller Schmerzen. Die Probanden waren in der Lage, den Schmerzstimulus während der Versuchsdurchführung zu adjustieren, um einer Intoleranz oder Desensibilisierung gegenüber den jeweiligen Schmerzstimuli entgegenzuwirken [84]. Basiskonzept des hier beschriebenen Schmerzmodells ist jedoch die Standardisierung und Kontrolle der Parameter wie Lokalisation, Dauer und Intensität, da diese die 
Quantität nozizeptiver Informationen aus der Peripherie zum zentralen Nervensystem bestimmen $[57,59]$. Die interindividuelle Empfindung der experimentell induzierten Schmerzen darf daher variabel sein, solange die Intensität im Durchschnitt nicht unter die definierte, signifikante Grenze von $\geq 6$ auf einer nummerischen Schmerzskala fällt.

\subsubsection{Ausschluss von Bias - exogene Faktoren}

\subsubsection{Umgebungstemperatur}

Exogene Faktoren spielen bei der Perzeption und Wahrnehmung eines nozizeptiven Reizes eine wichtige Rolle und sollten bei der Etablierung eines Schmerzmodells berücksichtigt werden.

Die Umgebungstemperatur übt einen signifikanten Einfluss auf die Wahrnehmung thermischer Schmerzstimuli aus. Die Hauttemperatur ist abhängig von der Umgebungstemperatur: Ist diese niedrig, werden Kältestimuli als schmerzhafter empfunden. Bei hoher Umgebungstemperatur hingegen werden Wärmestimuli als schmerzintensiver bewertet [85]. Vor diesem Hintergrund wurden die gesamten Versuche dieser Studie stets bei einer Umgebungstemperatur von $21-23{ }^{\circ} \mathrm{C}$ und nach einer Akklimatisationszeit von $\geq 30$ Minuten durchgeführt.

\subsubsection{Tageszeitpunkt}

Die Perzeption von Schmerzen unterliegt einer circadianen Rhythmik. Die aktuelle Studienlage ist aber bedingt durch die Anwendung unterschiedlicher Studiendesigns und verschiedener Schmerzmodelle zum Teil inkongruent. Aviram et al. eruierten bei 48 männlichen Studienteilnehmern eine signifikant niedriger empfundene Schmerzintensität von Hitze- und Kältestimuli in den Morgenstunden [86]. Ähnliche Ergebnisse wurden auch bei der Untersuchung von elektrisch evoziertem Schmerz erhoben: Zusätzlich zu der Reduktion der individuell angegebenen Schmerzstärke, konnten auch verminderte Amplituden der durch nozizeptive Stimuli evozierten Potentiale im EEG aufgezeigt werden [87]. Die diurnale Variation der Schmerzperzeption bedingt daher bei gewissen Fragestellungen einen konstanten Untersuchungszeitpunkt. Unter Berücksichtigung dieser Erkenntnisse wurden die hier beschriebenen Versuche in einem Zeitraum von 16 - 19 Uhr durchgeführt.

\subsubsection{Reliabilität und Validät der QST- Messung}

Gegenüber Schmerzmodellen, die mit elektrisch oder mechanisch (z. B. durch Frey Elemente) evozierten Schmerzstimuli arbeiten, bietet die Anwendung thermischer Schmerzreize durch das Peltier-Element eines QST-Gerätes mehrere Vorteile. QST-Geräte nehmen heutzutage bei der Diagnostik neuropathischer Schmerzen einen großen Stellenwert ein, sodass von einer großen Verfügbarkeit der Geräte ausgegangen werden kann. Die Stimulusparameter lassen sich mithilfe der mitgelieferten Software problemlos adjustieren. Die Quantitativ Sensorische Testung zeichnet sich etwa in Bezug auf die Messung thermischer Schmerzschwellen auch über längere Observationszeiträume hinweg durch eine hohe Reliabilität aus [88]. Nach Geber et al. gilt dies nicht nur für die Test-Retest-Reliabilität, sondern auch für die InterobserverReliabilität, obgleich in anderen Studien auch alternierendes Personal als Ursache für inkongruente Daten identifiziert wurde [89-91]. Standardisierte Erhebungen von Messergebnissen und Schulungen der Versuchsdurchführenden stellen wichtige Faktoren zum Erreichen konsistenter Ergebnisse der Quantitativ Sensorischen Testung dar [92]. Vor diesem Hintergrund 
führte in der hier beschriebenen Versuchsanordnung lediglich ein geschulter Prüfer sämtliche Vor- und Haupt- und Nachversuche durch.

\subsubsection{Anpressdruck der Thermode}

Mit Hilfe einer speziell entwickelten Thermode mit Drucksensoren konnte nachgewiesen werden, dass die inter- und intraindividuelle Reproduzierbarkeit von Hitze- und Kälteschmerzschwellen unabhängig von dem Anpressdruck der Thermode auf der Haut ist [93]. Allerdings zeigte sich in den hier beschriebenen Vorversuchen, dass ein erhöhter Anpressdruck die empfundene Schmerzintensität deutlich erhöhte. Eine mögliche Ursache ist die Stimulation tiefsitzender Nozizeptoren, etwa im Bereich der Sehnenscheiden oder des Periosts. Wichtig ist folglich ein einheitlicher Thermodenanpressdruck, um vor allem interindividuelle Unterschiede bei der Schmerzbewertung möglichst gering ausfallen zu lassen.

\subsubsection{Studiendesign}

Bei Akutschmerzmodellen stellt die Verblindung eine Limitation dar. In der hier beschriebenen Studie wurde durch die Etablierung einer Kontrollgruppe, die topische Behandlung aller Versuchsteilnehmer und das Einbinden einer versuchsunabhängigen Hilfsperson ein doppelt-verblindetes Studiendesign zu etablieren versucht. Es muss jedoch kritisch angemerkt werden, dass bereits bei Auftreten der neurogenen Inflammation im Rahmen der Capsaicinapplikation offensichtlich wird, welcher Studiengruppe man zugeteilt wurde. Zumindest führt jedoch das Anbringen der Thermoden durch die Hilfsperson dazu, dass der Versuchsleiter in Gänze verblindet wird.

Die Etablierung der Kontrollgruppe bietet einen weiteren Vorteil: Untersucht man z. B. potentielle Bioparameter zur Quantifizierung von Schmerzen, kann ein Vergleich der Versuchsgruppen detektieren, ob die Konzentrationsänderung eines untersuchten Parameters auf die Anwendung von Capsaicin, die Applikation eines nozizeptiven Stimulus oder einen spezifischen thermischen Stimulus zurückzuführen ist.

\subsection{Diskussion der Ergebnisse}

\subsubsection{Adaptation und Sensibilisierung}

In den Vorversuchen der hier beschriebenen Studie ließ sich eine deutliche Abnahme der empfundenen Schmerzstärke im Verlauf eines singulären, tonischen, thermischen Stimulus objektivieren. Dieses Phänomen der Habituation war bereits Gegenstand wissenschaftlicher Forschungen. Es wird auf verschiedene zentrale und periphere Mechanismen, wie etwa die sensorische Adaptation polymodaler Rezeptoren zurückgeführt. Bereits im Jahr 1978 konnten LaMotte et al. aufzeigen, dass repetitive Stimulation durch dermal applizierte Hitzeimpulse zu einer signifikanten Verminderung der Reaktion von auf C-Fasern lokalisierten Nozizeptoren und damit zu einer deutlichen Verminderung der empfundenen Schmerzstärke führt [94]. Für den TRPV1-Kanal wird eine Calcium-abhängige Dephosphorylierung als Ursache der Desensibilisierung vermutet [95]. Im Tiermodell konnte zusätzlich nachgewiesen werden, dass repetitive Hitzestimuli in einem zeitlichen Abstand von 30 Sekunden einen um $50 \%$ verminderten loneneinstrom in Hinterwurzelganglien bewirken [96]. Andere Studien lassen zentrale Ursachen für die Habituation vermuten, entweder durch Abnahme spinaler, nozizeptiver Aktivität oder durch erhöhte Aktivität antinozizeptiver Areale im Gehirn [97-101]. Die Intensität des gesetzten Schmerzstimulus hat dabei großen Einfluss auf das Ausmaß der Adaptations- und 
Summationsmechanismen. Weissmann-Fogel et al. konnten im Jahr 2015 in einer Kombination aus Schmerzstimulation und Gegenirritationsverfahren durch ein TENS-Gerät aufzeigen, dass eine Schmerzadaptation nur bei Schmerzstimuli niedriger Intensität stattfindet und primär auf periphere Adaptationsmechanismen zurückzuführen ist [102].

Periphere Adaptationsmechanismen können hingegen auch durch eine zentrale Sensibilisierung kompensiert werden. Zwei Mechanismen der zentralen Sensibilisierung sind zeitliche und örtliche Summationseffekte [103, 104]. Die örtliche Summation von Schmerzen ist auf die Rekrutierung und erhöhte Aktivität der zweiten und dritten Neurone der afferenten Schmerzbahn zurückzuführen, mit dem Resultat einer erhöhten empfundenen Schmerzstärke und einer Erniedrigung der individuellen Schmerzschwelle auf unterschiedliche Schmerzstimuli [105]. Dem Phänomen der zeitlichen Summation liegt eine erhöhte Aktivität der WDR-Neurone im Hinterhorn des Rückenmarks durch repetitive Stimulation der C-Fasern zu Grunde. Dies tritt insbesondere bei Schmerzstimuli mit einer Frequenz von $\leq 3 \mathrm{~s}$ auf $[68,106]$. In der Literatur werden heute die Begrifflichkeiten temporale Summation und Wind-Up oft als gleichbedeutend verwendet. Dabei ist Wind-Up ein Phänomen, das erstmals von Mendell und Wall im Jahr 1965 im Tiermodell als elektrophysiologisch detektierte Antwort von Hinterhornneuronen auf repetitive Stimulation peripherer C-Fasern beschrieben wurde. Mendell et al. konnten aufzeigen, dass unter konstanter Intensität der Stimuli gesteigerte Aktionspotentiale, sowohl die Höhe als auch Dauer betreffend, generiert werden. Es wird angenommen, dass hierfür die Summation langsamer post-synaptischer Potentiale mit einhergehender Depolarisation ursächlich ist $[103,107]$. Da in-vivo Untersuchungen diesbezüglich bei Menschen fehlen, wurden Methoden (wie die Quantitativ Sensorische Testung) etabliert, um zeitliche Summationseffekte als klinisches Korrelat des Wind-Up zu detektieren. Wie bereits Woolf im Jahr 1996 kommentierte, sollte Wind-Up als eine von multiplen Entitäten der zentralen Sensibilisierung betrachtet werden [108]. Die Studienlage zur zeitlichen Summation ist in Bezug auf die Dauer der schmerzhaften Stimuli inkongruent. Entgegen der Annahme, dass die zeitliche Summation nur bei schmerzhaften Stimuli mit einer Frequenz $\leq 3 \mathrm{~s}$ auftritt, wird dieser Effekt auch bei länger anhaltenden, tonischen Stimuli beschrieben [107, 109-111].

Bei der Etablierung eines Akutschmerzmodells ist in jedem Fall zu bedenken, dass es bei der Applikation repetitiver, schmerzhafter Hitzeimpulse durch die oben beschriebenen Adaptationsprozesse zu einer Abnahme des empfundenen primären Schmerzes kommt, dessen Qualität als scharf empfunden wird. Im weiteren Verlauf bestimmt sodann ein zunehmender, dumpfer Schmerz (sekundärer Schmerz) das sensorische Empfinden.

Insgesamt werden die Phänomene der Sensibilisierung auf eine aktivitätsabhängige Zunahme der neuronalen Erregung, im Falle von Schmerzen insbesondere der WDR- Neurone zurückgeführt. Der Mechanismus dieser zentralen Sensibilisierung basiert unter anderem auf einer Aktivierung von postsynaptischen N-methyl-D-Aspartat (NMDA)- Rezeptoren. Diese sind nicht selektive Ionenkanäle, mit einer hohen Permeabilität für Calciumionen. Während NMDA-Rezeptoren im Ruhemembranpotential durch Magnesium geblockt sind, führen exzitatorische Aminosäuren wie Glutamat und Neuropeptide afferenter Fasern während der Depolarisation zur Freisetzung des Magnesiums und Öffnung der Kanäle. Der Calciumeinstrom bedingt eine Vielzahl intrazellulärer, biochemischer Prozesse, die bei der Langzeitpotenzierung und somit 
der synaptischen Plastizität eine herausragende Rolle einnehmen. Nicht nur die Phosphorylierung von Membranproteinen, sondern auch eine Hochregulation von Genprodukten führt zu einer dauerhaften Veränderung der neuronalen Erregbarkeit [112-114]. So führt die Applikation von NMDA-Rezeptorantagonisten wie Dextromethorphan oder Ketamin zu einer deutlichen Reduktion des sekundären Schmerzes bei repetitiven, schmerzhaften Hitzeimpulsen führt $[115,116]$.

\subsubsection{Geschlechterspezifische Unterschiede}

Frauen geben im Vergleich zu Männern signifikant höhere Schmerzen bei Stimuli gleicher Intensität an. Dieses Phänomen wurde in experimentellen Schmerzstudien nachgewiesen und gilt insbesondere für tonische Schmerzstimuli und den sogenannten "tiefen Schmerz" [117, 118]. In den in dieser Studie durchgeführten Versuchen konnten jedoch nie statistisch signifikante Unterschiede nachgewiesen werden. Die Ursache hierfür liegt mutmaßlich in der Größe des Probandenkollektivs. In einem Review bezüglich geschlechterspezifischer Unterschiede bei der Schmerzwahrnehmung konnten Riley et al. feststellen, dass diese Effekte vor allem bei thermischen Schmerzstimuli weniger signifikant ausfallen. Eine Probandenzahl von mindestens 41 pro Versuchsgruppe sind laut Riley et al. notwendig, um den Nachweis geschlechterspezifischer Unterschiede mit einer ausreichenden statistischen Power erbringen zu können [118].

\subsection{Ausblick}

\subsubsection{Erweiterung der Versuchsanordnung durch Menthol}

Menthol wirkt agonistisch am TRPM8-Rezeptor und führt zur Herabsetzung der thermischen Schmerzschwelle für Kältereize. Flühr et al. wiesen in einem Probandenkollektiv von 75 Versuchsteilnehmern nach, dass sich die thermische Schmerzschwelle für Kältestimuli nach dermaler Applikation eines Mentholpflasters signifikant änderte - von $13^{\circ} \mathrm{C}\left( \pm 8,4{ }^{\circ} \mathrm{C}\right)$ auf $19,3{ }^{\circ} \mathrm{C}$ $\left( \pm 9,2{ }^{\circ} \mathrm{C}\right)$ [36]. Die topische Anwendung von Menthol in einem Akutschmerzmodell, das auf Kältereizen basiert, kann daher erwogen werden. Allerdings besitzt Menthol auch analgetische Eigenschaften. Die Ursache dieser Wirkung ist nach aktueller Studienlage noch immer unklar. Diskutiert wird die Inhibition von Natrium- und Calciumkanälen in dorsalen Wurzelganglien [43, 119]. Autoren anderer Studien führten die analgetischen Effekte von Menthol auf eine Aktivierung des endogenen Opioidsystems zurück [120,121]. Diese Effekte treten abhängig von der Applikationsdauer und der Konzentration des Menthols auf. Die dermale Applikation von hochprozentigem Menthol (> $30 \%$ ) bedingt schmerzhafte Sensationen und geht mit einer erniedrigten Schmerzschwelle für Kältereize einher [41]. Niedrige Konzentration hingegen vermitteln analgetische Effekte und eine Desensibilisierung nozizeptiver C-Fasern [42]. Eine gute Übersicht lieferten Pergolizzi et al. in einem im Jahr 2018 veröffentlichten Review zum aktuellen Forschungsstand topischer Mentholprodukte in der analgetischen Therapie [122].

Ähnliche Wirkungen zeigen sich auch nach topischer Applikation von Capsaicin. Neben den hier genutzten hyperalgetischen Effekten nimmt Capsaicin auch eine wichtige Rolle bei der Therapie neuropathischer Schmerzen als Analgetikum ein. Dieser Effekt ist ebenfalls stark abhängig von der Konzentration und Applikationsdauer. Bereits im Jahr 1999 wurde festgestellt, 
dass die mehrfache tägliche Anwendung von kutan appliziertem Capsaicin (0,075 \%] über einen Zeitraum von drei Wochen zu einer Degeneration epidermaler Nervenfasern führt [76]. Der analgetische Effekt von höherprozentigem Capsaicin (z. B. in Form von Pflastern mit Wirkkonzentration von $179 \mathrm{mg} / 280 \mathrm{~cm}^{2}$, Qutenza ${ }^{\circledR}$, Grünenthal $\mathrm{GmbH}$ ) ist mittlerweile wissenschaftlich gut untersucht und sowohl auf eine Desensibilisierung der TRPV1-Kanäle, als auch auf die bereits beschriebene Degeneration von sensorischen Fasern zurückzuführen [123]. Während folglich bei Menthol hohe Dosierungen zum Herabsetzen thermischer Schmerzschwellen benötigt werden, kann bei Capsaicin bereits eine niedrige Konzentration, wie sie in handelsüblichen, capsaicinhaltigen Cremes vorkommt, einen hyperalgetischen Effekt auf Hitzestimuli bedingen.

Die Aktivierung des endogenen Opioidsystems, wie sie u. a. als Ursache des analgetischen Effektes von Menthol diskutiert wird, sowie analgetische Effekte, die sich bereits bei niedrigen Konzentrationen einstellen, stellen möglicherweise Störfaktoren z. B. bei der Untersuchung potentieller Bioparameter zur Quantifizierung von Schmerzen dar. Zum Ausschluss weiterer Störfaktoren wurde in der hier beschriebenen Studie nur Capsaicin als topisches Adjuvans verwendet. Die Verwendung von Menthol in Kombination mit diesem Schmerzmodell kann aber unter bestimmten Fragestellungen sinnvoll sein, da gerade bei Adjustierungen der Intervalllängen von Kältestimuli stets eine potentielle Schädigung der Dermis berücksichtigt werden muss.

\subsubsection{Dynamische Schmerzmodelle}

Wird ein in seiner Intensität gleicher Hitzestimulus an beiden Unterarmen nacheinander induziert, bedingen zuvor genannte Sensibilisierungsphänomene eine höhere Schmerzintensität des konsekutiven Schmerzreizes. Zu diesen Ergebnissen kamen Jepma et al. in einer Studie aus dem Jahre 2014. An 100 Versuchsteilnehmern wurden jeweils 24 nozizeptive Hitzestimuli an 8 Versuchsarealen der Unterarme induziert. Bei der unilateralen Stimulation kam es zu einer Habituation mit Abnahme der empfundenen Schmerzintensität. Wurden die Stimuli im Sinne eines dynamischen Modells an beiden Unterarmen nacheinander induziert, lies sich zumindest für die ersten 7 - 8 Folgereize auf der kontralateralen Seite eine Sensibilisierung mit erhöhter Schmerzempfindung nachweisen [78].

Die Integration eines dynamischen Modells in das hier vorliegende kann daher im Hinblick auf die Vermeidung von Gewebeschäden sinnvoll sein. Unter Ausnutzung dieser Sensibilisierungsphänomene ist die Verlängerung der Versuchsdauer bei anhaltend hoher Schmerzintensität möglich, wenn die oben genannten Spezifika (Limitationen) berücksichtigt werden.

\subsubsection{Anpassung der Parameter des Schmerzmodells}

Anhand der graphischen Auswertung des Hauptversuchs konnte aufgezeigt werden, dass sowohl in der Hitze- als auch in der Kälteschmerzgruppe erst nach einer Stimulationsdauer von 2 - 3 Minuten eine mittlere empfundene Schmerzstärke von NRS $\geq 6$ erzielt werden konnte. Aus Gründen der Schmerztoleranz wurde dieses Charakteristikum in dieser Studie toleriert. Eine Anpassung der initialen Thermodentemperatur (Erhöhung für die Hitzeschmerzgruppe, respektive Erniedrigung für die Kälteschmerzgruppe) kann die empfundenen Schmerzintensitäten in der ersten Versuchsminuten deutlich erhöhen. Auch die Applikation hochfrequenter 
Stimuli und das Vergrößern des affektierten Areals kann, wie zuvor beschrieben, durch zeitliche und räumliche Summation eine deutliche Erhöhung der empfundenen Schmerzstärke bewirken. Zu beachten ist jedoch, dass dadurch nicht nur das Risiko von Gewebeschäden erhöht wird, sondern zeitgleich eine erhöhte Intoleranz der Studienteilnehmer gegenüber den schmerzhaften Stimuli zu vermehrten Versuchsabbrüchen führen kann. Naert et al. etablierten im Jahr 2007 ein Schmerzmodell, in dem ein tonischer Hitzestimulus von $46-49{ }^{\circ} \mathrm{C}$ über eine Dauer von 7 Minuten am Oberschenkel induziert wurde. Hierbei konnte zwar eine durchschnittliche, empfundene Schmerzstärke von NRS $=6,2( \pm 0,4)$ erreicht werden, die Abbruchquote von etwa $20 \%$ ist aber kritisch zu betrachten [109]. Auch die Inkonsistenz bezüglich Adaptation und Sensibilisierung auf die applizierten Stimuli unter den Versuchsteilnehmer offenbart Schwächen in dieser Versuchsanordnung.

\subsubsection{Limitationen}

Wissenschaftliche Erkenntnisse, die aus Akutschmerzmodellen gewonnen wurden, müssen immer bezüglich ihrer Anwendbarkeit auf chronischen, aber auch klinischen Schmerz kritisch hinterfragt werden. Die meisten etablierten Akutschmerzmodelle verwenden, ebenso wie das hier beschriebene, phasische, nozizeptive Stimuli - ein Charakteristikum, das klinischer Schmerz nicht immer aufweist. Akutschmerzmodelle mit tonischen Schmerzreizen und variabel verlängerbarer Versuchsdauer könnten in Zukunft Fragen bezüglich der Vergleichbarkeit dieser Entitäten beantworten.

In zukünftigen Studien muss daher untersucht werden, ob die induzierte Schmerzstärke und die Dauer des gesetzten Stimulus ausreichend sind, um z. B. signifikant potentielle Bioparameter zur Quantifizierung von Schmerzen detektieren zu können. Sollte dies nicht der Fall sein, wäre beispielsweise eine zusätzliche Ausweitung des Versuchsareals zur Ausnutzung räumlicher Summationseffekte denkbar.

\subsection{Fazit}

Als Fazit der hier vorliegenden Studie lässt sich zusammenfassen (gemäß der dazugehörigen Publikation [11]:

Das in vorliegender Arbeit beschriebene Akutschmerzmodell ermöglicht die Induktion eines Hitze- oder Kälteschmerzes

- definierter Intensität und erweiterbarer Dauer

- bei guter Tolerierbarkeit

- ohne Induktion von schweren reversiblen oder irreversiblen Gewebeschäden

mittels eines QST-Geräts. Die Versuchsdurchführung erfolgt unter größtmöglichem Ausschluss von Einflussfaktoren auf die Schmerzperzeption.

Es ist somit zur weiteren Erforschung des Akutschmerzes im Menschen geeignet und leicht zu etablieren. 


\section{Literaturverzeichnis}

1. Pain terms: a list with definitions and notes on usage. Recommended by the IASP Subcommittee on Taxonomy. Pain, 1979. 6(3): p. 249.

2. Pape, H.-C., et al., Physiologie. 2014, Stuttgart: Georg Thieme.

3. Bonica, J.J., Neurophysiologic and pathologic aspects of acute and chronic pain. Arch Surg, 1977. 112(6): p. 750-61.

4. Auvray, M., E. Myin, and C. Spence, The sensory-discriminative and affective-motivational aspects of pain. Neurosci Biobehav Rev, 2010. 34(2): p. 214-23.

5. Turk, D.C., The role of psychological factors in chronic pain. Acta Anaesthesiol Scand, 1999. 43(9): p. 885-8.

6. Chapman, S.L. and S.F. Brena, Patterns of conscious failure to provide accurate self-report data in patients with low back pain. Clin J Pain, 1990. 6(3): p. 178-90.

7. Diatchenko, L., et al., Genetic architecture of human pain perception. Trends Genet, 2007. 23(12): p. 605-13.

8. Mao, J., Translational pain research: achievements and challenges. J Pain, 2009. 10(10): p. 1001-11.

9. Curatolo, M., S. Petersen-Felix, and L. Arendt-Nielsen, Sensory assessment of regional analgesia in humans: a review of methods and applications. Anesthesiology, 2000. 93(6): p. 1517-30.

10. Olesen, A.E., et al., Human experimental pain models for assessing the therapeutic efficacy of analgesic drugs. Pharmacol Rev, 2012. 64(3): p. 722-79.

11. Lüke, P., et al., Etablierung eines adaptierbaren Akutschmerzmodells zur Induktion nozizeptiver Stimuli definierter Intensität und Dauer mittels thermischer Reize. Der Schmerz, 2020.

12. Price, D.D., et al., A comparison of pain measurement characteristics of mechanical visual analogue and simple numerical rating scales. Pain, 1994. 56(2): p. 217-26.

13. Hjermstad, M.J., et al., Studies comparing Numerical Rating Scales, Verbal Rating Scales, and Visual Analogue Scales for assessment of pain intensity in adults: a systematic literature review. J Pain Symptom Manage, 2011. 41(6): p. 1073-93.

14. Warden, V., A.C. Hurley, and L. Volicer, Development and psychometric evaluation of the Pain Assessment in Advanced Dementia (PAINAD) scale. J Am Med Dir Assoc, 2003. 4(1): p. 9-15.

15. Wary, B. and C. Doloplus, [Doloplus-2, a scale for pain measurement]. Soins Gerontol, 1999(19): p. 25-7.

16. Pickering, G., et al., Reliability study in five languages of the translation of the pain behavioural scale Doloplus. Eur J Pain, 2010. 14(5): p. 545 e1-10.

17. Barkin, R.L., S.J. Barkin, and D.S. Barkin, Perception, assessment, treatment, and management of pain in the elderly. Clin Geriatr Med, 2005. 21(3): p. 465-90, v.

18. Zwakhalen, S.M., et al., Pain in elderly people with severe dementia: a systematic review of behavioural pain assessment tools. BMC Geriatr, 2006. 6: p. 3.

19. Schmidt, C.O., et al., Back pain in the German adult population: prevalence, severity, and sociodemographic correlates in a multiregional survey. Spine (Phila Pa 1976), 2007. 32(18): p. 2005-11.

20. Wenig, C.M., et al., Costs of back pain in Germany. Eur J Pain, 2009. 13(3): p. 280-6.

21. Behrends, J., J. Bischofberger, and R. Deutzmann, Duale Reihe Physiologie. 2012, Stuttgart: Thieme.

22. Montell, C., The TRP superfamily of cation channels. Sci STKE, 2005. 2005(272): p. re3.

23. Wu, L.J., T.B. Sweet, and D.E. Clapham, International Union of Basic and Clinical Pharmacology. LXXVI. Current progress in the mammalian TRP ion channel family. Pharmacol Rev, 2010. 62(3): p. 381-404. 
24. Nilius, B., TRP channels in disease. Biochim Biophys Acta, 2007. 1772(8): p. 805-12.

25. Zhang, Y., et al., Coding of sweet, bitter, and umami tastes: different receptor cells sharing similar signaling pathways. Cell, 2003. 112(3): p. 293-301.

26. Caterina, M.J., et al., The capsaicin receptor: a heat-activated ion channel in the pain pathway. Nature, 1997. 389(6653): p. 816-24.

27. Peier, A.M., et al., A TRP channel that senses cold stimuli and menthol. Cell, 2002. 108(5): $\mathrm{p}$. 705-15.

28. Suzuki, M., et al., Impaired pressure sensation in mice lacking TRPV4. J Biol Chem, 2003. 278(25): p. 22664-8.

29. Tominaga, M., et al., The cloned capsaicin receptor integrates multiple pain-producing stimuli. Neuron, 1998. 21(3): p. 531-43.

30. Holzer, P., Capsaicin: cellular targets, mechanisms of action, and selectivity for thin sensory neurons. Pharmacol Rev, 1991. 43(2): p. 143-201.

31. Szolcsanyi, J., A pharmacological approach to elucidation of the role of different nerve fibres and receptor endings in mediation of pain. J Physiol (Paris), 1977. 73(3): p. 251-9.

32. Szolcsanyi, J., A. Jancso-Gabor, and F. Joo, Functional and fine structural characteristics of the sensory neuron blocking effect of capsaicin. Naunyn Schmiedebergs Arch Pharmacol, 1975. 287(2): p. 157-69.

33. Kaufman, M.P., et al., Effects of capsaicin and bradykinin on afferent fibers with ending in skeletal muscle. Circ Res, 1982. 50(1): p. 133-9.

34. Rodrigues, T., F. Sieglitz, and G.J. Bernardes, Natural product modulators of transient receptor potential (TRP) channels as potential anti-cancer agents. Chem Soc Rev, 2016. 45(22): p. 6130-6137.

35. Römpp, H., J. Falbe, and M. Regitz, Römpp Lexikon Chemie. Bd. 1 Bd. 1. 1996.

36. Fluhr, K., T.J. Neddermeyer, and J. Lotsch, Capsaicin or menthol sensitization induces quantitative but no qualitative changes to thermal and mechanical pain thresholds. Clin J Pain, 2009. 25(2): p. 128-31.

37. Simone, D.A., et al., Intradermal injection of capsaicin in humans produces degeneration and subsequent reinnervation of epidermal nerve fibers: correlation with sensory function. J Neurosci, 1998. 18(21): p. 8947-59.

38. Anand, P. and K. Bley, Topical capsaicin for pain management: therapeutic potential and mechanisms of action of the new high-concentration capsaicin 8\% patch. Br J Anaesth, 2011. 107(4): p. 490-502.

39. McKemy, D.D., W.M. Neuhausser, and D. Julius, Identification of a cold receptor reveals a general role for TRP channels in thermosensation. Nature, 2002. 416(6876): p. 52-8.

40. Hensel, H. and Y. Zotterman, The effect of menthol on the thermoreceptors. Acta Physiol Scand, 1951. 24(1): p. 27-34.

41. Binder, A., et al., Topical high-concentration (40\%) menthol-somatosensory profile of a human surrogate pain model. J Pain, 2011. 12(7): p. 764-73.

42. Cliff, M.A. and B.G. Green, Sensory irritation and coolness produced by menthol: evidence for selective desensitization of irritation. Physiol Behav, 1994. 56(5): p. 1021-9.

43. Haeseler, G., et al., Voltage-dependent block of neuronal and skeletal muscle sodium channels by thymol and menthol. Eur J Anaesthesiol, 2002. 19(8): p. 571-9.

44. Galeotti, N., et al., Local anaesthetic activity of (+)- and (-)-menthol. Planta Med, 2001. 67(2): p. 174-6.

45. Gaudioso, C., et al., Menthol pain relief through cumulative inactivation of voltage-gated sodium channels. Pain, 2012. 153(2): p. 473-84.

46. Blomqvist, A., E.T. Zhang, and A.D. Craig, Cytoarchitectonic and immunohistochemical characterization of a specific pain and temperature relay, the posterior portion of the ventral medial nucleus, in the human thalamus. Brain, 2000. 123 Pt 3: p. 601-19.

47. Craig, A.D., Pain mechanisms: labeled lines versus convergence in central processing. Annu Rev Neurosci, 2003. 26: p. 1-30. 
48. Melzack, R., Pain and the neuromatrix in the brain. J Dent Educ, 2001. 65(12): p. 1378-82.

49. Iannetti, G.D. and A. Mouraux, From the neuromatrix to the pain matrix (and back). Exp Brain Res, 2010. 205(1): p. 1-12.

50. Treede, R.D., Spinothalamic and thalamocortical nociceptive pathways. J Pain, 2002. 3(2): p. 109-12; discussion 113-4.

51. Ikeda, H., et al., Synaptic plasticity in spinal lamina I projection neurons that mediate hyperalgesia. Science, 2003. 299(5610): p. 1237-40.

52. Xia, Z., et al., Calcium influx via the NMDA receptor induces immediate early gene transcription by a MAP kinase/ERK-dependent mechanism. J Neurosci, 1996. 16(17): p. 542536.

53. Willis, W.D., Long-term potentiation in spinothalamic neurons. Brain Res Brain Res Rev, 2002. 40(1-3): p. 202-14.

54. Sandkuhler, J., Learning and memory in pain pathways. Pain, 2000. 88(2): p. 113-8.

55. Quiton, R.L. and J.D. Greenspan, Sex differences in endogenous pain modulation by distracting and painful conditioning stimulation. Pain, 2007. 132 Suppl 1: p. S134-49.

56. Campbell, C.M., et al., Ethnic differences in diffuse noxious inhibitory controls. J Pain, 2008. 9(8): p. 759-66.

57. Arendt-Nielsen, L., M. Curatolo, and A. Drewes, Human experimental pain models in drug development: translational pain research. Curr Opin Investig Drugs, 2007. 8(1): p. 41-53.

58. Staahl, C., et al., Assessing analgesic actions of opioids by experimental pain models in healthy volunteers - an updated review. Br J Clin Pharmacol, 2009. 68(2): p. 149-68.

59. Staahl, C. and A.M. Drewes, Experimental human pain models: a review of standardised methods for preclinical testing of analgesics. Basic Clin Pharmacol Toxicol, 2004. 95(3): p. 97111.

60. Handwerker, H.O. and G. Kobal, Psychophysiology of experimentally induced pain. Physiol Rev, 1993. 73(3): p. 639-71.

61. Traynor, R. and J.C. MacDermid, Immersion in Cold-Water Evaluation (ICE) and self-reported cold intolerance are reliable but unrelated measures. Hand (N Y), 2008. 3(3): p. 212-9.

62. Pedersen, J.L., Inflammatory pain in experimental burns in man. Dan Med Bull, 2000. 47(3): p. 168-95.

63. Raja, S.N., R.A. Meyer, and J.N. Campbell, Peripheral mechanisms of somatic pain. Anesthesiology, 1988. 68(4): p. 571-90.

64. Van Hees, J. and J. Gybels, C nociceptor activity in human nerve during painful and non painful skin stimulation. J Neurol Neurosurg Psychiatry, 1981. 44(7): p. 600-7.

65. Ringkamp, M., et al., Capsaicin responses in heat-sensitive and heat-insensitive A-fiber nociceptors. J Neurosci, 2001. 21(12): p. 4460-8.

66. Campbell, J.N. and R.H. LaMotte, Latency to detection of first pain. Brain Res, 1983. 266(2): p. 203-8.

67. Treede, R.D., et al., Evidence for two different heat transduction mechanisms in nociceptive primary afferents innervating monkey skin. J Physiol, 1995. 483 ( Pt 3): p. 747-58.

68. Price, D.D. and R. Dubner, Mechanisms of first and second pain in the peripheral and central nervous systems. J Invest Dermatol, 1977. 69(1): p. 167-71.

69. Schepers, R.J. and M. Ringkamp, Thermoreceptors and thermosensitive afferents. Neurosci Biobehav Rev, 2010. 34(2): p. 177-84.

70. Bautista, D.M., et al., The menthol receptor TRPM8 is the principal detector of environmental cold. Nature, 2007. 448(7150): p. 204-8.

71. Karashima, Y., et al., TRPA1 acts as a cold sensor in vitro and in vivo. Proc Natl Acad Sci U S A, 2009. 106(4): p. 1273-8.

72. Nielsen, T.A., et al., Psychophysical and vasomotor evidence for interdependency of TRPA1 and TRPV1-evoked nociceptive responses in human skin: an experimental study. Pain, 2018. 159(10): p. 1989-2001. 
73. Dirks, J., K.L. Petersen, and J.B. Dahl, The heat/capsaicin sensitization model: a methodologic study. J Pain, 2003. 4(3): p. 122-8.

74. Petty, B.G., et al., The effect of systemically administered recombinant human nerve growth factor in healthy human subjects. Ann Neurol, 1994. 36(2): p. 244-6.

75. Koppert, W., et al., A new model of electrically evoked pain and hyperalgesia in human skin: the effects of intravenous alfentanil, S(+)-ketamine, and lidocaine. Anesthesiology, 2001. 95(2): p. 395-402.

76. Nolano, M., et al., Topical capsaicin in humans: parallel loss of epidermal nerve fibers and pain sensation. Pain, 1999. 81(1-2): p. 135-45.

77. Rheinecker, S.B., Wound management: the occlusive dressing. J Athl Train, 1995. 30(2): p. 143-6.

78. Zhai, H. and H.I. Maibach, Effects of skin occlusion on percutaneous absorption: an overview. Skin Pharmacol Appl Skin Physiol, 2001. 14(1): p. 1-10.

79. Jepma, M., M. Jones, and T.D. Wager, The dynamics of pain: evidence for simultaneous sitespecific habituation and site-nonspecific sensitization in thermal pain. J Pain, 2014. 15(7): p. 734-46.

80. Chen, L., et al., Altered quantitative sensory testing outcome in subjects with opioid therapy. Pain, 2009. 143(1-2): p. 65-70.

81. Rolke, R., et al., Quantitative sensory testing in the German Research Network on Neuropathic Pain (DFNS): standardized protocol and reference values. Pain, 2006. 123(3): p. 231-43.

82. Sacco, P., et al., Repetitive transcranial magnetic stimulation over primary motor vs nonmotor cortical targets; effects on experimental hyperalgesia in healthy subjects. BMC Neurol, 2014. 14: p. 166.

83. Müller, B. and H.-D. Basler, Kurzfragebogen zur aktuellen Beanspruchung: KAB. 1993, Weinheim: Beltz.

84. Price, R.C., et al., Characterization of a novel capsaicin/heat ongoing pain model. Eur J Pain, 2018. 22(2): p. 370-384.

85. Strigo, I.A., F. Carli, and M.C. Bushnell, Effect of ambient temperature on human pain and temperature perception. Anesthesiology, 2000. 92(3): p. 699-707.

86. Aviram, J., T. Shochat, and D. Pud, Pain perception in healthy young men is modified by timeof-day and is modality dependent. Pain Med, 2015. 16(6): p. 1137-44.

87. Davis, G.C., M.S. Buchsbaum, and W.E. Bunney, Jr., Naloxone decreases diurnal variation in pain sensitivity and somatosensory evoked potentials. Life Sci, 1978. 23(14): p. 1449-59.

88. Nothnagel, H., et al., How stable are quantitative sensory testing measurements over time? Report on 10-week reliability and agreement of results in healthy volunteers. J Pain Res, 2017. 10: p. 2067-2078.

89. Geber, C., et al., Test-retest and interobserver reliability of quantitative sensory testing according to the protocol of the German Research Network on Neuropathic Pain (DFNS): a multi-centre study. Pain, 2011. 152(3): p. 548-56.

90. Becser, N., T. Sand, and J.A. Zwart, Reliability of cephalic thermal thresholds in healthy subjects. Cephalalgia, 1998. 18(8): p. 574-82.

91. Moloney, N.A., T.M. Hall, and C.M. Doody, Reliability of thermal quantitative sensory testing: a systematic review. J Rehabil Res Dev, 2012. 49(2): p. 191-207.

92. Bird, S.J., et al., Value of repeated measures of nerve conduction and quantitative sensory testing in a diabetic neuropathy trial. Muscle Nerve, 2006. 34(2): p. 214-24.

93. Pavlakovic, G., et al., Effect of thermode application pressure on thermal threshold detection. Muscle Nerve, 2008. 38(5): p. 1498-1505.

94. LaMotte, R.H. and J.N. Campbell, Comparison of responses of warm and nociceptive C-fiber afferents in monkey with human judgments of thermal pain. J Neurophysiol, 1978. 41(2): p. 509-28. 
95. Piper, A.S., et al., A study of the voltage dependence of capsaicin-activated membrane currents in rat sensory neurones before and after acute desensitization. J Physiol, 1999. 518 ( Pt 3): p. 721-33.

96. Schwarz, S., et al., Inactivation and tachyphylaxis of heat-evoked inward currents in nociceptive primary sensory neurones of rats. J Physiol, 2000. 528(Pt 3): p. 539-49.

97. Kenshalo, D.R., Jr., et al., Responses of primate spinothalamic neurons to graded and to repeated noxious heat stimuli. J Neurophysiol, 1979. 42(5): p. 1370-89.

98. Coghill, R.C., D.J. Mayer, and D.D. Price, Wide dynamic range but not nociceptive-specific neurons encode multidimensional features of prolonged repetitive heat pain. J Neurophysiol, 1993. 69(3): p. 703-16.

99. Sandkuhler, J., et al., Low-frequency stimulation of afferent Adelta-fibers induces long-term depression at primary afferent synapses with substantia gelatinosa neurons in the rat. J Neurosci, 1997. 17(16): p. 6483-91.

100. Bingel, U., et al., Habituation to painful stimulation involves the antinociceptive system. Pain, 2007. 131(1-2): p. 21-30.

101. Bingel, U., et al., Habituation to painful stimulation involves the antinociceptive system--a 1year follow-up of 10 participants. Pain, 2008. 140(2): p. 393-4.

102. Weissman-Fogel, I., A. Dror, and R. Defrin, Temporal and spatial aspects of experimental tonic pain: Understanding pain adaptation and intensification. Eur J Pain, 2015. 19(3): p. 40818.

103. Mendell, L.M. and P.D. Wall, Responses of Single Dorsal Cord Cells to Peripheral Cutaneous Unmyelinated Fibres. Nature, 1965. 206: p. 97-9.

104. Price, D.D., et al., Peripheral suppression of first pain and central summation of second pain evoked by noxious heat pulses. Pain, 1977. 3(1): p. 57-68.

105. Kojo, I. and A. Pertovaara, The effects of stimulus area and adaptation temperature on warm and heat pain thresholds in man. Int J Neurosci, 1987. 32(3-4): p. 875-80.

106. Coghill, R.C., D.J. Mayer, and D.D. Price, The roles of spatial recruitment and discharge frequency in spinal cord coding of pain: a combined electrophysiological and imaging investigation. Pain, 1993. 53(3): p. 295-309.

107. Price, D.D., C.D. Hull, and N.A. Buchwald, Intracellular responses of dorsal horn cells to cutaneous and sural nerve $A$ and $C$ fiber stimuli. Exp Neurol, 1971. 33(2): p. 291-309.

108. Woolf, C.J., Windup and central sensitization are not equivalent. Pain, 1996. 66(2-3): p. 105-8.

109. Naert, A.L., H. Kehlet, and R. Kupers, Characterization of a novel model of tonic heat pain stimulation in healthy volunteers. Pain, 2008. 138(1): p. 163-71.

110. Granot, M., E. Sprecher, and D. Yarnitsky, Psychophysics of phasic and tonic heat pain stimuli by quantitative sensory testing in healthy subjects. Eur J Pain, 2003. 7(2): p. 139-43.

111. Granot, M., et al., Contact heat-evoked temporal summation: tonic versus repetitive-phasic stimulation. Pain, 2006. 122(3): p. 295-305.

112. Willis, W.D., et al., Cooperative mechanisms of neurotransmitter action in central nervous sensitization. Prog Brain Res, 1996. 110: p. 151-66.

113. Dickenson, A.H., V. Chapman, and G.M. Green, The pharmacology of excitatory and inhibitory amino acid-mediated events in the transmission and modulation of pain in the spinal cord. Gen Pharmacol, 1997. 28(5): p. 633-8.

114. Eide, P.K., Wind-up and the NMDA receptor complex from a clinical perspective. Eur J Pain, 2000. 4(1): p. 5-15.

115. Price, D.D., et al., The N-methyl-D-aspartate receptor antagonist dextromethorphan selectively reduces temporal summation of second pain in man. Pain, 1994. 59(2): p. 165-74.

116. Arendt-Nielsen, L., et al., The effect of $\mathrm{N}$-methyl-D-aspartate antagonist (ketamine) on single and repeated nociceptive stimuli: a placebo-controlled experimental human study. Anesth Analg, 1995. 81(1): p. 63-8.

117. Berkley, K.J., Sex differences in pain. Behav Brain Sci, 1997. 20(3): p. 371-80; discussion 435513. 
118. Riley, J.L., 3rd, et al., Sex differences in the perception of noxious experimental stimuli: a meta-analysis. Pain, 1998. 74(2-3): p. 181-7.

119. Swandulla, D., et al., Effect of menthol on two types of Ca currents in cultured sensory neurons of vertebrates. Pflugers Arch, 1987. 409(1-2): p. 52-9.

120. Taniguchi, Y., et al., [Antinociceptive effects of counterirritants]. Nihon Yakurigaku Zasshi, 1994. 104(6): p. 433-46.

121. Galeotti, N., et al., Menthol: a natural analgesic compound. Neurosci Lett, 2002. 322(3): p. 145-8.

122. Pergolizzi, J.V., Jr., et al., The role and mechanism of action of menthol in topical analgesic products. J Clin Pharm Ther, 2018. 43(3): p. 313-319.

123. Fattori, V., et al., Capsaicin: Current Understanding of Its Mechanisms and Therapy of Pain and Other Pre-Clinical and Clinical Uses. Molecules, 2016. 21(7). 


\section{Zusammenfassung}

In den vergangenen Jahren wurden diverse Akutschmerzmodell zur Erforschung pathophysiologischer Mechanismen von Schmerzen und Validierung medikamentöser Therapieverfahren beschrieben. Aufgrund unterschiedlicher Fragestellungen sowie fehlender, standardisierter Protokolle sind die damit erlangten Forschungsergebnisse jedoch nur eingeschränkt vergleichund reproduzierbar. Die erworbenen Erkenntnisse müssen auch wegen der überwiegend kurzen Versuchsdauern der bereits beschriebenen Akutschmerzmodelle im Hinblick auf ihre Übertragbarkeit auf klinischen Schmerz kritisch hinterfragt werden.

Das Ziel dieser Studie war daher die Etablierung eines standardisierten Protokolls eines Akutschmerzmodells. Durch ein Gerät zur quantitativen sensorischen Testung wurden nozizeptive thermische Stimuli definierter Intensität und variabler Versuchsdauer induziert. Zur Reduktion des Risikos von thermischen Hautschäden und zur Amplifikation der Schmerzintensität von Hitzestimuli erfolgte die Anwendung einer Capsaicin-Creme.

Die geeigneten Stimuluslängen und Thermodentemperaturen für ein Kälte- und Hitzeschmerzmodell wurden aus Vorversuchen abgeleitet, in denen neben den thermischen Schmerzschwellen auch die zeitlichen Aspekte einer peripheren und zentralen Schmerzadaptation untersucht wurden. Über eine variable Zeitdauer konnten so signifikante, nozizeptive Kälte- und Hitzeschmerzreize induziert werden, die von den Versuchsprobanden im Durchschnitt mit einer Schmerzintensität von NRS $\geq 6$ bewertet wurden. Dabei bestand keine Gefahr von schweren oder irreversiblen thermischen Gewebeschäden und es kam zu keinem durch Schmerzintoleranz bedingten Versuchsabbruch. 


\section{Anhang}

\subsection{KAB Score}

Kurzfragebogen zur aktuellen Beanspruchung

KAB

Name oder Code-Nr.

Alter in Jahren:

Geschlecht:

weiblich

männlich

Situation

Bitte kreuzen Sie jeweils an, wie Sie sich jetzt fühlen.

Bitte setzen Sie in jeder Zeile nur ein Kreuz, zum Beispiel:

Jetzt fühle ich mich:

$\begin{array}{llllllll} & \text { sehr } & \text { ziemlich } & \text { eher } & \text { eher } & \text { ziemlich } & \text { sehr } & \\ \text { 1. frisch } & \mathrm{a} & \mathrm{b} & \mathrm{c} & \mathrm{a} & \mathrm{e} & \mathrm{f} & \text { matt } \\ \text { 2. voller Elan } & \mathrm{a} & \mathrm{b} & \mathrm{c} & \mathrm{d} & & \mathrm{f} & \text { kraftlos }\end{array}$

Jetzt fühle ich mich:

\begin{tabular}{llllllll} 
& sehr & ziemlich & eher & eher & ziemlich & sehr & \\
1. angespannt & $\mathrm{a}$ & $\mathrm{b}$ & $\mathrm{C}$ & $\mathrm{d}$ & $\mathrm{e}$ & $\mathrm{f}$ & gelassen \\
2. gelöst & $\mathrm{a}$ & $\mathrm{b}$ & $\mathrm{c}$ & $\mathrm{d}$ & $\mathrm{e}$ & $\mathrm{f}$ & beklommen \\
3. besorgt & $\mathrm{a}$ & $\mathrm{b}$ & $\mathrm{c}$ & $\mathrm{d}$ & $\mathrm{e}$ & $\mathrm{f}$ & unbekümmert \\
4. entspannt & $\mathrm{a}$ & $\mathrm{b}$ & $\mathrm{c}$ & $\mathrm{d}$ & $\mathrm{e}$ & $\mathrm{f}$ & unruhig \\
5. skeptisch & $\mathrm{a}$ & $\mathrm{b}$ & $\mathrm{c}$ & $\mathrm{d}$ & $\mathrm{e}$ & $\mathrm{f}$ & vertrauensvoll \\
6. behaglich & $\mathrm{a}$ & $\mathrm{b}$ & $\mathrm{c}$ & $\mathrm{d}$ & $\mathrm{e}$ & $\mathrm{f}$ & unwohl \\
\hline
\end{tabular}


9.2. Befundbogen

\section{Befundbogen}

Datum.

Patient:

\#__ / Gruppe

Alter:

Bildung:

Geschlecht:

$\mathrm{mO} \quad$ w O

Gewicht:

kg

Größe:

$\mathrm{cm}$

BMl:

Nüchtern:

$\mathrm{JaO} \quad$ Nein $\mathrm{O}$

NRS Ruhe: $/ 10$

NRS Bewegung: / 10

NRS mean letzten 24h: $/ 10$

Zielkonflikt:

ja $\mathrm{O}$ nein $\mathrm{O}$

Schmerzakzeptanz:

ja $\mathrm{O}$ nein $\mathrm{O}$

Schmerzmedikation:

NSAID ja O nein $\mathrm{O}$
Basisch ja O nein $\mathrm{O}$
Co-Analgetika ja $\mathrm{O}$ nein $\mathrm{O}$
Opioide: ja $\mathrm{O}$ nein $\mathrm{O}$

Bedarf an Schmerzmedikamenten in den letzten 4 Wochen:

ja $\mathrm{O}$ nein $\mathrm{O}$ 
KHK

Raucher/in:

Diabetes mellitus:

CRP

$\mathrm{HbA1c}$ :

Kreatinin:

GFR:

Cholesterin ges:

LDL

HDL

Art. Hypertonus:

Blutdruck:

MAP:

Herzfrequenz:

Temperatur:

Weitere: Vorerkrankungen

Weitere Medikation:

KAB:

ADS:

ja $\mathrm{O}$ nein $\mathrm{O}$

Ja O

Nein $\mathrm{O}$

ja $\mathrm{O}$ nein $\mathrm{O}$

ja $\mathrm{O}$ nein $\mathrm{O}$

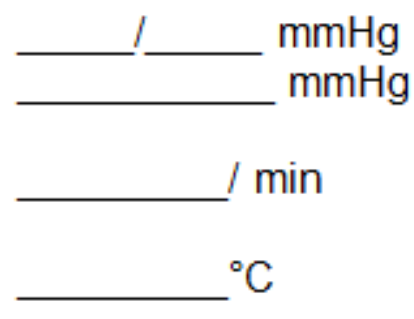
$\mathrm{mmHg}$ $\mathrm{mmHg}$ 


\section{Danksagung}

An erster Stelle ist meine herausragende Doktormutter Frau Professor Dr. med. Shahnaz Christina Azad zu nennen. Bereits während des Studiums weckte sie meine Begeisterung für die Anästhesie und Schmerzmedizin und stellt zweifelsohne mein Vorbild in fachlicher und sozialer Kompetenz dar. Ich danke Dir herzlich für Deine Muse und Unterstützung.

Ich danke Herrn Professor Dr. med. B. Zwißler, der mir die Möglichkeit gab, an seiner Klinik die Dissertation durchzuführen.

Bedanken möchte ich mich auch bei Herrn PD. Dr. med. Benjamin Luchting für kreative Diskussionen während der Versuchsplanung sowie den zahlreichen Versuchsteilnehmer und fleißigen Gehilfen, ohne die diese Studie nicht zu verwirklichen gewesen wäre.

Ich danke herzlich meiner Familie für den liebevollen Beistand während der Fertigstellung dieser Arbeit. 


\section{Eidesstattliche Versicherung}

Ich, Philipp Lüke, erkläre hiermit an Eides statt, dass ich die vorliegende Dissertation mit dem Thema „Etablierung eines adaptierbaren Akutschmerzmodells zur Induktion nozizeptiver Stimuli definierter Intensität und Dauer mittels thermischer Reize“

selbständig verfasst, mich außer der angegebenen keiner weiteren Hilfsmittel bedient und alle Erkenntnisse, die aus dem Schrifttum ganz oder annähernd übernommen sind, als solche kenntlich gemacht und nach ihrer Herkunft unter Bezeichnung der Fundstelle einzeln nachgewiesen habe.

Ich erkläre des Weiteren, dass die hier vorgelegte Dissertation nicht in gleicher oder in ähnlicher Form bei einer anderen Stelle zur Erlangung eines akademischen Grades eingereicht wurde.

München, den 02.02.2022

Philipp Lüke 


\section{Stellungnahme zur Vorveröffentlichung}

Ich, Philipp Lüke, erkläre hiermit, dass die Ergebnisse dieser Studie veröffentlicht wurden [11]. Mein Tätigkeitsfeld umfasste die Projektplanung in Zusammenarbeit mit Frau Prof. Shahnaz Christina Azad, die Probandenakquise und Durchführung der Studie, sowie die Datenerhebung, statistische Auswertung und Ergebniszusammenschrift mitsamt Veröffentlichung. In der vorliegenden Dissertation werden daher ausgewiesene Formulierungen und Abbildungen aufgeführt, die Bestandteil der dazugehörigen Publikation sind. 